FHWA/IN/JTRP-2008/18

Final Report

USE OF MICROPILES FOR FOUNDATIONS OF

TRANSPORTATION STRUCTURES

Hoyoung Seo

Monica Prezzi

December 2008 


\section{TECHNICAL Summary}

INDOT Research

Technology Transfer and Project Implementation Information

TRB Subject Code: 62-1 Foundation Soils

Publication No. FHWA/IN/JTRP-2008/18, SPR-2931

December 2008

Final Report

\section{Use of Micropiles for Foundations of Transportation Structures}

\section{Introduction}

Pile foundations have been used in construction for thousands of years as an economical means of transmitting the loads from superstructures to the underlying soil or rock strata. In pile design, piles must be able to sustain axial loads from the superstructure without failing in bearing capacity or settling so much that structural damage occurs or serviceability of the superstructure is jeopardized. In general, settlement controls the design in most cases because, by the time a pile has failed in terms of bearing capacity, it is very likely that serviceability will have already been compromised. Therefore, realistic estimation of settlement for the given load is very important in design of axially loaded piles. This notwithstanding, pile design has relied on calculations of ultimate resistances reduced by factors of safety that would indirectly prevent settlement-based limit states. This is in part due to the lack of accessible realistic analysis tools for estimation of settlement, especially for piles installed in layered soil.

Micropiles are small-diameter piles that are sometimes called minipiles, root piles, pin piles or needle piles. The conceptual idea behind this important technological development was to create a type of pile that would be able to carry large loads while causing minimal vibration or disturbance to in situ materials at the time of installation. The rigs required to install them are often relatively small. Because of these important advantages, micropiles have been widely used in seismic retrofitting, in the rehabilitation of foundations of structures that are very sensitive, and in locations with low headroom and severely restricted access conditions. Furthermore, micropiles have been increasingly used, not only as underpinning foundation elements, but also as foundations for new structures.

Prevalent design methods for micropiles are adaptations of methods originally developed for drilled shafts. However, installation of micropiles differs considerably from that of drilled shafts, and micropiles have higher pile length to diameter ratios than those of drilled shafts. Improved understanding of the load-transfer characteristics of micropiles and the development of pile settlement estimation tools consistent with the load-transfer response of these foundation elements is needed.

\section{Findings}

We obtained explicit analytical solutions for an axially loaded pile in a multilayered soil or rock. Using these solutions, we performed extensive parametric studies. We also developed a userfriendly spreadsheet program ALPAXL to facilitate the use of our analysis. To investigate the load-transfer behavior of a rock-socketed micropile, a fully instrumented static load test was performed.

\section{Piles in a multilayered soil}

We performed extensive parametric studies to investigate pile slenderness ratio and layering effects.

The results from FEA and our analysis for a multilayered soil showed good agreement; the results from our analysis for end-bearing piles also compared well with results from previous studies.

When the soil layer surrounding the pile shaft becomes very stiff or the pile slenderness ratio is large, as is the case for micropiles, the 
normalized pile head stiffness is practically independent of the soil properties below the pile base.

In the case of piles in multilayered soil, the elastic response of the pile depends on soil layering, with the uppermost soil having the most effect on the pile head stiffness. A single layer with a simple weighted average of the soil modulus of different soil layers with layer thicknesses as weights will not produce correct pile head stiffness values.

\section{Rock-socketed piles}

For rock-socketed piles, we performed parametric studies to investigate pile socket geometry, stiffness of rock mass, and quality of in situ rock mass.

The load-settlement response of shorter socket was largely affected by the stiffness of the rock at the base, whereas that of longer socket was less sensitive to the stiffness of the rock at the base. Most of the applied load was carried by the pile shaft even for relatively short-socket length. This implies that base capacity may be ignored in design when a micropile is embedded in a very stiff rock, as there will be practically no load transferred to the base under working load.

Normalized pile stiffness increases with increasing rock mass modulus, irrespective of socket geometry. When the rock mass deformation modulus becomes larger than the elastic modulus of the pile, for practical purposes, socket geometry does not affect pile stiffness.

$R Q D$ has a more pronounced effect on load-transfer and load-settlement response for pile embedded in hard than in weak rocks. As the $R Q D$ increases, less load is transferred to the pile base, and the pile response becomes stiffer.

For soft rocks, normalized pile stiffness increases as $L_{s} / B$ increases. However, this trend vanishes and pile stiffness becomes independent of socket geometry as the rock becomes stiffer.

A fully instrumented load test on a rocksocketed micropile confirmed that most of the applied load was carried by the pile shaft with high slenderness ratio and high stiffness of the surrounding rock. The shaft capacity of hard limestone obtained from the load test at the final loading step was 1.4 times larger than the shaft capacity that is obtained using the highest value of limit unit shaft resistance suggested by FHWA (the limit unit shaft resistance $q_{s L}$ from the load test was $2950 \mathrm{kPa}$, while the suggested values from FHWA were 1035 - $2070 \mathrm{kPa}$ ). Using pile and soil properties, predictions were also made using ALPAXL. The results from ALPAXL were in good agreement with the measured data at the design load level.

\section{Implementation}

We have developed a user-friendly spread sheet program ALPAXL to facilitate the implementation of our analysis in the design of axially loaded piles. However, the analytical solutions presented in this report are obtained from the assumption that soil and rock behave as linear elastic materials. Therefore, results from the parametric study are valid only when pile behavior is approximately elastic, as it tends to be under working loads. Furthermore, estimation of soil and rock elastic modulus values is very important.

In order to successfully use micropiles as foundations of new transportation structures, we recommend the following:

(1) Extensive laboratory and in situ tests need to be performed to allow development of reasonable correlations for estimation of the elastic properties of soils and rocks typically found in Indiana for use as input in ALPAXL.

(2) Micropiles are usually installed in rock to support large loads from superstructures. The FHWA manual (2000) does not give guidance on how to select proper limit unit shaft resistance values for in design, suggesting only wide ranges. Development of a database containing in situ rock mass quality, such as $R Q D$ values, and load test data will be very beneficial to establish proper guidelines in the future.

(3) The base capacity of micropiles is usually ignored in design. However, when the surrounding rock is weak and pile or socket length is short, it would be more reasonable to consider base capacity as well in the design. More analyses are necessary to investigate the contribution of the stiffness of the base rock to the load-settlement response at the pile head for shorter socket installed in weak rock.

(4) When the soil is very stiff or dense, micropiles are potentially advantageous as foundations of new structures. To gain confidence in the use of micropiles for more general site conditions, instrumented load tests on micropiles installed in multilayered soil profiles are necessary.

(5) ALPAXL is sufficiently general to be used not only for micropiles but also for drilled 
shafts. However, in the case of driven piles, the state of the soil surrounding the pile changes significantly during installation. Therefore, more research is necessary to investigate the effects of pile installation. This would be necessary for use of ALPAXL to design driven piles as well.

\section{Contacts}

For more information:

\section{Prof. Monica Prezzi}

Principal Investigator

School of Civil Engineering

Purdue University

West Lafayette IN 47907

Phone: (765) 494-5034

Fax: (765) 496-1364

E-mail: mprezzi@purdue.edu
Indiana Department of Transportation

Division of Research

1205 Montgomery Street

P.O. Box 2279

West Lafayette, IN 47906

Phone: (765) 463-1521

Fax: (765) 497-1665

\section{Purdue University}

Joint Transportation Research Program

School of Civil Engineering

West Lafayette, IN 47907-1284

Phone: (765) 494-9310

Fax: (765) 496-7996

E-mail: jtrp@ecn.purdue.edu

http://www.purdue.edu/jtrp 
Final Report

FHWA/IN/JTRP-2008/18

\title{
USE OF MICROPILES FOR FOUNDATIONS OF TRANSPORTATION STRUCTURES
}

\author{
Hoyoung Seo \\ Graduate Research Assistant \\ and \\ Monica Prezzi \\ Associate Professor \\ Geotechnical Engineering \\ School of Civil Engineering \\ Purdue University \\ Joint Transportation Research Program \\ Project No: C-36-52V \\ File No: 06-20-21 \\ SPR-2931 \\ Prepared in Cooperation with the \\ Indiana Department of Transportation and \\ The U.S. Department of Transportation \\ Federal Highway Administration
}

The contents of this report reflect the views of the authors who are responsible for the facts and the accuracy of the data presented herein. The contents do not necessarily reflect the official views or policies of the Federal Highway Administration and the Indiana Department of Transportation. This report does not constitute a standard, specification or regulation.

Purdue University

West Lafayette, Indiana

December 31, 2008 
TECHNICAL REPORT STANDARD TITLE PAGE

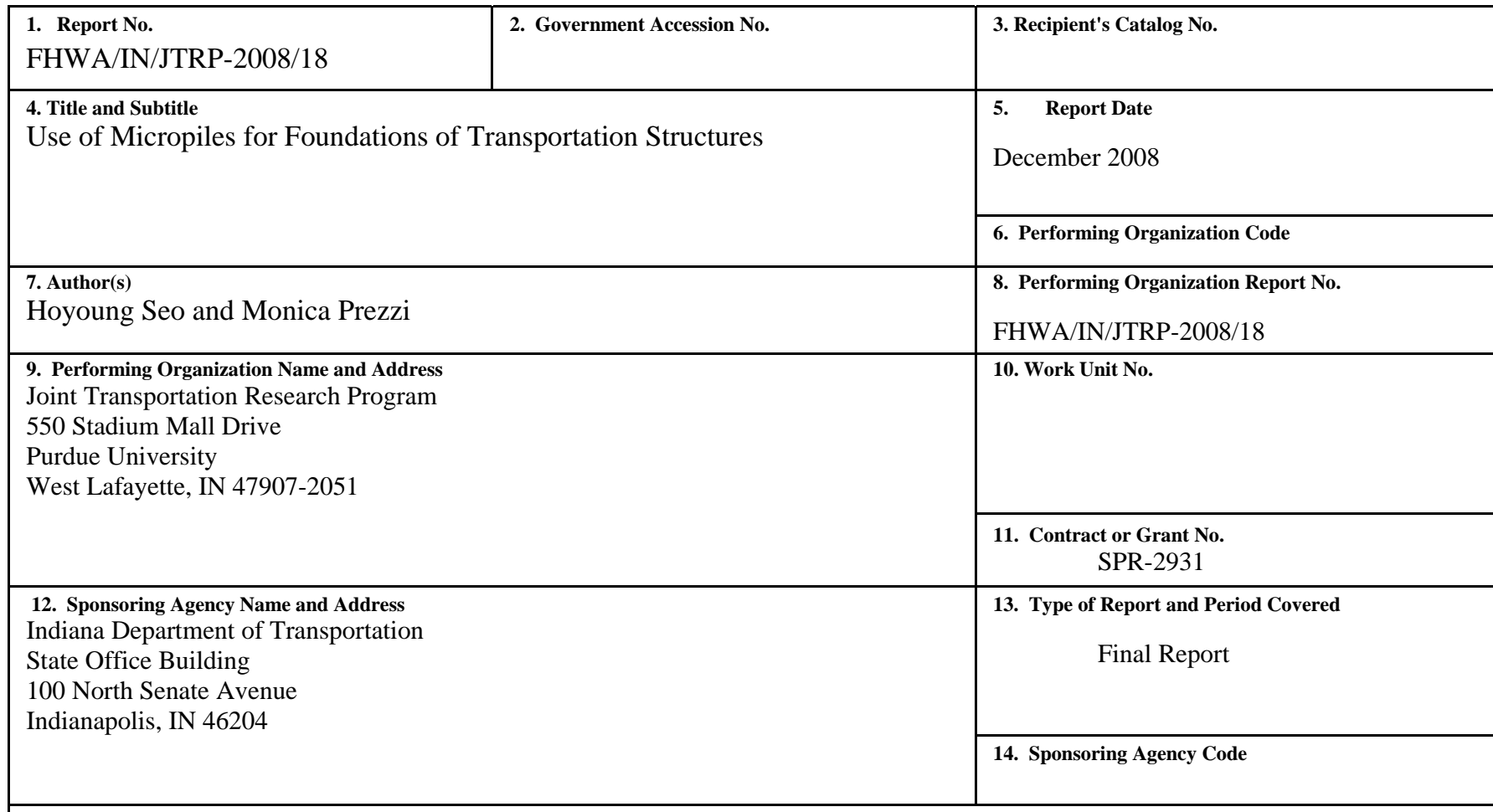

\section{Supplementary Notes}

Prepared in cooperation with the Indiana Department of Transportation and Federal Highway Administration.

\section{Abstract}

In pile design, piles must be able to sustain axial loads from the superstructure without bearing capacity failure or structural damage. In addition, piles must not settle or deflect excessively in order for the serviceability of the superstructures to be maintained. In general, settlement controls the design of piles in most cases because, by the time a pile has failed in terms of bearing capacity, it is very likely that serviceability will have already been compromised. Therefore, realistic estimation of settlement for a given load is very important in design of axially loaded piles. This notwithstanding, pile design has relied on calculations of ultimate resistances reduced by factors of safety that would indirectly prevent settlement-based limit states. This is in part due to the lack of accessible realistic analysis tools for estimation of settlement, especially for piles installed in layered soil. Micropiles have been increasingly used, not only as underpinning foundation elements but also as foundations of new structures. Prevalent design methods for micropiles are adaptations of methods originally developed for drilled shafts. However, the installation of micropiles differs considerably from that of drilled shafts, and micropiles have higher pile length to diameter ratios than those of drilled shafts. Improved understanding of the load-transfer characteristics of micropiles and the development of pile settlement estimation tools consistent with the load-transfer response of these foundation elements are the main goals of the proposed research. A rigorous analysis tool for assessment of the load-settlement response of an axially loaded pile was developed in this study. We obtained explicit analytical solutions for an axially loaded pile in a multilayered soil or rock. The soil was assumed to behave as a linear elastic material. The governing differential equations were derived based on energy principles and calculus of variations. In addition, solutions for a pile embedded in a multilayered soil with the base resting on a rigid material were obtained by changing the boundary conditions of the problem. We also obtained solutions for a pile embedded in a multilayered soil subjected to tensile loading. We then compared our solutions with the results from FEA and also with other solutions available in the literature. Finally, we compared the results of a pile load test from the literature with the results obtained using the solutions proposed in this study. Using the obtained elastic solutions, we also performed extensive parametric studies on the load-transfer and load-settlement response of rock-socketed piles. The effects of geometry of rock socket, rock mass deformation modulus, and in situ rock mass quality were investigated. To facilitate the use of our analysis, a user-friendly spreadsheet program ALPAXL was developed. This program is based on the elastic solution obtained in this study and uses built-in functions of Microsoft Excel. ALPAXL provides the results of the analysis, the deformed configuration of the pile-soil system and the load-settlement curve in seconds. It can be downloaded at http://cobweb.ecn.purdue.edu/ mprezzi. In the context of an INDOT project, a fully instrumented load test was performed on a rock-socketed micropile. The results of this micropile load test, on a pile with high slenderness ratio and high stiffness of surrounding rock, confirmed that most of the applied load was carried by the pile shaft. The shaft capacity of hard limestone obtained from the load test at the final loading step was 1.4 times larger than the shaft capacity that is obtained using the highest value of limit unit shaft resistance suggested by FHWA (the limit unit shaft resistance $q_{s L}$ from the load test was $2950 \mathrm{kPa}$, while the suggested values from FHWA were 1035 - $2070 \mathrm{kPa}$ ). Using pile and soil properties, predictions were also made using ALPAXL. The results from ALPAXL were in good agreement with the measured data at the design load level.

17. Key Words

Micropile; Pile Settlement; Multilayered Soil; Rock-Socketed Pile; Pile Load Test.

\section{Distribution Statement}

No restrictions. This document is available to the public through the National Technical Information Service, Springfield, VA 22161
19. Security Classif. (of this report)

Unclassified
20. Security Classif. (of this page)

Unclassified

21. No. of Pages

131 


\section{TABLE OF CONTENTS}

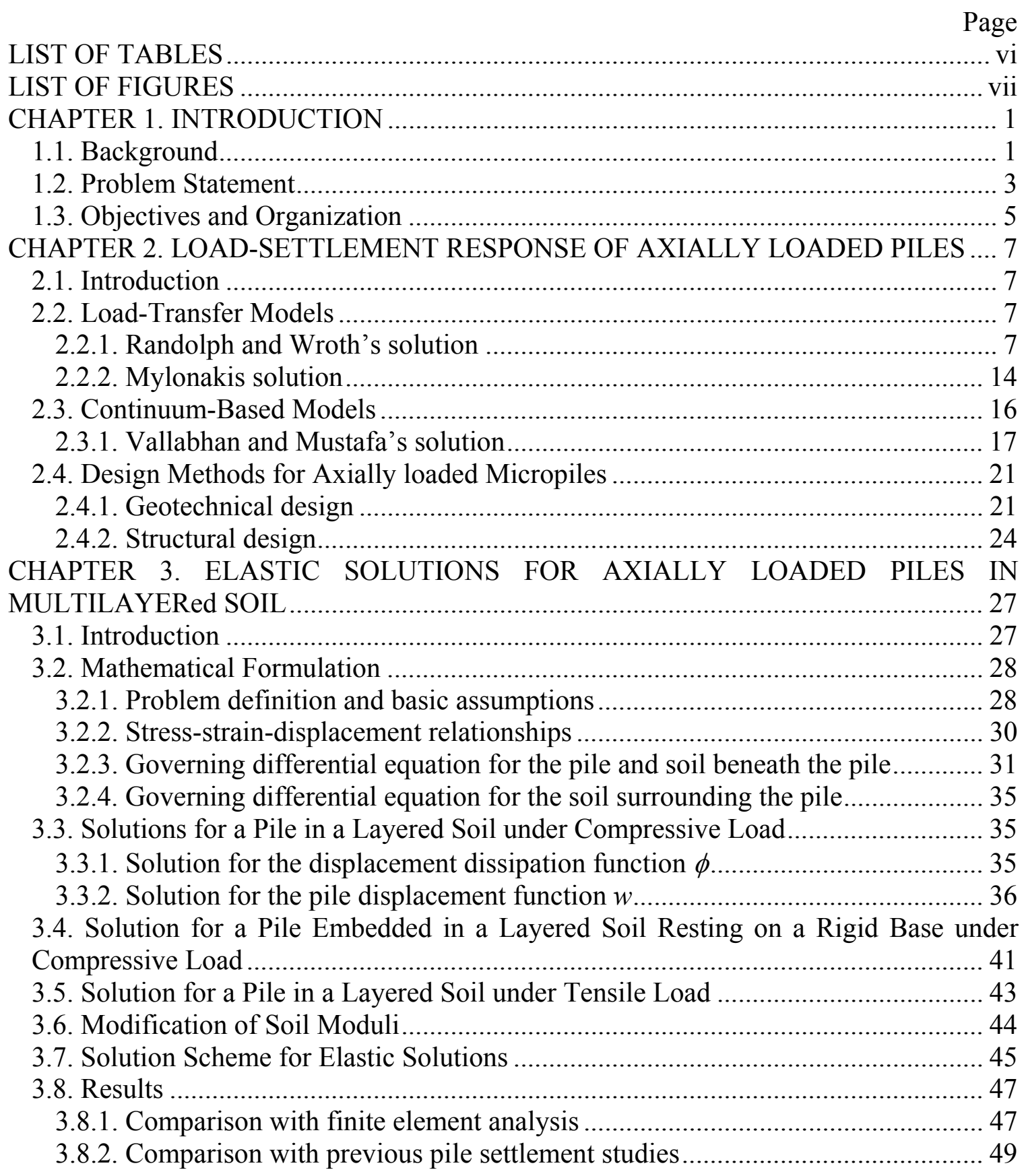




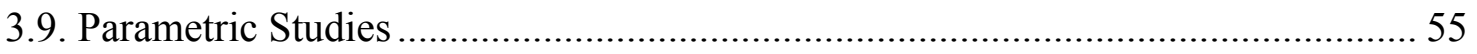

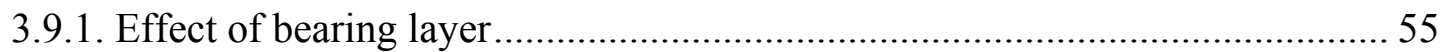

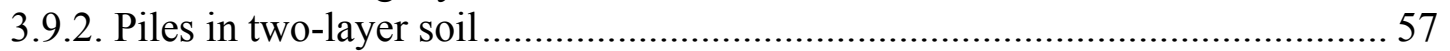

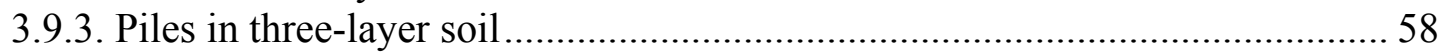

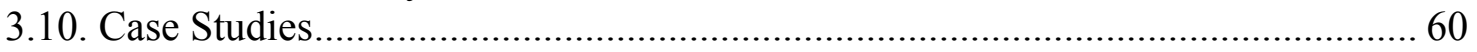

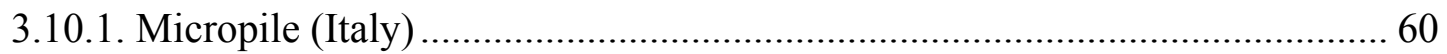

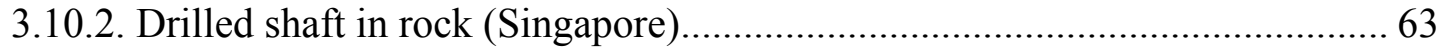

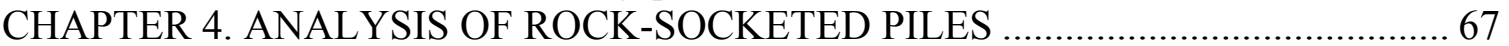

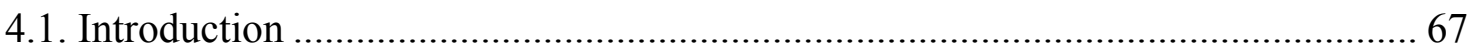

4.2. Estimation of deformation modulus of rock mass................................................ 67

4.2.1. Correlation with unconfined compressive strength of intact rock .................... 68

4.2.2. Correlation with in situ rock mass quality …………...................................... 68

4.3. Analysis of load-transfer behavior of rock-socketed piles .................................... 72

4.3.1. Effect of rock-socket geometry …………………....................................... 73

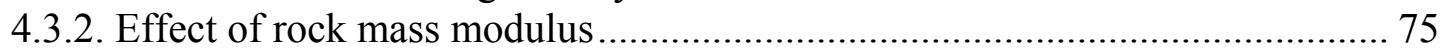

4.3.3. Effect of rock mass quality …………………………………………….... 76

4.4. Analysis of the load-settlement response of rock-socketed piles ........................... 78

4.4.1. Effect of socket geometry ……………………….................................... 78

4.4.2. Effect of rock mass deformation modulus ..................................................... 79

4.4.3. Effect of rock mass quality ……………………….................................. 79

CHAPTER 5. DEVELOPMENT OF A USER-FRIENDLY SPREADSHEET

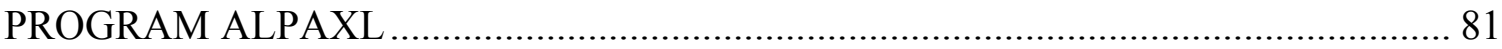

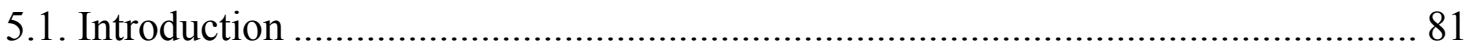

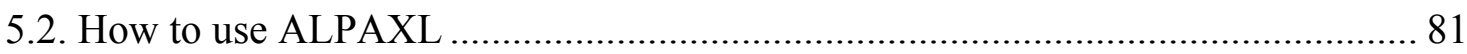

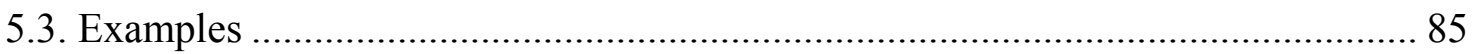

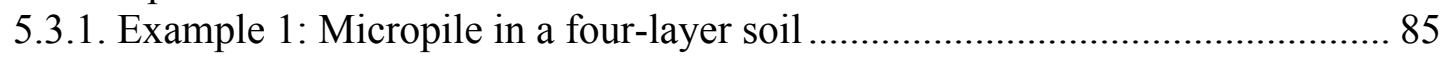

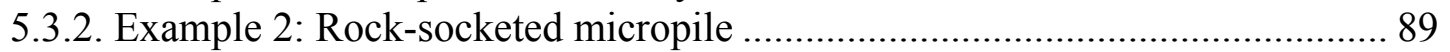

CHAPTER 6. FIELD LOAD TEST ON A ROCK-SOCKETED MICROPILE............... 92

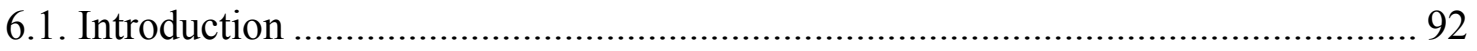

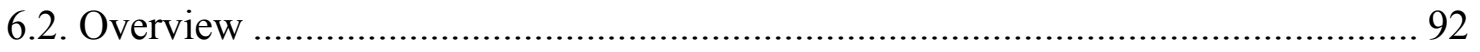

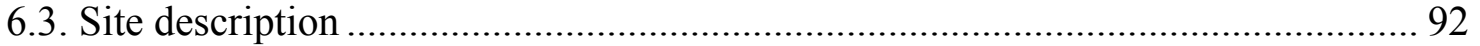

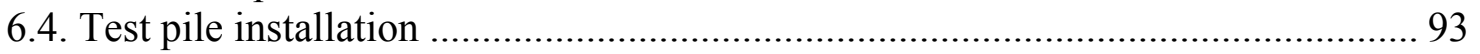

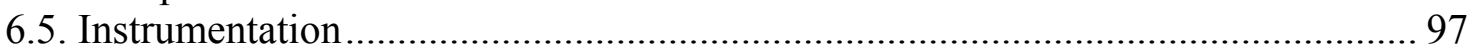

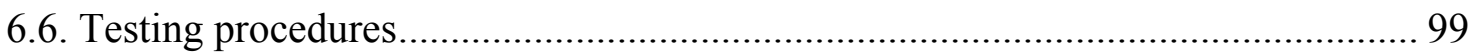

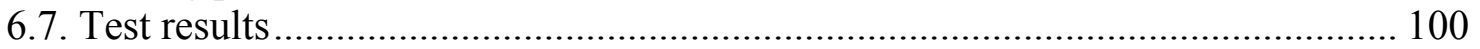

6.7.1. Evaluation of Young's modulus of the micropile .......................................... 100

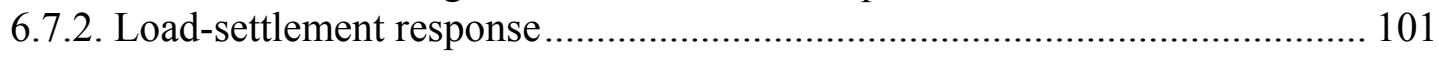

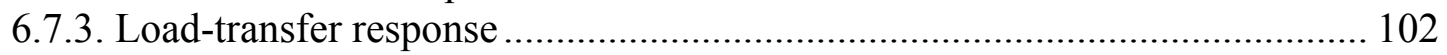

6.8. Analysis of the pile load test with ALPAXL.................................................... 105

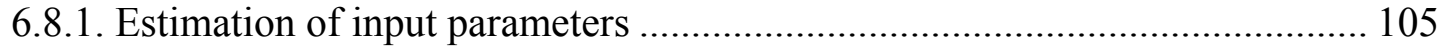

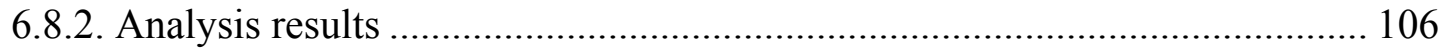

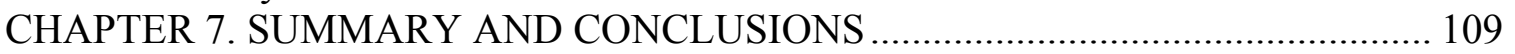

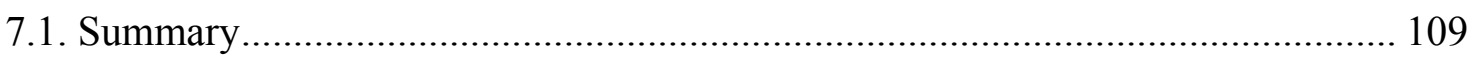

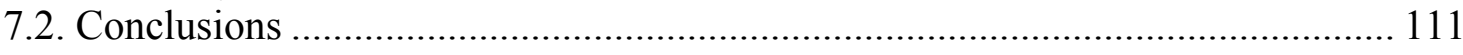

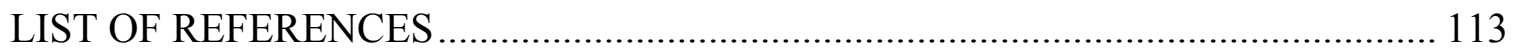




\section{LIST OF TABLES}

Table

Page

Table 2.1 Values of $\mathrm{q}_{\mathrm{sL}} / \mathrm{q}_{\mathrm{c}}$ and limit values of $\mathrm{q}_{\mathrm{sL}} / \mathrm{p}_{\mathrm{A}}$ (modified after Bustamante and Gianeselli 1982) 21

Table 2.2 Summary of available recommendations for preliminary design of micropiles suggested by FHWA (modified after FHWA 1997) ............................................. 22

Table 2.3 Summary of typical values of limit unit shaft resistance (modified after FHWA

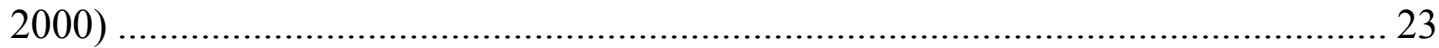

Table 3.1 Comparison between solutions in layered soil ......................................... 55

Table 3.2 Input values for the analysis of the microplile load-tested in Italy $\left(B=0.2 \mathrm{~m} ; L_{p}\right.$

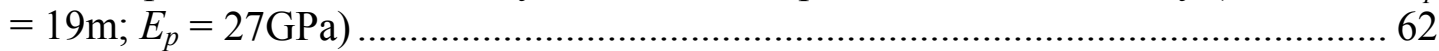

Table 3.3 Input values for the analysis of the drilled shaft load-tested in Singapore $\left(L_{p}=\right.$

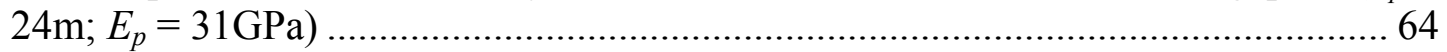

Table 4.1 RMR (rock mass rating) for jointed rock (modified after Bieniawski 1989) .... 70

Table 4.2 Typical values of elastic modulus of intact rocks (modified after AASHTO,

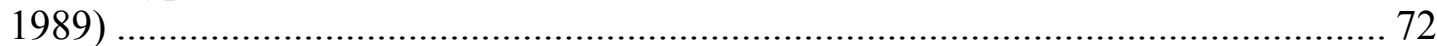

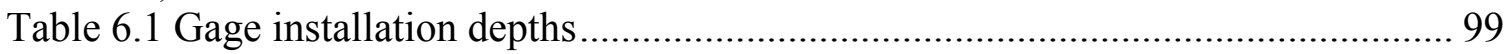

Table 6.2 Estimation of Young's modulus of soil or rock layer................................. 106 


\section{LIST OF FIGURES}

Figure

Page

Figure 1.1 Sources of pile resistances.................................................................... 1

Figure 1.2 Typical load-settlement response of pile (modified after Franke 1991) .......... 2

Figure 2.1 Detail of a composite reinforced micropile (after FHWA 2000) ................... 25

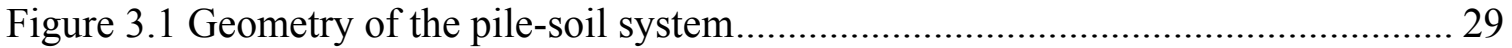

Figure 3.2 Illustration of two sources of soil resistance .......................................... 33

Figure 3.3 Pile embedded in a multilayered soil with the base resting on a rigid material

Figure 3.5 Flowchart for the iterative procedure ...................................................... 46

Figure 3.6 A comparison between displacements obtained using the analytical method and FEA for a 30-m-long pile: (a) pile displacement versus depth; (b) vertical soil displacement at the ground surface versus horizontal distance from pile center ....... 49

Figure 3.7 Comparison of normalized pile head stiffness versus normalized pile length of

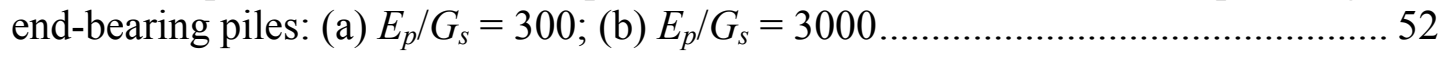

Figure 3.8 Layered soil profiles for settlement analyses (modified after Poulos 1979) ... 54

Figure 3.9 Normalized pile head stiffness versus modulus ratio of the base soil to shaft soil $G_{s b}{ }^{*} / G_{s}^{*}$ 56

Figure 3.10 Normalized pile head stiffness in two-layer soil versus (a) $h / L_{p}$ and (b)

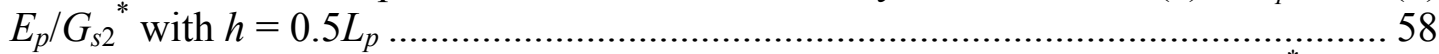

Figure 3.11 Normalized pile head stiffness in three-layer soil versus (a) $E_{p} / G_{s}{ }^{*}$ and (b) $L_{p} / B$

Figure 3.12 Soil profile at the micropile test site 61

Figure 3.13 Comparison between the results from the present analysis and measured data (Italy case): (a) load-pile head settlement curves; (b) load-transfer curves 63

Figure 3.14 Comparison between the results from the present analysis and measured data (Singapore case): (a) load-pile head settlement curves; (b) load-transfer curves ...... 66

Figure 4.1 Distribution of axial load versus normalized depth for rock-socketed piles

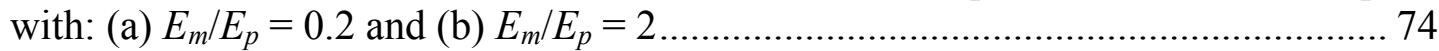

Figure 4.2 Distribution of axial load versus normalized depth for a rock-socketed pile with $L_{p} / B=3$ 75

Figure 4.3 Distribution of axial load versus normalized depth for a rock-socketed pile: (a) $E_{r} / E_{p}=1 / 3$ and (b) $E_{r} / E_{p}=3$ 77

Figure 4.4 Normalized pile head stiffness $K_{N}$ versus $L_{s} / B$ for $E_{m} / E_{p}=0.02,0.2$, and 3 .. 78 Figure 4.5 Normalized pile head stiffness $K_{N}$ versus $E_{m} / E_{p}$ for $L_{s} / B=1,2,5$, and $10 \ldots . .79$

Figure 4.6 Normalized pile head stiffness $K_{N}$ versus $R Q D$ for $E_{m} / E_{p}=1 / 3$ and $3 \ldots \ldots \ldots . . .80$ 


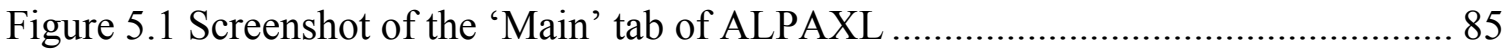

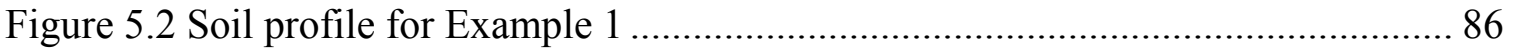

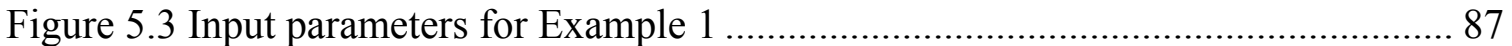

Figure 5.4 Results from ALPAXL (Example 1): (a) load-settlement curve; (b) soil displacement in the radial direction at the level of the pile head and base; (c) pile displacement along the pile length; and (d) load-transfer curve ............................... 88

Figure 5.5 Deformed configuration of pile-soil system after loading for Example 1....... 89

Figure 5.6 Soil profile and pile of Example 2 ………............................................... 90

Figure 5.7 Input and output sections for Example 2 ………..................................... 90

Figure 5.8 Pile displacement and axial load distribution with depth obtained from

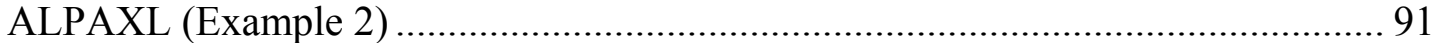

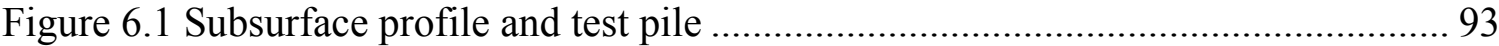

Figure 6.2 Drilling tools used to install test pile......................................................... 94

Figure 6.3 A view of (a) folded and (b) expanded drilling bit........................................ 95

Figure 6.4 Installation of test pile: (a) drilling of the hole into the ground; (b) connecting the rod and casing; (c) grouting; (d) insertion of instrumented pipe; (e) positioning properly the instrumentation cables; (f) completed test pile...................................... 96

Figure 6.5 Test pile instrumentation: (a) three instrumented pipe segments; (b) manufactured pipe connector; (c) connection of pipe segments with threaded rebar; (d) positioning the instrumented pipes for insertion into the grout-filled casing....... 98

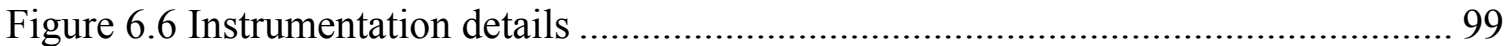

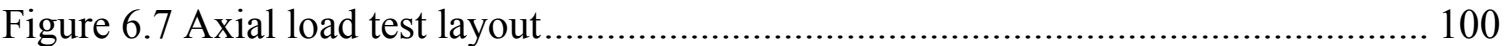

Figure 6.8 Determination of micropile Young's modulus $\left(r^{2}=\right.$ coefficient of correlation) 101

Figure 6.9 Load-settlement response of test pile ..................................................... 102

Figure 6.10 Distribution of axial load versus depth.................................................... 103

Figure 6.11 Pile head settlement versus applied head load, shaft load, and base load... 104

Figure 6.12 Screenshot of the input values and results from ALPAXL for the Orange

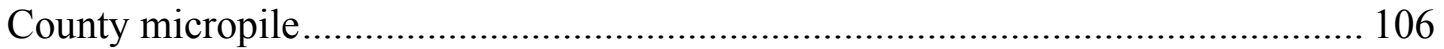

Figure 6.13 Measured and predicted load-settlement curve for the Orange County

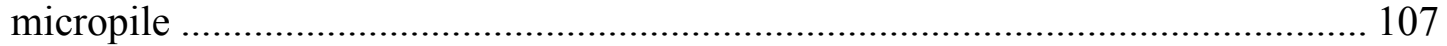

Figure 6.14 Measured and predicted load-transfer curves for a load of $1610 \mathrm{kN}$......... 108 


\section{CHAPTER 1. INTRODUCTION}

\subsection{Background}

Pile foundations have been used in construction for thousands of years as an economical means of transmitting the loads from superstructures to the underlying soil or rock strata. Piles support the load applied from the superstructure $Q_{t}$ through basically two sources: 1) friction between the pile shaft and the surrounding soil and 2) compressive resistance of the soil below the pile base. The frictional resistance offered by the soil surrounding the pile is called shaft resistance $Q_{s}$, and the compressive resistance offered by the soil at the base is referred to as base resistance $Q_{b}$ (Figure 1.1).

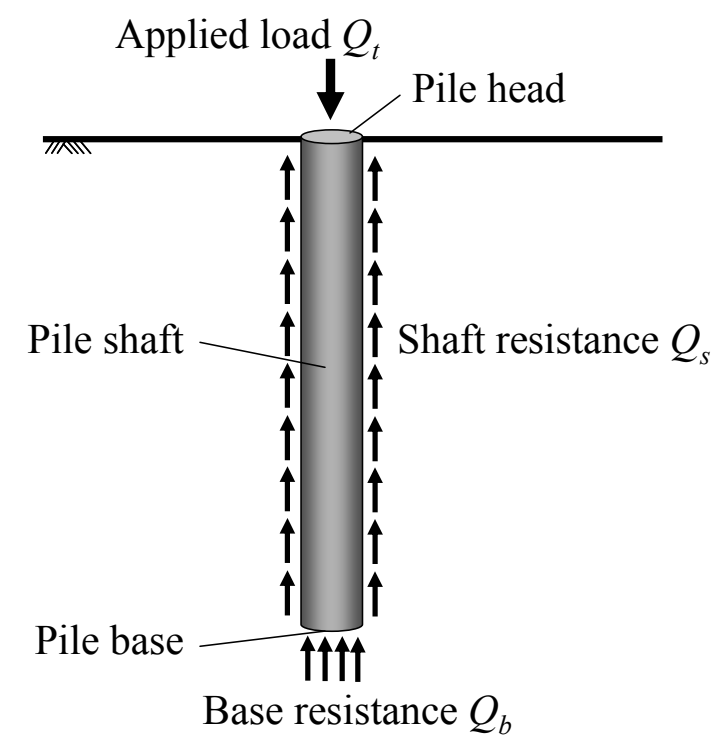

Figure 1.1 Sources of pile resistances

As the applied load at the pile head is increased, pile settlement increases until eventually the pile plunges into the ground when the shaft and base resistances reach their 
limit values. During this loading process, there is high localization of shearing within a thin layer of soil around the pile shaft. As the thickness of this layer (shear zone) is very small, only a small amount of axial displacement of the pile is sufficient for full mobilization of the limit shaft capacity $\left(Q_{s L}\right)$. In contrast to the shaft resistance mobilization mechanism, mobilization of the base resistance involves substantial amount of soil compression and requires large pile settlements. In fact, it is almost impossible for the plunging load or limit load $Q_{L}$ of piles routinely used in practice to be reached with conventional equipment unless the soil profile is very weak. Therefore, ultimate load $\left(Q_{u l t}\right)$ criteria have been traditionally used to define the capacity of a pile. In the case of the $10 \%$-relative-settlement criterion, $Q_{u l t}$ corresponds to the load for which the pile head displacement is $10 \%$ of the pile diameter; this is an example of an ultimate load criterion that is widely used in practice. Figure 1.2 illustrates these concepts.

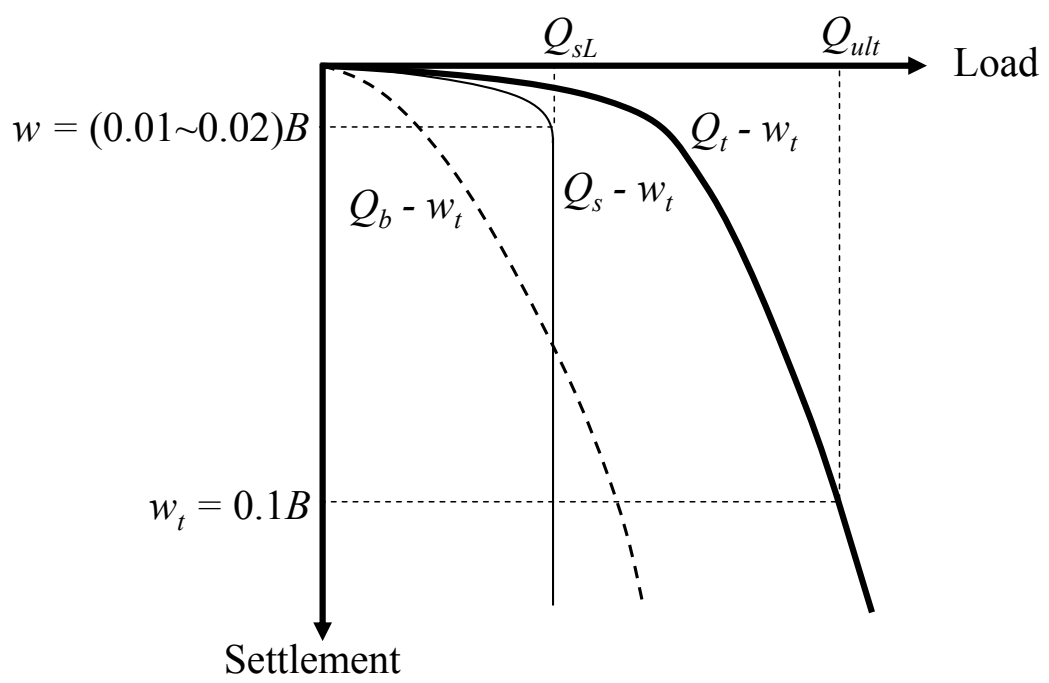

Figure 1.2 Typical load-settlement response of pile (modified after Franke 1991)

Micropiles are small-diameter piles that are sometimes called minipiles, root piles, pin piles or needle piles. The motivation behind this important technological development was the need of developing a small-diameter pile that would be able to carry large loads and, at the same time, cause minimal vibration or disturbance of the in situ soil during installation. Because of these important advantages, micropiles have been 
widely used in situations where minimal disturbance of existing structures is a requirement, such as in seismic retrofitting and in the rehabilitation of foundations of structures that are very sensitive (Taylor et al. 1998; Zelenko et el. 1998; Davie and Senapathy 2002; Macklin et al. 2004; Stulgis et al. 2004), as well as in locations with low headroom and severely restricted access conditions (Scherer et al. 1996). Micropiles have also been increasingly used, not only as foundation underpinning elements but also as foundations of new structures.

Micropiles can be installed through both rock and soil. Installation of micropiles involves three basic steps: 1) drilling a borehole, 2) placing the reinforcement and grouting the hole, and 3) injecting more grout under pressure as required. As a result of the way micropiles are installed, they are classified as nondisplacement or replacement piles. Typically, they are 100 to $300 \mathrm{~mm}$ in diameter (4-12 in) with lengths up to $30 \mathrm{~m}$ or more (Bruce et al. 1999). When micropiles are installed in competent rock within a reasonable depth below the ground surface, they are capable of resisting very large loads (Traylor and Bruce 2002; Bedenis et al. 2004a and 2004b).

Micropiles are designed to transfer the structural loads to competent soils or rocks through frictional resistance, with end bearing being usually neglected. The available unit friction resistance depends on the characteristics of the in situ materials, the method selected for drilling the holes, and the grouting procedures.

\subsection{Problem Statement}

In pile design, piles must be able to sustain axial loads from the superstructure without bearing capacity failure or structural damage. In addition, piles must not settle or deflect excessively in order for the serviceability of the superstructures to be maintained. In general, settlement controls the design of piles in most cases because, by the time a pile has failed in terms of bearing capacity, it is very likely that serviceability will have already been compromised. Therefore, realistic estimation of settlement for a given load is very important in design of axially loaded piles. This notwithstanding, pile design has relied on calculations of ultimate resistances reduced by factors of safety that would indirectly prevent settlement-based limit states. This is in part due to the lack of 
accessible realistic analysis tools for estimation of settlement, especially for piles installed in layered soil.

It is well known that the shaft resistance of a pile is usually fully mobilized at relatively small pile head displacements and well before the base resistance reaches its maximum value (except in the case of a floating pile). After full mobilization of shaft resistance, any additional load applied at the pile head is completely transferred to the pile base. However, the pile shaft load-displacement response, even at very small settlement levels, will not be perfectly linear because the stress-strain relationships of soils are highly nonlinear, except at very small strains (typically smaller than $10^{-6}$ ). Considering that pile head settlement results from the compression of the pile material itself and the settlement of the soil at the pile base, a useful analysis tool must be able to account for pile compressibility as well. Furthermore, the load-settlement response of piles in multilayered soil is not the same as that observed for a pile installed in a singlelayer soil.

Most of the analyses available in the literature for assessment of the loadsettlement response of an axially loaded pile were developed for either a homogeneous soil or Gibson soil (Poulos and Davis 1968; Randolph and Wroth 1978; Guo and Randolph 1997; Guo 2000). Although there are analysis methods (Poulos 1979; Lee 1991; Lee and Small 1991; Guo and Randolph 1997; Guo 2000) or closed-form solutions (Vallabhan and Mustafa 1996; Lee and Xiao 1999; Seo and Prezzi 2007) that are applicable to layered soils, these analyses are valid only for elastic soils. Therefore, development of advanced analysis tools that are able to capture realistically the pile axial load-settlement response in a multilayered soil is one of the goals of the present study.

Micropiles have been increasingly used, not only as foundations of new structures, but also as underpinning foundation elements. However, there are no design methods specifically developed for micropiles. Prevalent design methods are adaptations of methods originally developed for drilled shafts. However, the installation of micropiles differs from that of drilled shafts, and micropiles have higher pile length to diameter ratios than those of drilled shafts. Additionally, drilled shafts and micropiles differ structurally as well. In fact, results of a number of field axial load tests indicate that the 
actual capacity of micropiles embedded in rock is grossly underestimated (Finno et al. 2002; Bedenis et al. 2004b). Improved understanding of the load-transfer characteristics of micropiles and the development of pile settlement estimation tools consistent with the load-transfer response of these foundation elements are the main goals of the proposed research.

\subsection{Objectives and Organization}

In this report, we develop a new analysis method for assessment of the load-settlement response of axially loaded piles installed in multilayered soil or rock. We then perform extensive parametric studies on the load-settlement response of axially loaded piles installed in layered soil and rock-socketed piles. We also report the results of a static load test on a fully instrumented micropile embedded in hard limestone performed in cooperation with INDOT to investigate the load-transfer characteristics of rock-socketed micropiles. We compare the load test results with those obtained using the analysis developed in this study.

In Chapter 2, we review the analytical models available in the literature and examine the assumptions typically made in the analysis for axially loaded piles. Furthermore, we review the micropile design methods available in the literature.

In Chapter 3, using energy principles, we obtain the governing differential equations for an axially loaded pile installed in a multilayered linear elastic soil. We solve these differential equations and obtain explicit analytical solutions. We then compare the results from our solutions with those from finite element analyses.

In Chapter 4, we present the analysis results for rock-socketed piles. Extensive parametric studies are performed to investigate the load-settlement and load-transfer response of rock-socketed piles.

In Chapter 5, we present a user-friendly spreadsheet program ALPAXL developed in this study. The ALPAXL uses elastic solutions obtained in Chapter 3. We show how ALPAXL works and illustrate its use with a few micropile examples.

In Chapter 6, we present and analyze the results of the static load test performed in cooperation with INDOT on a micropile installed in rock. 
In Chapter 7, we present summarize the conclusions drawn from this study. 


\section{CHAPTER 2. LOAD-SETTLEMENT RESPONSE OF AXIALLY LOADED PILES}

\subsection{Introduction}

The available analyses for load-settlement response of axially loaded piles either assume that the soil resistance can be represented by a series of independent springs (the spring stiffness is determined through theoretical, experimental or empirical means) or treat the soil as a continuum (either homogeneous soil or Gibson soil). In this Chapter, we review the available tools for analysis of axially loaded piles. We also discuss the advantages and limitations of these methods of analysis for the load-settlement response of axially loaded piles.

\subsection{Load-Transfer Models}

The load-transfer models (Seed and Reese 1957; Coyle and Reese 1966; Murff 1975; Randolph and Wroth 1978; Kraft et al. 1981; Armaleh and Desai 1987; Kodikara and Johnston 1994; Motta 1994; Guo and Randolph 1997; Guo 2000) assume that the soil resistance can be represented by a series of independent springs (the spring stiffness is determined through theoretical, experimental or empirical means). This approach has the advantage that approximate analytical or simple numerical solutions of pile settlement can be easily obtained (Randolph and Wroth 1978; Armaleh and Desai 1987; Motta 1994; Mylonakis 2001).

\subsubsection{Randolph and Wroth's solution}

Randolph and Wroth (1978) presented a closed-form solution for the load-settlement response of an axially loaded pile. Their solution has been used as the basis for many 
other solutions that have been recently developed (Kraft et al. 1981; Guo and Randolph 1997; Guo 2000). The Randolph and Wroth's solution is presented next.

Randolph and Wroth (1978) assumed that the deformation of the soil surrounding the pile shaft may be idealized as shearing of concentric cylinders. Based on this assumption, the vertical equilibrium of a soil element is represented as follows:

$$
\frac{\partial}{\partial r}\left(r \tau_{r z}\right)+r \frac{\partial \sigma_{z}}{\partial z}=0
$$

where $r=$ radial distance from the pile axis; $z=$ depth; $\tau_{r z}=$ shear stress; $\sigma_{z}=$ vertical stress (taking compressive stresses as positive). These authors argued that the vertical stress $\sigma_{z}$ term in Eq. (2.1) could be neglected because the increase in shear stress is much larger than the increase in vertical stress near the pile when the pile is loaded. Therefore, Eq. (2.1) is further simplified to:

$$
\frac{\partial}{\partial r}\left(r \tau_{r z}\right)=0
$$

Denoting shear stress at the pile-soil interface as $q_{s}$ at $r=r_{p}$, Eq. (2.2) is integrated to give:

$$
\tau_{r z}=\frac{q_{s} r_{p}}{r}
$$

where $q_{s}=$ shear stress at the pile-soil interface and $r_{p}=$ pile radius $(=B / 2$, where $B$ is pile diameter).

Considering that the vertical displacement of the soil $u_{z}$ is much larger than the radial displacement of the soil $u_{r}$, the shear strain (reduction in angle taken as negative) is simplified to: 


$$
\gamma=-\left(\frac{\partial u_{z}}{\partial r}+\frac{\partial u_{r}}{\partial z}\right) \approx-\frac{\partial u_{z}}{\partial r}
$$

Now using the relationship $\tau=G \gamma$, Eq. (2.3) is rewritten as:

$$
\frac{\partial u_{z}}{\partial r} \approx-\frac{q_{s} r_{p}}{r G}
$$

To solve Eq. (2.5), Randolph and Wroth (1978) assumed that there is a magical radius $r_{m}$ around the pile beyond which $u_{z}=0$. Integrating Eq. (2.5) with this boundary condition gives:

$$
u_{z}=\frac{q_{s} r_{p}}{G} \ln \left(\frac{r_{m}}{r}\right)
$$

Accordingly, the pile shaft displacement $w_{s}$ is obtained by replacing $r$ with $r_{p}$ in Eq. (2.6):

$$
w_{s}=\frac{q_{s} r_{p}}{G} \ln \left(\frac{r_{m}}{r_{p}}\right)=\zeta \frac{q_{s} r_{p}}{G}
$$

in which $\zeta=\ln \left(r_{m} / r_{p}\right)$.

Eq. (2.7) clearly shows that determination of the magical radius $r_{m}$ is crucial in the estimation of pile shaft displacement. Furthermore, $r_{m}$ varies with depth. Randolph and Wroth (1978) assumed that $r_{m}$ is constant with depth and presented a depth-independent empirical equation that can be used to obtain $r_{m}$ :

$$
r_{m}=2.5 \rho L_{p}\left(1-v_{s}\right)
$$


where $L_{p}=$ pile length; $v_{s}=$ Poisson's ratio of the soil; and $\rho=G / G_{L p}=$ inhomogeneity factor, which is defined as the ratio of the soil modulus at the pile mid-depth to that at the pile base ( $\rho$ becomes 1 for a homogeneous soil and 0.5 for a Gibson soil).

Randolph and Wroth (1978) used a rigid punch solution at the surface of an elastic half space to model the pile base response:

$$
w_{b}=\frac{Q_{b}\left(1-v_{s}\right)}{4 r_{p} G} \eta
$$

where $w_{b}=$ pile base settlement; $Q_{b}=$ load at the pile base; and $\eta=$ depth factor that accounts for the stiffening effect of the soil above the level of the loaded area. According to Randolph and Wroth (1978), $\eta$ can be taken as unity for a straight (not underreamed) pile.

In order to estimate the effect of pile compressibility on the pile head settlement, Eq. (2.7) is written as:

$$
w(z)=\frac{q_{s}(z) r_{p}}{G} \ln \left(\frac{r_{m}}{r_{p}}\right)=\zeta \frac{q_{s}(z) r_{p}}{G}
$$

where $w(z)=$ pile displacement at depth $z$, and $q_{s}(z)=$ shear stress at the pile-soil interface at depth $z$. The axial load in the pile $Q(z)$ at depth z can be determined from the elastic compression of the pile:

$$
Q(z)=E_{p} A_{p} \varepsilon_{z}=-E_{p} A_{p} \frac{d w(z)}{d z}
$$

where $E_{p}=$ Young's modulus of the pile and $A_{p}=$ cross sectional area of the pile. The change in load $d Q$ can be related to the shear stress $q_{s}$ by: 


$$
d Q(z)=-2 \pi r_{p} q_{s}(z) d z
$$

Relating Eqs. (2.11) and (2.12) gives:

$$
-E_{p} A_{p} \frac{d^{2} w(z)}{d z^{2}}+2 \pi r_{p} q_{s}(z)=0
$$

Eq. (2.13) can be written as:

$$
-E_{p} A_{p} \frac{d^{2} w(z)}{d z^{2}}+k(z) w(z)=0
$$

by defining:

$$
k(z)=2 \pi r_{p} q_{s}(z) / w(z)
$$

The term $k(z)$ is called a Winkler constant. This constant has $\mathrm{FL}^{-2}$ units (where $\mathrm{F}$ is force and $\mathrm{L}$ is length) and represents the unit shaft resistance per unit length of pile at depth $z$ divided by the displacement there. Eq. (2.14) is simplified, using Eq. (2.10), to:

$$
\frac{d^{2} w(z)}{d z^{2}}-\frac{2}{\psi \zeta r_{p}^{2}} w(z)=0
$$

where $\psi=E_{p} / G$ (ratio of the pile stiffness to the soil stiffness). Eq. (2.16) is a $2^{\text {nd }}$ order ordinary differential equation with a general solution given by:

$$
w(z)=B e^{\mu z}+C e^{-\mu z}
$$


where $\mu=\left[2 /\left(\psi \zeta r_{\mathrm{p}}{ }^{2}\right)\right]^{0.5}$. The integration constants $B$ and $C$ can be determined from two boundary conditions at the pile base:

$$
\begin{gathered}
w\left(L_{p}\right)=w_{b}=\frac{Q_{b}\left(1-v_{s}\right)}{4 r_{p} G} \eta \\
Q\left(L_{p}\right)=Q_{b}=-\left.E_{P} A_{p} \frac{d w}{d z}\right|_{z=L_{p}}
\end{gathered}
$$

Solving for $B \& C$ and substituting back into Eq. (2.17) gives:

$$
w(z)=\frac{Q_{b}}{r_{p} G}\left\{\frac{\eta\left(1-v_{s}\right)}{4} \cosh \left[\mu\left(L_{p}-z\right)\right]+\frac{1}{\pi r_{p} \psi \mu} \sinh \left[\mu\left(L_{p}-z\right)\right]\right\}
$$

Now, the axial load $Q$ at any depth $z$ can be obtained by integrating Eq. (2.12) using Eqs. (2.10) and (2.20):

$$
Q(z)=\frac{2 \pi Q_{b}}{\zeta r_{p}}\left\{\frac{\eta\left(1-v_{s}\right)}{4 \mu} \sinh \left[\mu\left(L_{p}-z\right)\right]+\frac{\zeta r_{p}}{2 \pi} \cosh \left[\mu\left(L_{p}-z\right)\right]\right\}
$$

The settlement and load at the pile head can be determined from Eqs. (2.20) and (2.21) by making $z=0$, respectively:

$$
\begin{aligned}
& w_{t}=w(0)=\frac{Q_{b}}{r_{p} G}\left\{\frac{\eta\left(1-v_{s}\right)}{4} \cosh \left(\mu L_{p}\right)+\frac{1}{\pi r_{p} \psi \mu} \sinh \left(\mu L_{p}\right)\right\} \\
& Q_{t}=Q(0)=\frac{2 \pi Q_{b}}{\zeta r_{p}}\left\{\frac{\eta\left(1-v_{s}\right)}{4 \mu} \sinh \left(\mu L_{p}\right)+\frac{\zeta r_{p}}{2 \pi} \cosh \left(\mu L_{p}\right)\right\}
\end{aligned}
$$

Finally, relating Eqs. (2.22) and (2.23) gives us the load-settlement relationship at the pile head: 


$$
w_{t}=\frac{Q_{t}}{r_{p} G} \frac{\left\{1+\frac{4}{\eta\left(1-v_{s}\right)} \frac{1}{\pi \psi} \frac{L_{p}}{r_{p}} \frac{\tanh \left(\mu L_{p}\right)}{\mu L_{p}}\right\}}{\left\{\frac{4}{\eta\left(1-v_{s}\right)}+\frac{2 \pi}{\zeta} \frac{L_{p}}{r_{p}} \frac{\tanh \left(\mu L_{p}\right)}{\mu L_{p}}\right\}}
$$

Although Eq. (2.24) is relatively simple, it contains key parameters that affect the load-settlement response of axially loaded piles such as: the pile-soil stiffness ratio $\psi$ and the slenderness ratio of the pile $L_{p} / r_{p}$. However, as Randolph and Wroth pointed out, Eq. (2.24) becomes unstable for long compressible piles. Furthermore, Eq. (2.24) is limited to linear elastic, homogeneous soils or Gibson soils.

Other researchers, working from Randolph and Wroth's solution, included the effects of soil nonhomogeneity and layering. For example, Guo and Randolph (1997) and Guo (2000), using the same conceptual framework as Randolph and Wroth, provided linear elastic solutions in which the soil shear modulus varies as a power function of the depth $z$. Based on extensive numerical simulations in which the stiffness of the soil layer below the pile base is different from that just above it, Fleming et al. (1992) proposed an alternative expression for the magical radius:

$$
r_{m}=\left\{0.25+\left[2.5\left(1-v_{s}\right) \frac{G}{G_{L_{p}}}-0.25\right] \frac{G_{L_{p}}}{G_{b}}\right\} L_{p}
$$

where $G_{b}$ is the shear modulus of the soil below the pile base. Note that Eq. (2.25) reduces to Eq. (2.8) when $G_{L p}=G_{b}$.

In summary, in seeking a closed-form solution for estimation of settlement of an axially loaded pile, Randolph and Wroth (1978) assumed that the deformation of the soil surrounding the pile may be idealized as shearing of concentric cylinders. They also assumed that the soil is homogeneous and linear elastic. The effect of the vertical stress in the equilibrium equation (Eq. (2.1)) was disregarded. They further assumed that the 
vertical displacement $u_{z}$ of the soil controls the load-settlement response of axially loaded piles, and, therefore, neglected the radial displacement $u_{r}$ in the displacement field of the soil. To solve the differential equation resulting from these assumptions, they further assumed that the vertical displacement becomes zero beyond a horizontal distance $r_{m}$ from the pile. They ignored the variation of $r_{m}$ with depth and presented a depthindependent empirical equation for $r_{m}$. Pile compressibility was taken into account by allowing variation of shear stress along depth. Randolph and Wroth (1978) solution is limited to piles installed in a single-layer soil.

\subsubsection{Mylonakis solution}

Mylonakis (2001) obtained analytical solutions for a solid cylindrical pile embedded in a homogeneous soil layer over a rigid base. Mylonakis also neglected the radial soil displacement $u_{r}$, but did consider the vertical stress $\sigma_{z}$ term in Eq. (2.1). However, Mylonakis simplified the stress-displacement relations for $\sigma_{z}$ and $\tau_{r z}$ as follows:

$$
\begin{gathered}
\sigma_{z} \approx-M_{s} \frac{\partial u_{z}}{\partial z} \\
\tau_{r z} \approx-G \frac{\partial u_{z}}{\partial r}
\end{gathered}
$$

where $M_{S}$ is a constant that is determined from assumptions related to the stresses and/or strains in the stress-strain relationship. For example, assumption of zero radial and tangential strains in the soil medium $\left(\varepsilon_{r}=0\right.$ and $\left.\varepsilon_{\theta}=0\right)$ gives $M_{s}=2 G\left(1-v_{s}\right) /\left(1-2 v_{s}\right)$. A problem arising from this assumption is that $M_{s}$ is very sensitive to the Poisson's ratio of the soil $\left(M_{s}\right.$ becomes infinity as $v_{s}$ approaches 0.5$)$. On the other hand, assumption of zero radial and tangential stresses in the soil medium $\left(\sigma_{r}=0\right.$ and $\left.\sigma_{\theta}=0\right)$ yields $M_{s}=$ $2 G\left(1+v_{s}\right)$. Mylonakis argued that a condition of $\sigma_{r}=0$ and $\varepsilon_{\theta}=0$ is the best choice for the soil surrounding axially loaded piles. With these assumptions, $M_{s}=2 G /\left(1-v_{s}\right)$. 
By defining $\chi^{2}=M_{s} / G$ and substituting Eqs. (2.26) and (2.27) into Eq. (2.1), we obtain:

$$
\frac{\partial}{\partial r}\left(r \frac{\partial u_{z}}{\partial r}\right)+\chi^{2} r \frac{\partial^{2} u_{z}}{\partial z^{2}}=0
$$

Imposing the boundary conditions of zero normal tractions at the ground surface and zero vertical displacement at $r=\infty$ we get:

$$
u_{z}(r, z)=B_{c} K_{0}(\alpha \chi r) \cos \alpha z
$$

where $K_{0}(\cdot)=$ the modified Bessel function of the second kind of zero order; $\alpha=$ positive variable; and $B_{c}=$ integration constant to be determined from the boundary condition. Using the relations $q_{s}(z)=\tau_{r z}\left(r_{p}, z\right)$ and $w(z)=u_{z}\left(r_{p}, z\right)$ with Eqs. (2.27) and (2.29), Eq. (2.13) can be solved for end-bearing piles:

$$
w(z)=\frac{2 Q_{t}}{E_{p} A_{p} L_{p}} \sum_{m=0}^{\infty} \frac{K_{0}\left(\chi \alpha_{m} r_{p}\right) \cos \alpha_{m} z}{\alpha_{m}^{2}\left[K_{0}\left(\chi \alpha_{m} r_{p}\right)+\frac{\pi r_{p} \chi G}{2 E_{p} A_{p} \alpha_{m}} K_{1}\left(\chi \alpha_{m} r_{p}\right)\right]}
$$

where $K_{1}(\cdot)=$ the modified Bessel function of the second kind of first order and $\alpha_{m}=$ $\pi(2 m+1) /\left(2 L_{p}\right)$. The variable $\alpha_{m}$ ensures that soil displacement vanishes at the pile base for end-bearing piles $\left(w\left(L_{p}\right)=0\right)$. Recalling that $k(z)=2 \pi r_{p} q_{s}(z) / w(z)$ [Eq. (2.15)], expression for depth-dependent Winkler modulus values can be obtained from Eqs. (2.27) and (2.30) using the relation $q_{s}(z)=\tau_{r z}\left(r_{p}, z\right)$. If an average (depth-independent) or representative Winkler modulus is obtained, then a much simpler closed-form solution can be derived by solving Eq. (2.14). Mylonakis (2001) obtained an average Winkler modulus by matching pile head settlement with results from depth-dependent Winkler modulus. Through further multi-variable regression analyses with key parameters, 
Mylonakis (2001) proposed a simplified average (depth-independent) Winkler modulus equation:

$$
\frac{k}{G} \approx 1.3\left(\frac{E_{p}}{E_{s}}\right)^{-1 / 40}\left[1+7\left(\frac{L_{p}}{B}\right)^{-0.6}\right]
$$

where $E_{s}=$ Young's modulus of the soil and $B=$ pile diameter.

In summary, Mylonakis (2001) presented an analytical solution for the settlement of axially loaded piles installed over a rigid layer. The soil within the pile length was assumed to be homogeneous and linear elastic. In the equilibrium equation, the contribution of the vertical stress term was considered. This allowed Mylonakis to find an analytical solution for the load-settlement response of an axially loaded pile without using the concept of magical radius $r_{m}$. In the displacement field, he ignored the radial displacement of the soil. Mylonakis further assumed that $\sigma_{r}=0$ and $\varepsilon_{\theta}=0$ to get simplified stress-displacement relations for the soil surrounding the pile. Finally, a closed-form solution was obtained by solving the differential equation resulting from these assumptions. For practical applications, Mylonakis presented an expression for calculation of a representative (depth-independent) Winkler modulus by matching pile head settlement with results obtained using depth-dependent Winkler modulus. Mylonakis solution is limited to elastic soils and considers only a homogeneous single soil layer within the pile. Furthermore, this solution is only applicable to an ideal endbearing pile

\subsection{Continuum-Based Models}

The continuum-based models treat the soil surrounding the pile as a three-dimensional continuum. Although these models are more appealing conceptually than the loadtransfer models, they have traditionally required expensive numerical techniques, such as the boundary integral method, the finite layer method or the finite element method, to 
obtain solutions (Poulos and Davis 1968; Mattes and Poulos 1969; Butterfield and Banerjee 1971; Poulos 1979; Rajapakse 1990; Lee and Small 1991).

Recently, new continuum-based models were developed for axially loaded piles based on energy principles and calculus of variation (Vallabhan and Mustafa 1996; Lee and Xiao 1999; Seo and Prezzi 2007). The main advantage of these models is that they produce in seconds pile displacements and soil displacements using closed-form solutions.

\subsubsection{Vallabhan and Mustafa's solution}

Vallabhan and Mustafa (1996), using an iterative procedure, presented a closed-form solution for settlement of axially loaded piles in two-layered soil. Their solution was obtained by solving the differential equation resulting from potential energy minimization.

The domain consisted of two soil layers. The first layer, with elastic constants $E_{s 1}$ and $v_{s 1}$, extends from the ground surface to the pile base $\left(z=L_{p}\right)$, and the second layer, with elastic constants $E_{s 2}$ and $v_{s 2}$, extends from the pile base to infinity in the vertical direction. Assuming that the radial displacement in the soil is negligible, the vertical displacement $u_{z}$ of the soil at any location may be expressed as:

$$
u_{z}(r, z)=w(z) \phi(r)
$$

where $w(z)$ is the vertical displacement of the pile at a depth $z$, and $\phi(r)$ is the soil displacement dissipation function in the radial direction. Assuming no slippage between pile and soil and zero displacement at a greater distance from the pile, we get boundary conditions of $\phi\left(r_{p}\right)=1$ and $\phi(\infty)=0$. From the strain-displacement relationships, we have:

$$
\varepsilon_{z}=-\frac{\partial u_{z}}{\partial z}=-\frac{d w}{d z} \phi
$$




$$
\gamma_{r z}=-\left(\frac{\partial u_{z}}{\partial r}+\frac{\partial u_{r}}{\partial z}\right) \approx-w \frac{d \phi}{d r}
$$

Now, the total potential energy of the pile-soil system is given as:

$$
\begin{aligned}
\Pi= & U_{\text {pile }}+U_{\text {soil }}-Q_{t} w(0) \\
= & \frac{1}{2} \int_{0}^{L_{p}} E_{p} A_{p}\left(\phi \frac{d w}{d z}\right)^{2} d z+\frac{1}{2} \int_{0}^{L_{p}} \int_{0}^{2 \pi} \int_{r_{p}}^{\infty} \sigma_{i j} \varepsilon_{i j} r d r d \theta d z \\
& +\frac{1}{2} \int_{L_{p}}^{\infty} \int_{0}^{2 \pi} \int_{0}^{\infty} \sigma_{i j} \varepsilon_{i j} r d r d \theta d z-Q_{t} w(0)
\end{aligned}
$$

where $\sigma_{i j}$ and $\varepsilon_{i j}$ are the stress and strain tensors.

Using variational calculus, Vallabhan and Mustafa obtained the following differential equation for the pile $\left(0 \leq z \leq L_{p}\right)$ :

$$
-\left(E_{p} A_{p}+2 t_{1}\right) \frac{d^{2} w_{1}(z)}{d z^{2}}+k_{1} w_{1}(z)=0
$$

where

$$
\begin{gathered}
k_{1}=2 \pi G_{1} \int_{r_{p}}^{\infty} r\left(\frac{d \phi}{d r}\right)^{2} d r \\
t_{1}=\frac{\pi E_{s 1}\left(1-v_{s 1}\right)}{\left(1+v_{s 1}\right)\left(1-2 v_{s 1}\right)} \int_{r_{p}}^{\infty} r \phi^{2} d r
\end{gathered}
$$

Natural boundary conditions follow from the minimization of the total potential energy:

$$
-\left.\left(E_{p} A_{p}+2 t_{1}\right) \frac{d w}{d z}\right|_{z=0}=Q_{t}
$$




$$
-\left.\left(E_{p} A_{p}+2 t_{1}\right) \frac{d w}{d z}\right|_{z=L_{p}}=\left[\sqrt{k_{2}\left(E_{s 2} \pi r_{p}^{2}+2 t_{2}\right)}\right] w_{b}
$$

where $k_{2}$ and $t_{2}$ are obtained for the soil layer below the pile base from Eqs. (2.37) and (2.38), respectively, by replacing the subscript 1 with 2 .

The differential equation for the soil surrounding pile is given by:

$$
\frac{d^{2} \phi}{d r^{2}}+\frac{1}{r} \frac{d \phi}{d r}-\beta^{2} \phi=0
$$

The parameter $\beta$ in Eq. (2.41) is defined as:

$$
\beta=\sqrt{\frac{\frac{2 \pi E_{s 1}\left(1-v_{s 1}\right)}{\left(1+v_{s 1}\right)\left(1-2 v_{s 1}\right)} \int_{0}^{L_{p}}\left(\frac{d w_{1}}{d z}\right)^{2} d z+\frac{\pi E_{s 2}\left(1-v_{s 2}\right)}{\left(1+v_{s 2}\right)\left(1-2 v_{s 2}\right)}\left(\lambda_{b} w_{b}^{2}\right)}{2 \pi G_{1} \int_{0}^{L_{p}} w_{1}^{2} d z+\pi G_{2} w_{b}^{2} / \lambda_{b}}}
$$

where

$$
\lambda_{b}=\sqrt{\frac{k_{2}}{\frac{\pi r_{p}^{2} E_{s 2}\left(1-v_{s 2}\right)}{\left(1+v_{s 2}\right)\left(1-2 v_{s 2}\right)}+2 t_{2}}}
$$

Imposing the boundary conditions of $\phi\left(r_{p}\right)=1$ and $\phi(\infty)=0$, the solution for Eq. (2.41) is given as:

$$
\phi(r)=\frac{K_{0}(\beta r)}{K_{0}\left(\beta r_{p}\right)}
$$

Similarly, using the two boundary conditions expressed by Eqs. (2.39) and (2.40), the solution for Eq. (2.36) is given as: 


$$
\begin{aligned}
w(z) & =\frac{Q_{t} e^{\lambda L_{p}}\left(a_{2}+a_{1}\right)}{\left[e^{\lambda L_{p}}\left(a_{2}+a_{1}\right)+e^{-\lambda L_{p}}\left(a_{2}-a_{1}\right)\right] a_{1}} e^{\lambda z} \\
& +\frac{-Q_{t} e^{-\lambda L_{p}}\left(a_{2}-a_{1}\right)}{\left[e^{\lambda L_{p}}\left(a_{2}+a_{1}\right)+e^{-\lambda L_{p}}\left(a_{2}-a_{1}\right)\right] a_{1}} e^{-\lambda z}
\end{aligned}
$$

where

$$
\begin{gathered}
\lambda=\sqrt{\frac{k_{1}}{E_{p} A_{p}+2 t_{1}}} \\
a_{1}=\sqrt{k_{1}\left(E_{p} A_{p}+2 t_{1}\right)} \\
a_{2}=\sqrt{k_{2}\left(E_{s 2} \pi r_{p}^{2}+2 t_{2}\right)}
\end{gathered}
$$

The parameters $\lambda, a_{1}$, and $a_{2}$ in Eq. (2.45) contain $k_{1}, t_{1}, k_{2}$, and $t_{2}$ which are functions of $\phi$. Therefore, an iterative procedure is necessary to calculate $w(z)$. By assuming initially that $\beta=1$, values for $k$ and $t$ can be computed from Eqs. (2.37) and (2.38). Using these values, $\lambda, a_{1}$, and $a_{2}$ can then be determined from Eqs. (2.46) through (2.48), and, finally, $w(z)$ can be obtained from Eq. (2.45). A new $\beta$ value can be determined from Eq. (2.42). This iteration process is repeated until $\beta$ converges.

In summary, based on an iterative procedure, Vallabhan and Mustafa (1996) presented a closed-form solution for the response of axially loaded piles in two-layered linear elastic soil. The first layer extends from the ground surface to the pile base, while the second layer extends from the pile base to infinity in the vertical direction. They assumed that the radial displacement in the soil is negligible and that the vertical soil displacement can be expressed as multiplication of two independent functions: the pile displacement function and the soil displacement decay function. Although Vallabhan and Mustafa's solution requires an iterative procedure, it does not rely on the concept of the "magical radius". Also, it does satisfy the boundary conditions of the given problem both 
vertically and horizontally. Furthermore their solution overcomes the shortcomings of solutions presented by Randolph and Wroth (1978) and Mylonakis (2001) in that it is applicable to two-layered soil profiles.

\subsection{Design Methods for Axially loaded Micropiles}

\subsubsection{Geotechnical design}

\section{- Bustamante and Gianeselli (1982)}

Based on results from a large number of pile load tests and cone penetration tests (CPT), Bustamante and Gianeselli (1982) proposed an empirically-based design method that contains factors that depend on pile and soil type. They classified micropiles with low injection pressures into Category IA together with drilled shafts, CFA piles, and barrettes. High pressure grouted micropiles with diameters less than $250 \mathrm{~mm}$ were classified into Category IIIB. Table 2.1 gives the values of $\mathrm{q}_{\mathrm{sL}} / \mathrm{q}_{\mathrm{c}}$, where $\mathrm{q}_{\mathrm{sL}}$ is limit unit shaft resistance and $\mathrm{q}_{\mathrm{c}}$ is cone penetration resistance, for piles in Category IA and limit values of $\mathrm{q}_{\mathrm{sL}} / \mathrm{p}_{\mathrm{A}}$, where $\mathrm{p}_{\mathrm{A}}=$ reference stress $=100 \mathrm{kPa}$, for piles in Category IA and IIIB.

Table 2.1 Values of $\mathrm{q}_{\mathrm{sL}} / \mathrm{q}_{\mathrm{c}}$ and limit values of $\mathrm{q}_{\mathrm{sL}} / \mathrm{p}_{\mathrm{A}}$ (modified after Bustamante and Gianeselli 1982) 


\begin{tabular}{|c|c|c|c|c|}
\hline \multirow{2}{*}{ Soil type } & \multirow{2}{*}{$\mathrm{q}_{\mathrm{c}} / \mathrm{p}_{\mathrm{A}}$} & \multicolumn{2}{|c|}{$\mathrm{q}_{\mathrm{sL}} / \mathrm{q}_{\mathrm{c}}$} & \multicolumn{2}{|c|}{ Limit values of $\mathrm{q}_{\mathrm{sL}} / \mathrm{p}_{\mathrm{A}}$} \\
\cline { 3 - 5 } & & $\mathrm{IA}^{*}$ & $\mathrm{IA}$ & $\mathrm{IIIB}^{* *}$ \\
\hline Soft clay and mud & 10 & 0.0333 & 0.15 & - \\
\hline Moderately compact clay & $10-50$ & 0.0250 & $0.35(0.8)$ & $\geq 1.2$ \\
\hline Silt and loose sand & $\leq 50$ & 0.0167 & 0.35 & - \\
\hline Compact to stiff clay and compact silt & $>50$ & 0.0167 & $0.35(0.8)$ & $\geq 2.0$ \\
\hline Soft chalk & $<50$ & 0.0100 & 0.35 & - \\
\hline Moderately compact sand and gravel & $50-120$ & 0.0100 & $0.8(1.2)$ & $\geq 2.0$ \\
\hline Weathered to fragmented chalk & $>50$ & 0.0167 & $1.2(1.5)$ & $\geq 2.0$ \\
\hline Compact to very compact sand and gravel & $>120$ & 0.0067 & $1.2(1.5)$ & $\geq 2.0$ \\
\hline
\end{tabular}

Note: $\mathrm{p}_{\mathrm{A}}=$ reference stress $=100 \mathrm{kPa}=0.1 \mathrm{MPa} \approx 1 \mathrm{tsf}=2000 \mathrm{psf} ; \mathrm{q}_{\mathrm{sL}}=$ limit unit shaft resistance and $\mathrm{q}_{\mathrm{c}}=$ cone penetration resistance

* Category IA = micropiles grouted under low pressure, drilled shafts, CFA piles, and barrettes

** Category IIIB $=$ micropiles grouted under high pressure with diameters $<250 \mathrm{~mm}$

\section{- FHWA (1997)}

FHWA (1997) reviewed the literature and summarized the available recommendations for preliminary design of micropiles (Table 2.2). The authors of the report emphasized that extreme caution is required when using the recommended values in the design of micropiles. This is because most of the suggested design values were obtained from a database of load tests on drilled shafts, which have different installation methods and ratios of pile diameter to pile length.

Table 2.2 Summary of available recommendations for preliminary design of micropiles suggested by FHWA (modified after FHWA 1997) 


\begin{tabular}{|c|c|c|}
\hline \multirow[b]{2}{*}{ Soil Type } & \multicolumn{2}{|c|}{ Micropile Type } \\
\hline & $\begin{array}{c}\text { Type A } \\
\text { Tremie-Grouted }\end{array}$ & $\begin{array}{c}\text { Type B } \\
\text { Pressure-Grouted } \\
\end{array}$ \\
\hline Cohesionless & $\begin{aligned} \mathrm{q}_{\mathrm{sL}} & =\beta \sigma_{\mathrm{v}}^{\prime} \\
\beta & =\mathrm{K} \tan \phi^{\prime} \\
\mathrm{K} & =0.7\end{aligned}$ & $\begin{array}{c}\mathrm{q}_{\mathrm{sL}}=\mathrm{p}_{\mathrm{g}} \tan \phi^{\prime} \\
\mathrm{q}_{\mathrm{sL}}=\beta \sigma_{\mathrm{v}}^{\prime} \\
\beta=\mathrm{K} \tan \phi^{\prime} \\
\mathrm{K}=4-7 \text { for fine to medium sands } \\
\text { to coarse sands and gravels }\end{array}$ \\
\hline Cohesive & $\begin{array}{l}\mathrm{q}_{\mathrm{sL}}=\alpha \mathrm{s}_{\mathrm{u}} \\
\alpha=0.6-0.8\end{array}$ & Similar to type A \\
\hline Rocks & $\begin{array}{c}\mathrm{q}_{\mathrm{sL}}=\mathrm{q}_{\mathrm{u}} / 10 \leq 4 \mathrm{MPa} \\
\mathrm{q}_{\mathrm{sL}} / \mathrm{p}_{\mathrm{A}}=0.07 \mathrm{~N}_{\mathrm{SPT}}+1.2 \\
\text { for weathered granite } \\
\mathrm{q}_{\mathrm{sL}} / \mathrm{p}_{\mathrm{A}}=0.1 \mathrm{~N}_{\mathrm{SPT}} \\
\text { for stiff to hard chalk }\end{array}$ & Similar to type A \\
\hline
\end{tabular}

Note: $\mathrm{p}_{\mathrm{A}}=$ reference stress $=100 \mathrm{kPa}=0.1 \mathrm{MPa} \approx 1$ tsf $=2000 \mathrm{psf} ; \sigma^{\prime}{ }_{\mathrm{v}}=$ vertical effective stress in the center of the soil layer; $\mathrm{K}=$ coefficient of lateral earth pressure; $\phi^{\prime}=$ effective friction angle of the soil; $\mathrm{s}_{\mathrm{u}}=$ undrained shear strength of the soil; $\mathrm{q}_{\mathrm{u}}=$ unconfined compressive strength of intact rock; $\mathrm{q}_{\mathrm{sL}}=$ limit unit shaft resistance; $\mathrm{N}_{\mathrm{SPT}}=$ SPT blow counts; $p_{g}=$ grouting pressure

\section{- FHWA (2000)}

FHWA (2000) suggested typical ranges of values for limit unit shaft resistance $\mathrm{q}_{\mathrm{sL}}$ for various micropile installation methods and ground conditions (Table 2.3). This has been widely used in practice since 2000. The authors of the report indicated that the recommended design values are intended to assist the designer with the preliminary design but that higher values may be used if load test data is available for the specific conditions considered.

Table 2.3 Summary of typical values of limit unit shaft resistance (modified after FHWA 2000) 


\begin{tabular}{|c|c|c|c|c|}
\hline \multirow{2}{*}{ Soil / Rock Description } & \multicolumn{4}{|c|}{ Typical range of $\mathrm{q}_{\mathrm{sL}} / \mathrm{p}_{\mathrm{A}}$} \\
\hline & Type A & Type B & Type C & Type D \\
\hline $\begin{array}{l}\text { Silt \& Clay (some sand) } \\
\text { (soft, medium plastic) }\end{array}$ & $0.35-0.7$ & $\begin{array}{l}0.35- \\
0.95\end{array}$ & $0.5-1.2$ & $0.5-1.45$ \\
\hline $\begin{array}{l}\text { Silt \& Clay (some sand) } \\
\text { (stiff, dense to very dense) }\end{array}$ & $0.5-1.2$ & $0.7-1.9$ & $0.95-1.9$ & $0.95-1.9$ \\
\hline $\begin{array}{l}\text { Sand (some silt) } \\
\text { (fine, loose-medium dense) }\end{array}$ & $0.7-1.45$ & $0.7-1.9$ & $0.95-1.9$ & $0.95-2.4$ \\
\hline $\begin{array}{c}\text { Sand (some silt, gravel) } \\
\text { (fine-coarse, medium-very dense) }\end{array}$ & $\begin{array}{l}0.95- \\
2.15\end{array}$ & $1.2-3.6$ & $1.45-3.6$ & $\begin{array}{l}1.45- \\
3.85\end{array}$ \\
\hline $\begin{array}{l}\text { Gravel (some sand) } \\
\text { (medium-very dense) }\end{array}$ & $\begin{array}{l}0.95- \\
2.65\end{array}$ & $1.2-3.6$ & $1.45-3.6$ & $\begin{array}{l}1.45- \\
3.85\end{array}$ \\
\hline $\begin{array}{l}\text { Glacial Till (silt, sand, gravel) } \\
\text { (medium-very dense, cemented) }\end{array}$ & $0.95-1.9$ & $0.95-3.1$ & $1.2-3.1$ & $1.2-3.35$ \\
\hline $\begin{array}{l}\text { Soft Shales (fresh-moderate fracturing, } \\
\text { little to no weathering) }\end{array}$ & $2.05-5.5$ & $\mathrm{~N} / \mathrm{A}$ & $\mathrm{N} / \mathrm{A}$ & $\mathrm{N} / \mathrm{A}$ \\
\hline $\begin{array}{l}\text { Slates and Hard Shales (fresh-moderate } \\
\text { fracturing, little to no weathering) }\end{array}$ & $\begin{array}{c}5.15- \\
13.8 \\
\end{array}$ & $\mathrm{~N} / \mathrm{A}$ & N/A & N/A \\
\hline $\begin{array}{l}\text { Limestone (fresh-moderate fracturing, } \\
\text { little to no weathering) }\end{array}$ & $\begin{array}{c}10.35- \\
20.7\end{array}$ & $\mathrm{~N} / \mathrm{A}$ & N/A & $\mathrm{N} / \mathrm{A}$ \\
\hline $\begin{array}{l}\text { Sandstone (fresh-moderate fracturing, } \\
\text { little to no weathering) }\end{array}$ & $\begin{array}{c}5.2- \\
17.25 \\
\end{array}$ & N/A & $\mathrm{N} / \mathrm{A}$ & N/A \\
\hline $\begin{array}{l}\text { Granite and Basalt (fresh-moderate } \\
\text { fracturing, little to no weathering) }\end{array}$ & $13.8-42$ & $\mathrm{~N} / \mathrm{A}$ & $\mathrm{N} / \mathrm{A}$ & $\mathrm{N} / \mathrm{A}$ \\
\hline
\end{tabular}

Note: $\mathrm{p}_{\mathrm{A}}=$ reference stress $=100 \mathrm{kPa}=0.1 \mathrm{MPa} \approx 1 \mathrm{tsf}=2000 \mathrm{psf}$

Type A: Gravity grout only

Type B: Pressure grouted through the casing during casing withdrawal

Type C: Primary grout placed under gravity head, then one phase of secondary "global" pressure grouting

Type D: Primary grout placed under gravity head, then one or more phases of secondary "global" pressure grouting

\subsubsection{Structural design}

As micropile reinforcements are placed either before or after the initial grouting operations, micropiles function, in essence, as composite materials. Depending on the local practice, different reinforcement configurations are used. Figure 2.1 shows a typical configuration for the structural components of a micropile. The steel casing can either remain in the ground or be extracted. 


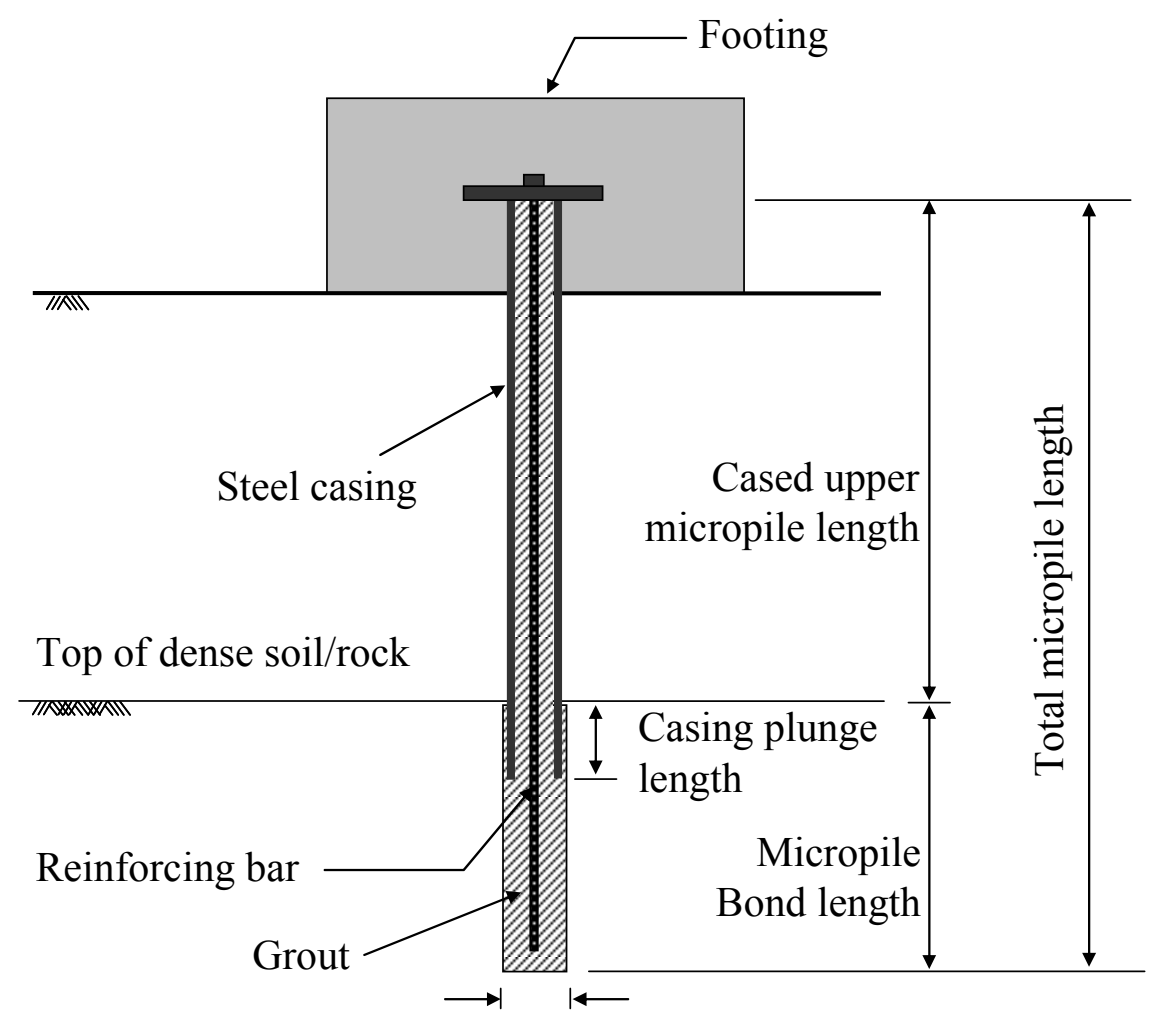

Grouted bond zone diameter

Figure 2.1 Detail of a composite reinforced micropile (after FHWA 2000)

- FHWA (2000)

FHWA (2000) uses highway bridge design codes [AASHTO (1996)] for the structural design of various components of micropiles. The maximum axial load $\mathrm{Q}_{0}$ the pile can structurally carry is given by:

$$
Q_{0}=0.85 f_{c}^{\prime} A_{c}+f_{y} A_{s}
$$

where $f_{c}^{\prime}=$ unconfined compressive strength of cement grout; $A_{c}=$ cross sectional area of cement grout; $f_{y}=$ yield stress of steel; $A_{s}=$ cross-sectional area of steel components. To ensure strain compatibility between the casing and the reinforcing bar, the yield stress for 


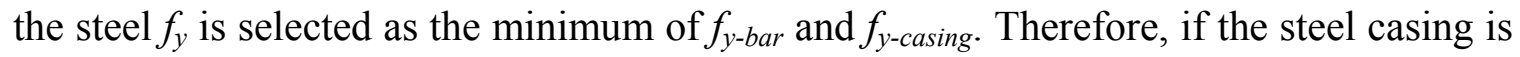
left in the ground, Eq. (2.50) can be written as:

$$
Q_{0}=0.85 f_{c}^{\prime} A_{c}+\min \left(f_{y \text {-bar }}, f_{y \text {-casing }}\right)\left(A_{\text {bar }}+A_{\text {casing }}\right)
$$

where $A_{b a r}=$ area of reinforcing bar; $A_{\text {casing }}=$ area of steel casing. Using factor of safety $\mathrm{FS}=2.12$, the allowable structural load is given by:

$$
Q_{0, \text { all }}=0.40 f_{c}^{\prime} A_{c}+0.47 \min \left(f_{y \text {-bar }}, f_{y \text {-casing }}\right)\left(A_{\text {bar }}+A_{\text {casing }}\right)
$$




\section{CHAPTER 3. ELASTIC SOLUTIONS FOR AXIALLY LOADED PILES IN MULTILAYERED SOIL}

\subsection{Introduction}

In CHAPTER 2, we reviewed the analytical models for the response of axially loaded piles. Most of these models offer analytical solutions for a homogeneous, single soil layer. However, in reality, piles are rarely installed in an ideal, homogeneous, single soil layer. For this reason, analytical solutions for axially loaded piles embedded in a nonhomogeneous soil deposit have been sought. Lee (1991) and Lee and Small (1991) proposed solutions for axially loaded piles in finite layered soil using a discrete layer analysis. Chin and Poulos (1991) presented solutions for an axially loaded pile embedded in a Gibson soil and a two-layered soil using the load-transfer method. Guo and Randolph (1997) and Guo (2000) obtained elastic-plastic solutions for the axial response of piles in a Gibson soil. Most of the analytical studies have been developed for a Gibson soil rather than for a multilayered soil because the mathematical treatment is easier in that case.

As we saw in CHAPTER 2, Vallabhan and Mustafa (1996) proposed a simple closed-form solution for an axially loaded pile embedded in a two-layer elastic soil medium based on energy principles. Lee and Xiao (1999) expanded the solution of Vallabhan and Mustafa (1996) to multilayered soil and compared their solution with the results from Poulos (1979) for three-layered soil. Although Lee and Xiao (1999) suggested an analytical method for an axially loaded pile in a multilayered soil, they did not obtain explicit analytical solutions.

In this chapter, we present explicit analytical solutions for an axially loaded pile in a multilayered soil. The soil is assumed to behave as a linear elastic material. The governing differential equations are derived based on energy principles and calculus of variations. The integration constants are determined using Cramer's rule and a recurrence formula. In addition, solutions for a pile embedded in a multilayered soil with the base 
resting on a rigid material are obtained by changing the boundary conditions of the problem. We also present solutions for a pile embedded in a multilayered soil subjected to tensile loading. We first review the mathematical formulation and the derivation of the equations using energy principles. We then compare our solutions with others from the literature. Finally, we use the results of a pile load test from the literature to verify the results obtained using the solutions proposed in this study.

\subsection{Mathematical Formulation}

\subsubsection{Problem definition and basic assumptions}

We consider a cylindrical pile of length $L_{p}$ and circular cross section of diameter $B\left(=2 r_{p}\right)$. The pile, which is subjected to an axial load $Q_{t}$, is embedded in a total of $N$ horizontal soil layers. The pile itself crosses $m$ layers, while $N-m$ layers exist below the base of the pile. All soil layers extend to infinity in the radial direction, and the bottom $\left(N^{\text {th }}\right)$ layer extends to infinity downward in the vertical direction. As shown in Figure 3.1, $H_{i}$ denotes the vertical depth from the ground surface to the bottom of any layer $i$, which implies that the thickness of layer $i$ is $H_{i}-H_{i-1}$ with $H_{0}=0$. 


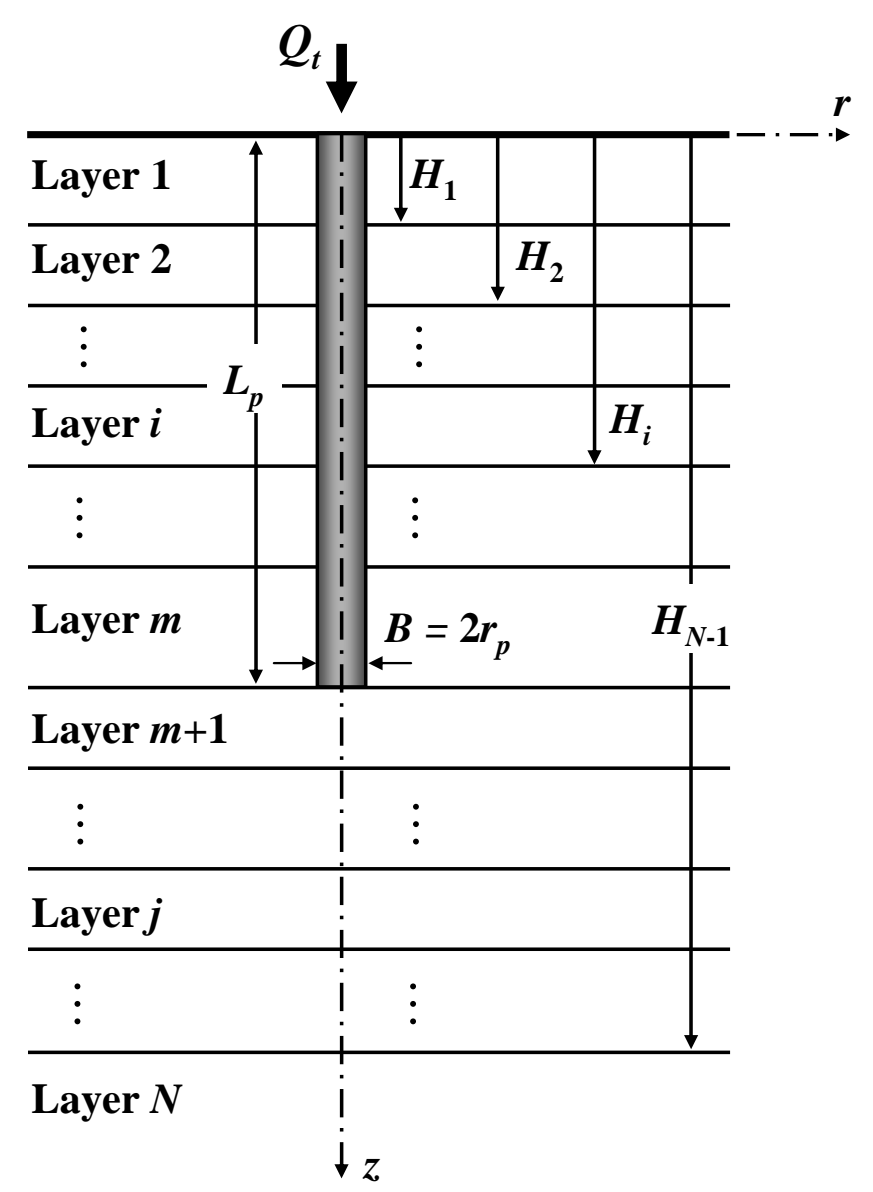

Figure 3.1 Geometry of the pile-soil system

We refer to the pile cross section at the top of the pile as the pile head and to the pile cross section at the base of the pile as the pile base. Since the problem is axisymmetric, we choose a system of cylindrical coordinates with the origin coinciding with the center of the pile cross section at the pile head, and the $z$ axis coinciding with the pile axis ( $z$ is positive in the downward direction). One of the assumptions we have made is that the pile and the surrounding soil have perfect compatibility of displacements at the pile-soil interface and at the boundaries between soil layers. In other words, it is assumed that there is no slippage or separation between the pile and the surrounding soil and between soil layers. Furthermore, the soil medium within each layer is assumed to be isotropic, homogeneous, and linear elastic. Since radial and tangential strains are very small when compared with the vertical strains, they are neglected. As previously done by 
Vallabhan and Mustafa (1996) and Lee and Xiao (1999), the vertical displacement at any point in the soil $u_{z}(r, z)$ is represented by:

$$
u_{z}(r, z)=w(z) \cdot \phi(r)
$$

where $w(z)$ is the vertical displacement of the pile at a depth equal to $z$, and $\phi(r)$ is the soil displacement dissipation function in the radial direction. The function $\phi(r)$ is a shape function that determines the rate at which the vertical soil displacement decreases in the radial direction with increasing distance from the pile. Since the vertical displacements within any given cross section of the pile are the same, we assume that $\phi(r)=1$ from $r=$ 0 to $r=r_{p}$. As the vertical soil displacement is zero as $r$ approaches infinity, we assume that $\phi(r)=0$ at $r \rightarrow \infty$.

\subsubsection{Stress-strain-displacement relationships}

The stress-strain relationship in an isotropic elastic soil medium can be expressed as:

$$
\left[\begin{array}{c}
\sigma_{r} \\
\sigma_{\theta} \\
\sigma_{z} \\
\tau_{r \theta} \\
\tau_{r z} \\
\tau_{\theta z}
\end{array}\right]=\left[\begin{array}{cccccc}
\lambda_{s}+2 G_{s} & \lambda_{s} & \lambda_{s} & 0 & 0 & 0 \\
\lambda_{s} & \lambda_{s}+2 G_{s} & \lambda_{s} & 0 & 0 & 0 \\
\lambda_{s} & \lambda_{s} & \lambda_{s}+2 G_{s} & 0 & 0 & 0 \\
0 & 0 & 0 & G_{s} & 0 & 0 \\
0 & 0 & 0 & 0 & G_{s} & 0 \\
0 & 0 & 0 & 0 & 0 & G_{s}
\end{array}\right]\left[\begin{array}{c}
\varepsilon_{r} \\
\varepsilon_{\theta} \\
\varepsilon_{z} \\
\gamma_{r \theta} \\
\gamma_{r z} \\
\gamma_{\theta z}
\end{array}\right]
$$

where $G_{s}$ and $\lambda_{s}=$ the elastic constants of the soil; $\sigma_{r}, \sigma_{\theta}, \sigma_{z}=$ normal stresses; $\tau_{r} \theta, \tau_{r z}, \tau_{\theta z}$ $=$ shear stresses; $\varepsilon_{r}, \varepsilon_{\theta}, \varepsilon_{z}=$ normal strains; $\gamma_{r} \theta, \gamma_{r z}, \gamma_{\theta z}=$ shear strains.

As the problem considered here is axisymmetric, all shear stresses and shear strains related to $\theta$ direction vanish. Accordingly, the strain-displacement relationship is given by 


$$
\left[\begin{array}{c}
\varepsilon_{r} \\
\varepsilon_{\theta} \\
\varepsilon_{z} \\
\gamma_{r \theta} \\
\gamma_{r z} \\
\gamma_{\theta z}
\end{array}\right]=\left[\begin{array}{c}
-\frac{\partial u_{r}}{\partial r} \\
-\frac{u_{r}}{r}-\frac{1}{r} \frac{\partial u_{\theta}}{\partial \theta} \\
-\frac{\partial u_{z}}{\partial z} \\
-\frac{1}{r} \frac{\partial u_{r}}{\partial \theta}-\frac{\partial u_{\theta}}{\partial r}+\frac{u_{\theta}}{r} \\
-\frac{\partial u_{z}}{\partial r}-\frac{\partial u_{r}}{\partial z} \\
-\frac{1}{r} \frac{\partial u_{z}}{\partial \theta}-\frac{\partial u_{\theta}}{\partial z}
\end{array}\right]=\left[\begin{array}{c}
0 \\
0 \\
-\phi(r) \frac{d w(z)}{d z} \\
0 \\
-w(z) \frac{d \phi(r)}{d r} \\
0
\end{array}\right]
$$

where $u_{r}, u_{\theta}, u_{z}=$ radial, tangential, and vertical displacement of the soil, respectively.

By substituting Eq. (3.3) into (3.2), we obtain the strain energy density function $W=1 / 2 \sigma_{p q} \varepsilon_{p q}$, with summation implied by the repetition of the indices $p$ and $q$ as required in indicial notation:

$$
\frac{1}{2} \sigma_{p q} \varepsilon_{p q}=\frac{1}{2}\left[\left(\lambda_{s}+2 G_{s}\right)\left(\phi \frac{d w}{d z}\right)^{2}+G_{s}\left(w \frac{d \phi}{d r}\right)^{2}\right]
$$

where $\sigma_{p q}$ and $\varepsilon_{p q}$ are the stress and strain tensors.

3.2.3. Governing differential equation for the pile and soil beneath the pile The total potential energy $\Pi$ of an elastic body is defined as the sum of the internal potential energy (the sum of the strain energy $U$ of the pile and soil) and the external potential energy (equal to minus the work done by the external forces applied to the pile in taking it from the at-rest condition to its configuration under load). The total potential energy of the soil-pile system subjected to an axial force $Q_{t}$ is given by: 


$$
\begin{aligned}
\Pi & =U_{\text {pile }}+U_{\text {soil }}-Q_{t} w(0) \\
& =\frac{1}{2} \int_{0}^{L_{p}} E_{p} A_{p}\left(\phi \frac{d w}{d z}\right)^{2} d z+\frac{1}{2} \int_{0}^{L_{p}} \int_{0}^{2 \pi} \int_{r_{p}}^{\infty} \sigma_{p q} \varepsilon_{p q} r d r d \theta d z \\
& +\frac{1}{2} \int_{L_{p}}^{\infty} \int_{0}^{2 \pi} \int_{0}^{\infty} \sigma_{p q} \varepsilon_{p q} r d r d \theta d z-Q_{t} w(0)
\end{aligned}
$$

Substituting (3.4) into (3.5) and integrating it with respect to $\theta$, we obtain:

$$
\begin{aligned}
\Pi= & \frac{1}{2} \int_{0}^{L_{p}} E_{p} A_{p}\left(\phi \frac{d w}{d z}\right)^{2} d z+\pi \int_{0}^{L_{p}} \int_{r_{p}}^{\infty}\left[\left(\lambda_{s}+2 G_{s}\right)\left(\phi \frac{d w}{d z}\right)^{2}+G_{s}\left(w \frac{d \phi}{d r}\right)^{2}\right] r d r d z \\
& +\pi \int_{L_{p}}^{\infty} \int_{0}^{\infty}\left[\left(\lambda_{s}+2 G_{s}\right)\left(\phi \frac{d w}{d z}\right)^{2}+G_{s}\left(w \frac{d \phi}{d r}\right)^{2}\right] r d r d z-Q_{t} w(0)
\end{aligned}
$$

We can now use calculus of variations to obtain the equilibrium equations. According to the principle of minimum total potential energy, exact solutions should minimize Eq. (3.6) and hence $\delta \Pi$ must be zero, where $\delta$ is a variational operator. Applying the principle of minimum potential energy yields an equation of the form:

$$
A(w) \delta w+B(\phi) \delta \phi=0
$$

Since the functions $w$ and $\phi$ are not known a priori, their variations $\delta w$ and $\delta \phi$ are not zero. Therefore, Eq. (3.7) is satisfied if and only if $A(w)=0$ and $B(\phi)=0$. These equations represent the governing differential equations of the functions $w(z)$ and $\phi(r)$, respectively; the equilibrium configuration of the pile-soil system is obtained by solving these equations.

For $0 \leq z \leq L_{p}$, the following differential equation for the pile displacement in any layer $i$ is obtained: 


$$
-\left(E_{p} A_{p}+2 t_{i}\right) \frac{d^{2} w_{i}}{d z^{2}}+k_{i} w_{i}=0 \text { for } 0 \leq z \leq L_{p}
$$

where,

$$
\begin{aligned}
& k_{i}=2 \pi G_{s i} \int_{r_{p}}^{\infty} r\left(\frac{d \phi}{d r}\right)^{2} d r \\
& t_{i}=\pi\left(\lambda_{s i}+2 G_{s i}\right) \int_{r_{p}}^{\infty} r \phi^{2} d r
\end{aligned}
$$

Since we have $m$ layers in this interval $\left(0 \leq z \leq L_{p}\right)$, Eq. (3.8) is valid for $i=1 \ldots$ $m$. The parameter $k_{i}$ has units of $\mathrm{FL}^{-2}$ (F and L denote force and length, respectively) and represents the shearing resistance of the soil in the vertical direction and, hence, the change in shear stress along the radial direction. On the other hand, $t_{i}$ has units of force and accounts for the soil resistance due to vertical compression of hollow cylinders around the pile (see Figure 3.2)

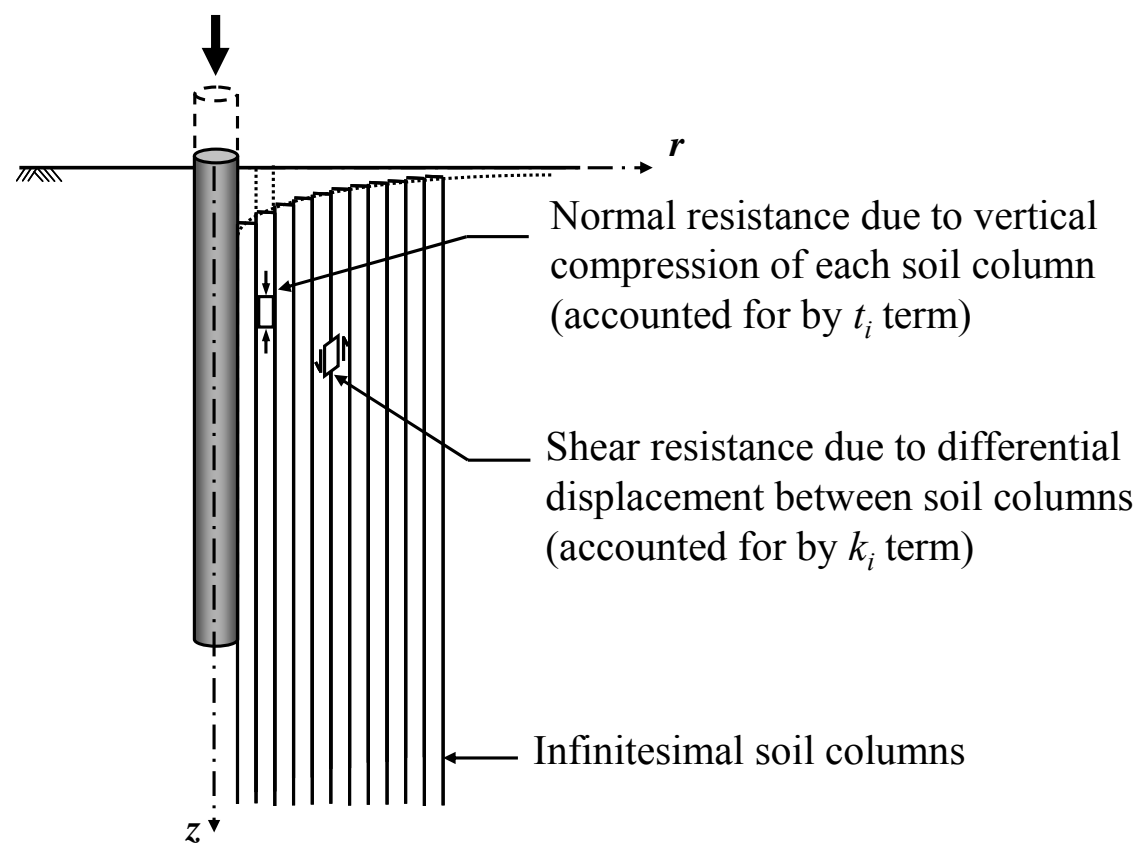

Figure 3.2 Illustration of two sources of soil resistance 
Similarly, we obtain the following differential equation for the soil displacement in any layer $j$ beneath the pile:

$$
-\left[\pi r_{p}^{2}\left(\lambda_{s j}+2 G_{s j}\right)+2 t_{j}\right] \frac{d^{2} w_{j}}{d z^{2}}+k_{j} w_{j}=0 \text { for } L_{p} \leq z \leq \infty
$$

where $k_{j}$ and $t_{j}$ are also defined by Eqs. (3.9) and (3.10) with $j$ in place of $i$. Equation (3.11) is valid for $j=m+1 \ldots N$.

Eqs. (3.8) and (3.11), which were obtained for different domains, can be consolidated into a single governing differential equation. This can be done by noting that $\lambda_{s i}+2 G_{s i}$ is a function of the Poisson's ratio $v_{s i}$ and the Young's modulus $E_{s i}$ of the soil. This leads to:

$$
\lambda_{s i}+2 G_{s i}=\frac{E_{s i}\left(1-v_{s i}\right)}{\left(1+v_{s i}\right)\left(1-2 v_{s i}\right)}=\bar{E}_{s i} \text { for } L_{p} \leq z \leq \infty
$$

where $\bar{E}_{s i}$ is the constrained modulus of the soil for a given layer $i$. Using this notation, we can get the governing differential equation for the pile and soil below it:

$$
-\left(E_{i} A_{i}+2 t_{i}\right) \frac{d^{2} w_{i}}{d z^{2}}+k_{i} w_{i}=0
$$

where $E_{i}=E_{p}$ and $A_{i}=A_{p}$ when $1 \leq i \leq m ; E_{i}=\bar{E}_{s i}$ and $A_{i}=\pi r_{p}^{2}$ when $m+1 \leq i \leq N$. This notation for $E_{i}$ and $A_{i}$ will be used hereafter unless otherwise stated. Note that both $k_{i}$ and $t_{i}$ are functions of $\phi$ and of the shear modulus of the soil. 
3.2.4. Governing differential equation for the soil surrounding the pile

As done earlier, we obtain the governing differential equation for the soil surrounding the pile by taking the variation of $\phi$ and then equating the coefficient of it to zero:

$$
\frac{d^{2} \phi}{d r^{2}}+\frac{1}{r} \frac{d \phi}{d r}-\beta^{2} \phi=0
$$

where

$$
\beta=\sqrt{\frac{n_{s}}{m_{s}}}
$$

and, $m_{s}$ and $n_{s}$ are given by:

$$
\begin{gathered}
m_{s}=\sum_{i=1}^{N} G_{s i} \int_{H_{i-1}}^{H_{i}} w_{i}^{2} d z \\
n_{s}=\sum_{i=1}^{N}\left(\lambda_{s i}+2 G_{s i}\right) \int_{H_{i-1}}^{H_{i}}\left(\frac{d w_{i}}{d z}\right)^{2} d z
\end{gathered}
$$

The parameter $m_{s}$ has units of FL, and $n_{s}$ has units of $\mathrm{FL}^{-1}$. Therefore, $\beta$ has units of $\mathrm{L}^{-1}$, and it determines the rate at which the vertical soil displacement diminishes in the radial direction.

\subsection{Solutions for a Pile in a Layered Soil under Compressive Load}

3.3.1. Solution for the displacement dissipation function $\phi$

Equation (3.14) is a form of the modified Bessel differential equation, and its general solution is given by: 


$$
\phi(r)=c_{1} I_{0}(\beta r)+c_{2} K_{0}(\beta r)
$$

where $I_{0}(\cdot)$ is the modified Bessel function of the first kind of zero order, and $K_{0}(\cdot)$ is the modified Bessel function of the second kind of zero order.

As discussed earlier, $\phi(r)=1$ at $r=r_{p}$, and $\phi=0$ at $r \rightarrow \infty$. Imposition of these boundary conditions leads to:

$$
\phi(r)=\frac{K_{0}(\beta r)}{K_{0}\left(\beta r_{p}\right)}
$$

Substituting Eq. (3.19) into Eqs. (3.9) and (3.10) and using the properties of the modified Bessel functions, we can now have explicit expressions for $k_{i}$ and $t_{i}$ :

$$
\begin{gathered}
k_{i}=\pi G_{s i} \frac{\left[K_{1}\left(\beta r_{p}\right)+\beta r_{p} K_{0}\left(\beta r_{p}\right)\right]^{2}-\left(\beta r_{p}^{2}+1\right)\left[K_{1}\left(\beta r_{p}\right)\right]^{2}}{\left[K_{0}\left(\beta r_{p}\right)\right]^{2}} \\
t_{i}=\frac{1}{2} \pi r_{p}^{2}\left(\lambda_{s i}+2 G_{s i}\right) \frac{\left[K_{1}\left(\beta r_{p}\right)\right]^{2}-\left[K_{0}\left(\beta r_{p}\right)\right]^{2}}{\left[K_{0}\left(\beta r_{p}\right)\right]^{2}}
\end{gathered}
$$

where $K_{1}(\cdot)$ is the modified Bessel function of the second kind of first order.

\subsubsection{Solution for the pile displacement function $w$}

The general solution of Eq. (3.13), which is a second-order linear differential equation, is given by

$$
w_{i}(z)=B_{i} e^{\lambda_{i} z}+C_{i} e^{-\lambda_{i} z}
$$

where 


$$
\lambda_{i}=\sqrt{\frac{k_{i}}{E_{i} A_{i}+2 t_{i}}}
$$

and $B_{i}$ and $C_{i}$ are integration constants. We obtain the pile axial strain by differentiating (3.22) with respect to $z$. Based on the relationship between the axial strain and the axial force, we get:

$$
Q_{i}(z)=-\left(E_{i} A_{i}+2 t_{i}\right) \frac{d w_{i}}{d z}
$$

where $Q_{i}(z)$ is the axial load acting in the pile at a depth $z$ in the $i^{\text {th }}$ layer.

Then, the following equation for the axial load transferred to the pile results:

$$
Q_{i}(z)=-a_{i} B_{i} e^{\lambda_{i} z}+a_{i} C_{i} e^{-\lambda_{i} z}
$$

where

$$
a_{i}=\lambda_{i}\left(E_{i} A_{i}+2 t_{i}\right)=\sqrt{k_{i}\left(E_{i} A_{i}+2 t_{i}\right)}
$$

As we have $2 N$ unknown integration constants $\left(B_{1}, C_{1}, B_{2}, C_{2}, \ldots, B_{N}, C_{N}\right)$, we need to identify $2 \mathrm{~N}$ boundary conditions in order to determine their values. First of all, the vertical soil displacement at an infinite depth below the pile base must be zero. Also, the magnitude of the load at the pile head should be equal to the applied external load. Finally, displacement and force should be the same at the interface between any two layers when calculated with the properties of either layer. These give us the $2 N$ boundary conditions, which can be used to determine all the integration constants. These boundary conditions can be expressed as follows:

$$
\left.w_{N}(z)\right|_{z \rightarrow \infty}=0
$$




$$
\begin{gathered}
\left.Q_{1}(z)\right|_{z=0}=Q_{t} \\
e^{\lambda_{i} H_{i}} B_{i}+e^{-\lambda_{i} H_{i}} C_{i}-e^{\lambda_{i+1} H_{i}} B_{i+1}-e^{-\lambda_{i+1} H_{i}} C_{i+1}=0 \text { for } 1 \leq i \leq N-1 \\
-a_{i} e^{\lambda_{i} H_{i}} B_{i}+a_{i} e^{-\lambda_{i} H_{i}} C_{i}+a_{i+1} e^{\lambda_{i+1} H_{i}} B_{i+1}-a_{i+1} e^{-\lambda_{i+1} H_{i}} C_{i+1}=0 \text { for } 1 \leq i \leq N-1
\end{gathered}
$$

From Eqs. (3.22) and (3.27) and Eqs. (3.25) and (3.28), we get:

$$
\begin{gathered}
B_{N}=0 \\
-a_{1} B_{1}+a_{1} C_{1}=Q_{t}
\end{gathered}
$$

No matter how many layers we have, Eqs. (3.31) and (3.32) always apply and remain unchanged. Equations (3.29) to (3.32) can be expressed in matrix form as follows:

$$
[M][X]=[V]
$$

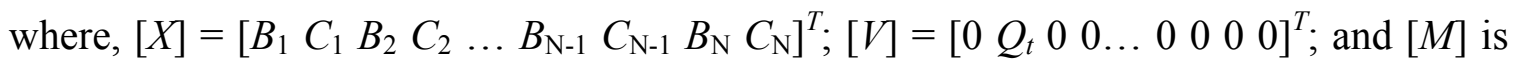
given as:

$[M]=\left[\begin{array}{ccccccccccccc}0 & 0 & 0 & 0 & 0 & 0 & \cdots & 0 & 0 & 0 & 0 & 1 & 0 \\ -a_{1} & a_{1} & 0 & 0 & 0 & 0 & \cdots & 0 & 0 & 0 & 0 & 0 & 0 \\ e^{\lambda_{1} H_{1}} & e^{-\lambda_{1} H_{1}} & -e^{\lambda_{2} H_{1}} & -e^{-\lambda_{2} H_{1}} & 0 & 0 & \cdots & 0 & 0 & 0 & 0 & 0 & 0 \\ -a_{1} e^{\lambda_{1} H_{1}} & a_{1} e^{-\lambda_{1} H_{1}} & a_{2} e^{\lambda_{2} H_{1}} & -a_{2} e^{-\lambda_{2} H_{1}} & 0 & 0 & \cdots & 0 & 0 & 0 & 0 & 0 & 0 \\ 0 & 0 & e^{\lambda_{2} H_{2}} & e^{-\lambda_{2} H_{2}} & -e^{\lambda_{3} H_{2}} & -e^{-\lambda_{3} H_{2}} & \cdots & 0 & 0 & 0 & 0 & 0 & 0 \\ 0 & 0 & -a_{2} e^{\lambda_{2} H_{2}} & a_{2} e^{-\lambda_{2} H_{2}} & a_{3} e^{\lambda_{3} H_{2}} & -a_{3} e^{-\lambda_{3} H_{2}} & \cdots & 0 & 0 & 0 & 0 & 0 & 0 \\ \vdots & \vdots & \vdots & \vdots & \vdots & \vdots & \ddots & \vdots & \vdots & \vdots & \vdots & \vdots \\ 0 & 0 & 0 & 0 & 0 & 0 & \cdots & 0 & 0 & e^{\lambda_{N-1} H_{N-1}} & e^{-\lambda_{N-1} H_{N-1}} & -e^{\lambda_{N} H_{N-1}} & -e^{-\lambda_{N} H_{N-1}} \\ 0 & 0 & 0 & 0 & 0 & 0 & \cdots & 0 & 0 & -a_{N-1} e^{\lambda_{N-1} H_{N-1}} & a_{N-1} e^{-\lambda_{N-1} H_{N-1}} & a_{N} e^{\lambda_{N} H_{N-1}} & -a_{N} e^{-\lambda_{N} H_{N-1}}\end{array}\right]$

The dimensions of $[M],[X]$, and $[V]$ are $[2 N \times 2 N],[2 N \times 1]$ and $[2 N \times 1]$, respectively. If we solve Eq.(3.33), which can be solved either analytically or numerically, we can determine the integration constants. However, a more efficient way to determine all the integration constants is by finding a recurrence relation based on the boundary conditions. For this purpose, we rewrite Eqs. (3.22) and (3.25) in matrix form: 


$$
\left[\begin{array}{c}
w_{i}(z) \\
Q_{i}(z)
\end{array}\right]=\left[\begin{array}{cc}
e^{\lambda_{i} z} & e^{-\lambda_{i} z} \\
-a_{i} e^{\lambda_{i} z} & a_{i} e^{-\lambda_{i} z}
\end{array}\right]\left[\begin{array}{l}
B_{i} \\
C_{i}
\end{array}\right]
$$

From the continuity condition of displacement and force at the interface between layers, we obtain the following:

$$
\left[\begin{array}{c}
w_{i}(z) \\
Q_{i}(z)
\end{array}\right]=\left[\begin{array}{cc}
e^{\lambda_{i} z} & e^{-\lambda_{i} z} \\
-a_{i} e^{\lambda_{i} z} & a_{i} e^{-\lambda_{i} z}
\end{array}\right]\left[\begin{array}{l}
B_{i} \\
C_{i}
\end{array}\right]
$$

Equations (3.35) and (3.36) give us the following recurrence formula for the integration constants:

$$
\left[\begin{array}{l}
B_{i} \\
C_{i}
\end{array}\right]=\frac{1}{2 a_{i}}\left[\begin{array}{cc}
\left(a_{i}+a_{i+1}\right) e^{-\left(\lambda_{i} H_{i}-\lambda_{i+1} H_{i}\right)} & \left(a_{i}-a_{i+1}\right) e^{-\left(\lambda_{i} H_{i}+\lambda_{i+1} H_{i}\right)} \\
\left(a_{i}-a_{i+1}\right) e^{\left(\lambda_{i} H_{i}+\lambda_{i+1} H_{i}\right)} & \left(a_{i}+a_{i+1}\right) e^{\left(\lambda_{i} H_{i}-\lambda_{i+1} H_{i}\right)}
\end{array}\right]\left[\begin{array}{l}
B_{i+1} \\
C_{i+1}
\end{array}\right] \text { for } 1 \leq i \leq N-1
$$

Therefore, if we determine $B_{N}$ and $C_{N}$, we can determine all $B_{i}$ 's and $C_{i}$ 's, in sequence.

Using Cramer's rule, $B_{i}$ and $C_{i}$ are obtained from:

$$
\begin{gathered}
B_{i}=\frac{\left|M_{2 i-1}\right|}{|M|} \\
C_{i}=\frac{\left|M_{2 i}\right|}{|M|}
\end{gathered}
$$

where $|M|=$ determinant of $[M] ;\left|M_{k}\right|=$ determinant of $[M]$ with the $k^{\text {th }}$ column replaced by the vector $[V]$. In order for a given problem to have physical meaning, $|M|$ must not be zero. Therefore, from (3.31) and (3.38), we obtain 


$$
\left|M_{2 N-1}\right|=0
$$

Similarly, $C_{N}$ is given by

$$
C_{N}=\frac{\left|M_{2 N}\right|}{|M|}
$$

where,

$$
\left|M_{2 N}\right|=\left|\begin{array}{ccccccccc}
0 & 0 & 0 & 0 & \cdots & 0 & 0 & 1 & 0 \\
-a_{1} & a_{1} & 0 & 0 & \cdots & 0 & 0 & 0 & Q_{t} \\
e^{\lambda_{1} H_{1}} & e^{-\lambda_{1} H_{1}} & -e^{\lambda_{2} H_{1}} & -e^{-\lambda_{2} H_{1}} & \cdots & 0 & 0 & 0 & 0 \\
\vdots & \vdots & \vdots & \vdots & \ddots & \vdots & \vdots & \vdots & \vdots \\
0 & 0 & 0 & 0 & \cdots & -a_{N-1} e^{\lambda_{N-1} H_{N-1}} & a_{N-1} e^{-\lambda_{N-1} H_{N-1}} & a_{N} e^{\lambda_{N} H_{N-1}} & 0
\end{array}\right|
$$

The determinant of $\left|M_{2 N}\right|$ is:

$$
\left|M_{2 N}\right|=2^{N-1} P \prod_{i=1}^{N-1} a_{i}
$$

where the symbol $\prod$ is used to indicate a product: $\prod_{i=1}^{k} x_{i}=x_{1} x_{2} x_{3} \cdots x_{k}$. If we substitute Eqs. (3.38) and (3.39) into Eq.(3.37), we get:

$$
\left[\begin{array}{c}
\left|M_{2 i-1}\right| \\
\left|M_{2 i}\right|
\end{array}\right]=\frac{1}{2 a_{i}}\left[\begin{array}{cc}
\left(a_{i}+a_{i+1}\right) e^{-\left(\lambda_{i} H_{i}-\lambda_{i+1} H_{i}\right)} & \left(a_{i}-a_{i+1}\right) e^{-\left(\lambda_{i} H_{i}+\lambda_{i+1} H_{i}\right)} \\
\left(a_{i}-a_{i+1}\right) e^{\left(\lambda_{i} H_{i}+\lambda_{i+1} H_{i}\right)} & \left(a_{i}+a_{i+1}\right) e^{\left(\lambda_{i} H_{i}-\lambda_{i+1} H_{i}\right)}
\end{array}\right]\left[\begin{array}{c}
\left|M_{2 i+1}\right| \mid \\
\left|M_{2 i+2}\right|
\end{array}\right] \text { for } 1 \leq i \leq N-1
$$

In order to obtain $|M|$, we will use the boundary condition at the pile head. By substituting $B_{1}=\left|M_{1}\right| /|M|$ and $C_{1}=\left|M_{2}\right| /|M|$ into Eq.(3.32), we obtain the following relationship: 


$$
|M|=\frac{a_{1}}{P}\left(\left|M_{2}\right|-\left|M_{1}\right|\right)
$$

Consequently, the numerators in Eqs. (3.38) and (3.39) can be recurrently determined from Eq. (3.44) by using Eqs. (3.40) and (3.43) as its ignition terms. The denominators in Eqs. (3.38) and (3.39) are obtained from (3.45). Finally, we determine all the integration constants using Eqs. (3.38) and (3.39). The displacement and force at each layer follow from Eqs. (3.22) and (3.25), respectively. Using this procedure, we can obtain explicit analytical solutions for a vertically loaded pile installed in a soil with $N$ layers.

In design, we are interested in estimating the settlement at the pile head when the pile is subjected to the design load. This can be obtained from the solution for the displacement within the first layer:

$$
w_{t}=w_{1}(0)=B_{1}+C_{1}=\frac{\left|M_{1}\right|}{|M|}+\frac{\left|M_{2}\right|}{|M|}
$$

\subsection{Solution for a Pile Embedded in a Layered Soil Resting on a Rigid Base under}

\section{Compressive Load}

Piles are often socketed in a competent layer or rock to obtain a large base capacity. If we know the elastic properties of such a layer, we can use the solution presented in the previous section. We can also obtain analytical solutions for a vertically loaded pile with the base resting on a rigid material that can be used when we do not know the elastic properties of the bearing layer but know it to be very stiff. We can do this by restricting the vertical displacement at the base of the pile to zero. The pile-soil system considered here is shown in Figure 3.3. 


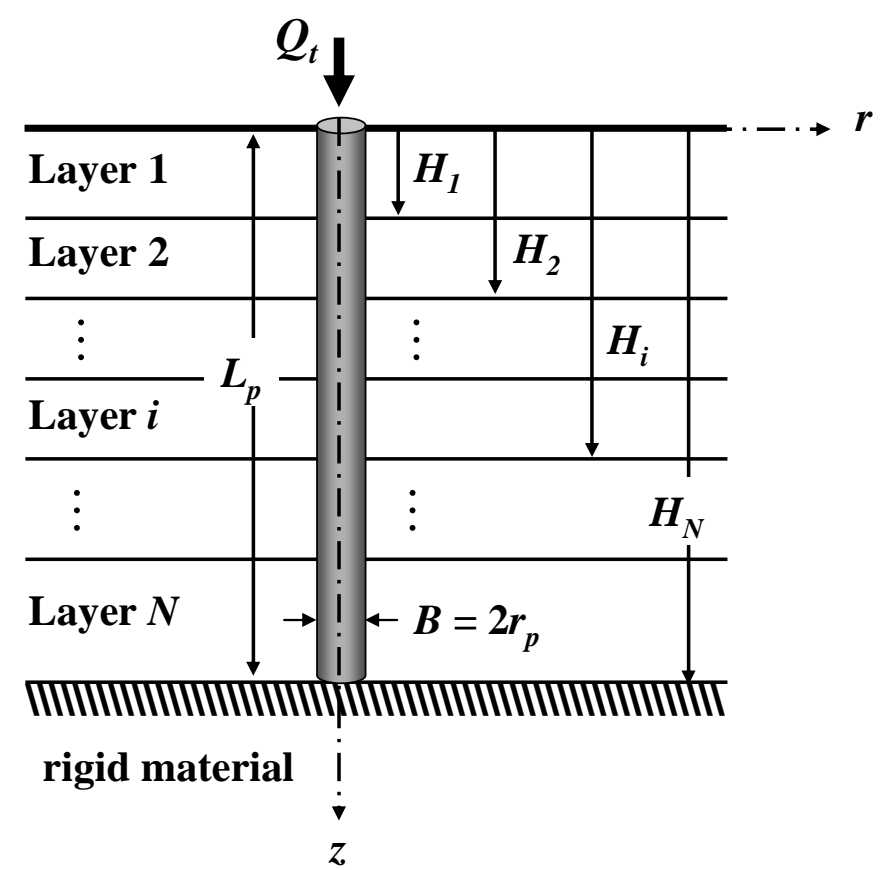

Figure 3.3 Pile embedded in a multilayered soil with the base resting on a rigid material

In this case, we have zero displacement at the base of the pile instead of at infinity. All other boundary conditions remain the same. Therefore, only Eq. (3.27) changes to the following:

$$
\left.w_{N}(z)\right|_{z \rightarrow L_{p}}=e^{\lambda_{N} L_{p}} B_{N}+e^{-\lambda_{N} L_{p}} C_{N}=0
$$

Now we have a new matrix $[M]$ for the case of an axially loaded pile with the base over a rigid material. As done before, we can calculate $\left|M_{2 N-1}\right|$ and $\left|M_{2 N}\right|$ :

$$
\begin{gathered}
\left|M_{2 N-1}\right|=-2^{N-1} e^{-\lambda_{N} L_{p}} P \prod_{i=1}^{N-1} a_{i} \\
\left|M_{2 N}\right|=2^{N-1} e^{\lambda_{N} L_{p}} P \prod_{i=1}^{N-1} a_{i}
\end{gathered}
$$


Using these two ignition terms and Eq. (3.44), we can get explicit analytical solutions for this case.

\subsection{Solution for a Pile in a Layered Soil under Tensile Load}

A limited number of approximate solutions for the response of axially loaded piles subjected to tensile loading are available in the literature (Misra et al. 2004, Alawneh 2005). Analytical solutions for an axially loaded pile in a multilayered soil subjected to tensile loading can be easily obtained by changing the pile base boundary condition. The pile-soil system considered here is shown in Figure 3.4.

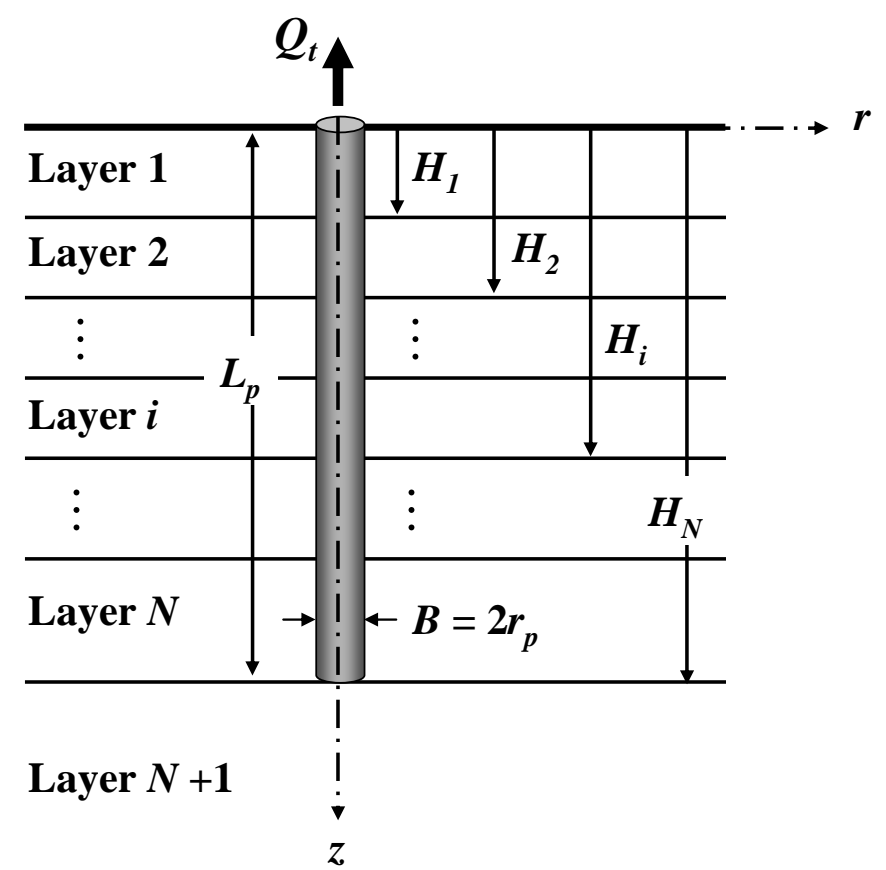

Figure 3.4 Pile embedded in a multilayered soil under tensile load

In the derivation of the governing differential equations for the pile-soil system within the domain $0 \leq z \leq L_{p}$, the strain energy from the soil below the pile base is assumed to be negligible. The governing differential equations remain the same as those derived for the case in which the pile is subjected to a compressive axial load (see Eqs. 
(3.8) and (3.14)). Therefore, the general solutions for the differential equations also remain the same (equations (3.19) and (3.22)). The boundary conditions for the soil displacement decay function $\phi(r)$ also remain unchanged $\left(\phi(r)=1\right.$ at $r=r_{p}$, and $\phi=0$ at $r$ $\rightarrow \infty$ ). On the other hand, we have a different boundary condition for the displacement function $w(z)$. In the case of tensile loading, the axial load transferred to the base of the pile is zero because the tensile resistance of the soil below the pile base is negligible, unless we have suction there (in fact, this is obtained as a natural boundary condition following from the minimization of the total potential energy). Therefore, instead of Eq. (3.27), we now have:

$$
\left.Q_{N}(z)\right|_{z=L_{p}}=-a_{N} B_{N} e^{\lambda_{N} L_{p}}+a_{N} C_{N} e^{-\lambda_{N} L_{p}}=0
$$

and a new matrix $[M]$. The $\left|M_{2 N-1}\right|$ and $\left|M_{2 N}\right|$ matrices are given as follows:

$$
\begin{gathered}
\left|M_{2 N-1}\right|=-2^{N-1} Q_{t} e^{-\lambda_{N} L_{p}} \prod_{i=1}^{N} a_{i} \\
\left|M_{2 N}\right|=-2^{N-1} Q_{t} e^{\lambda_{N} L_{p}} \prod_{i=1}^{N} a_{i}
\end{gathered}
$$

As done before, using these two ignition terms and (3.44), we can determine all the $M_{i}$ 's and, hence, all the integration constants $B_{i}$ 's and $C_{i}$ 's from Eqs. (3.38) and (3.39). By simply substituting these integration constants in Eq. (3.22), we obtain explicit analytical solutions for this case as well.

\subsection{Modification of Soil Moduli}

The above analysis assumes zero horizontal displacement in the soil. This assumption is not strictly valid, particularly near the pile head where the downward drag by the pile on the surrounding soil induces horizontal displacements that point towards the pile. Thus, 
restraining the horizontal displacement results in pile response that is stiffer than it is in reality. In fact, the term $\left(\lambda_{s i}+2 G_{s i}\right)$ in Eqs. (3.17) and (3.23) represents the soil constrained modulus, which is an indication that the analysis produces a stiff response. As the soil Poisson's ratio approaches 0.5 , the pile load-settlement response becomes increasingly stiffer (the constrained modulus is equal to infinity for a Poisson's ratio of $0.5)$.

In order to eliminate the artificial stiffness resulting from the assumption of zero lateral displacement for high $v_{s}$ values, we set $\lambda_{s i}=E_{s i} v_{s i} /\left(1+v_{s i}\right)\left(1-2 v_{s i}\right)=0\left(E_{s i}\right.$ is the soil Young's modulus of the $i^{\text {th }}$ layer), which is equivalent to making the soil Poisson's ratio $v_{s i}=0$ (removal of the artificial stiffness by setting $\lambda_{s i}=0$ was proposed for laterally loaded piles by Guo and Lee (2001)), and replace $G_{s i}$ by a modified shear modulus $G_{s i}{ }^{*}$. The effect of Poisson's ratio is indirectly taken into account through the modified shear modulus $G_{s i}{ }^{*}$ (a similar procedure was recommended by Randolph (1981) for laterally loaded piles). We propose the following expressions for the modified shear modulus $G_{s i}{ }^{*}$ by matching the pile responses obtained from our analyses with those obtained from FEA (performed for identical pile and soil conditions) using ABAQUS:

$$
G_{s i}^{*}=0.75 G_{s i}\left(1+1.25 v_{s i}^{2}\right)
$$

Accordingly, Eqs. (3.16), (3.17) and (3.20), (3.21) are modified by making $\lambda_{s i}=0$ (irrespective of the value of Poisson's ratio) and by replacing $G_{s i}$ by $G_{s i}{ }^{*}$.

\subsection{Solution Scheme for Elastic Solutions}

The $\beta$ parameter in Eq. (3.19), which depends on the pile settlement $w$ and its derivative $d w / d z$ (Eqs. (3.16) and (3.17)), must be determined before we calculate the parameters $k_{i}$ and $t_{i}$, which, in turn, are needed in the solution of Eq. (3.13) for the pile displacement. Hence, an iterative solution scheme is required. In the first iteration, an initial value is assumed for $\beta$, and the pile displacement and its derivative (obtained from the axial force) are calculated. At the end of the iteration, a new $\beta$. value is obtained using the 
calculated pile displacement and the values of its derivative; the calculated value of $\beta$ is compared with the assumed initial value. If the difference is greater than the prescribed tolerance, iterations are continued, with the calculated value of $\beta$ taken as the new input in the calculations. Successive iterations are continued until the value of $\beta$ obtained from two consecutive iterations falls below the prescribed limit. This iterative solution scheme is provided in the form of a flow chart in Figure 3.5.

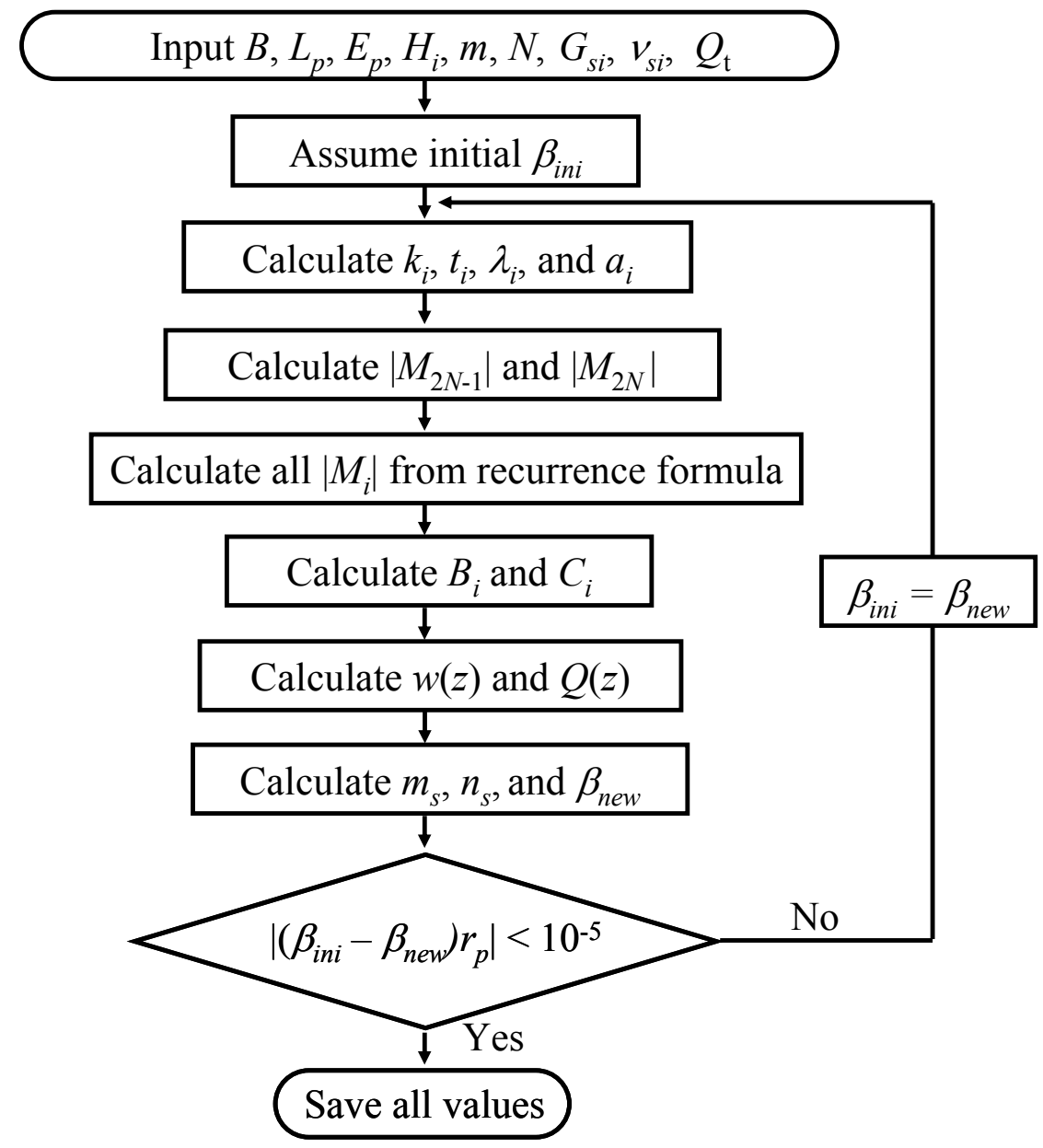

Figure 3.5 Flowchart for the iterative procedure 


\subsection{Results}

\subsubsection{Comparison with finite element analysis}

The results of our analysis are compared with those of finite element analysis (FEA) performed using ABAQUS. Twenty-noded brick elements were used to represent both the pile and the soil. The horizontal extent of the soil domain (from the pile axis) was taken to be at least 15 times the pile diameter, and the vertical extent of the soil domain below the pile base was taken as at least the pile length. The boundaries were varied to ensure that there were no boundary effects; convergence checks were also performed.

We consider a $30-\mathrm{m}$-long drilled shaft with $2 \mathrm{~m}$ of diameter embedded in a fourlayered soil. The axial force $Q_{t}$ at the head of the piles is $8000 \mathrm{kN}$. The Young's modulus of the piles is $E_{p}=25 \mathrm{GPa}$. The piles are embedded in a four-layer deposit with $H_{1}=2$ $\mathrm{m}, H_{2}=12 \mathrm{~m}$ and $H_{3}=22 \mathrm{~m}$ (the pile base rests in the fourth layer); $E_{s 1}=15 \mathrm{MPa}, E_{s 2}=$ $25 \mathrm{MPa}, E_{s 3}=30 \mathrm{MPa}$ and $E_{s 4}=100 \mathrm{MPa} ; v_{\mathrm{s} 1}=0.4, v_{s 2}=0.3, v_{s 3}=0.3$ and $v_{s 4}=0.15$ ( $E_{s i}$ and $v_{s i}$ are the Young's modulus and Poisson's ratio of the $i^{\text {th }}$ soil layer, respectively). The corresponding values of $G_{s}{ }^{*}$ for the four soil layers used along with $\lambda_{s i}=0$ in the analysis are $G_{s 1}{ }^{*}=4.8 \mathrm{MPa}, G_{s 2}{ }^{*}=8.0 \mathrm{MPa}, G_{s 3}{ }^{*}=9.6 \mathrm{MPa}$, and $G_{s 4}{ }^{*}=33.5 \mathrm{MPa}$ for the drilled shaft. 


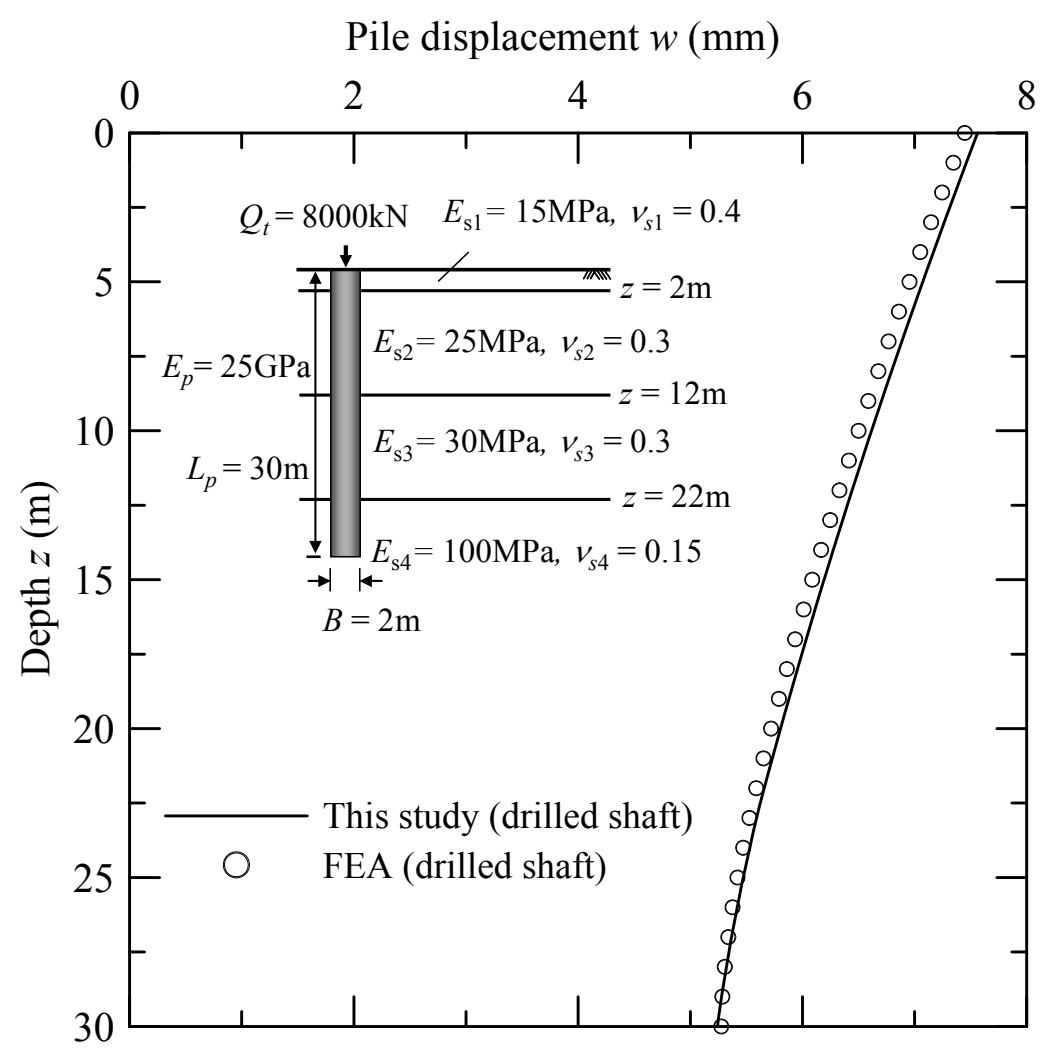

(a) 


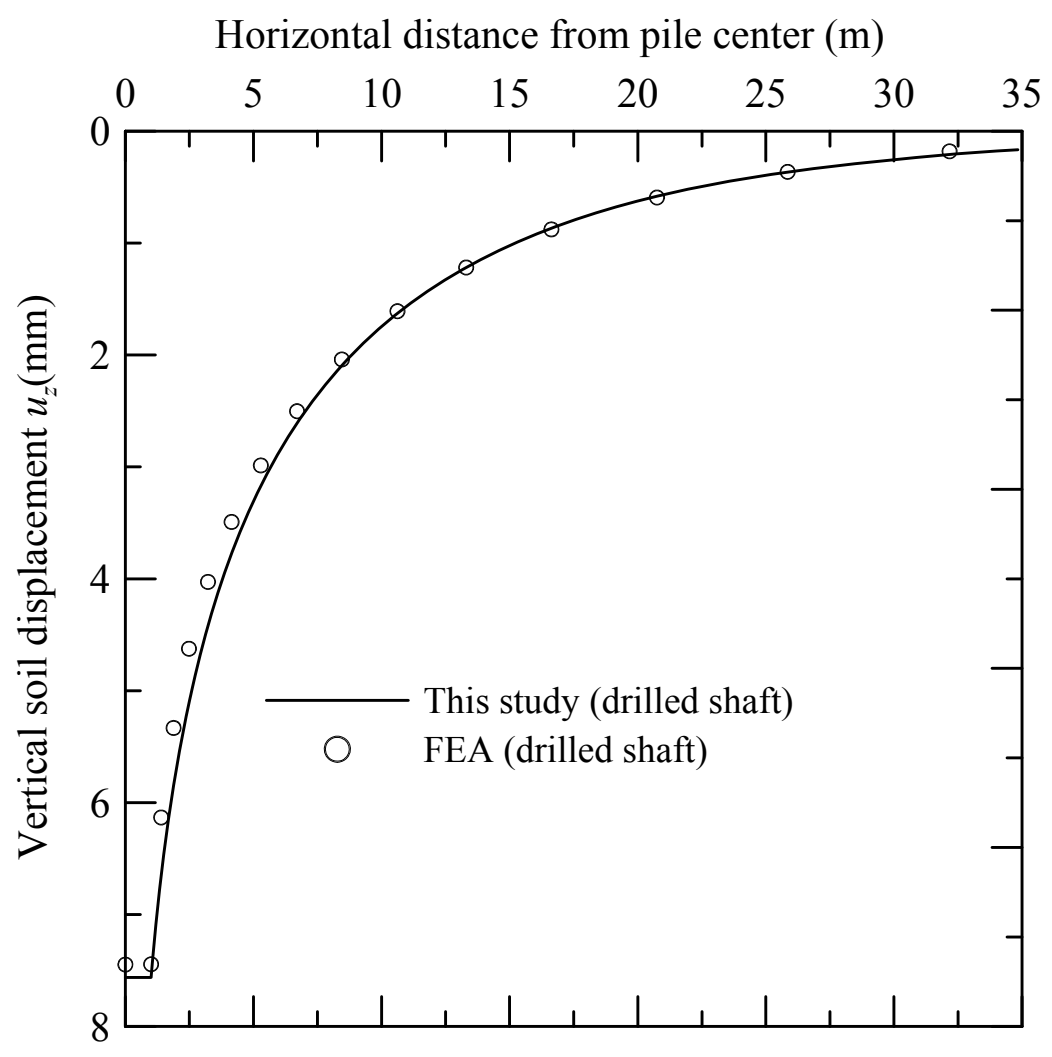

(b)

Figure 3.6 A comparison between displacements obtained using the analytical method and FEA for a 30-m-long pile: (a) pile displacement versus depth; (b) vertical soil displacement at the ground surface versus horizontal distance from pile center

Figure 3.6(a) shows the pile displacement as a function of depth, as obtained from our analysis and FEA. The results from our analytical solution are in good agreement with the FEA results. Figure 3.6 (b) shows the vertical soil displacements at the ground surface as a function of the horizontal distance from the pile center. The vertical soil displacements obtained from our analysis and FEA are in very good agreement.

\subsubsection{Comparison with previous pile settlement studies}

We compare results from our study with numerical or analytical solutions available in the literature (Blaney et al. 1976; Poulos and Davis 1980; El-Sharnouby and Novak 1990; 
Fleming et al. 1992; Mylonakis 2001). The results are presented in terms of the normalized pile head stiffness $K_{N}$ defined as:

$$
K_{N}=\frac{Q_{t}}{w_{t} E_{p} B}
$$

where $Q_{t}=$ applied load at the pile head; $w_{t}=$ settlement at the pile head; $E_{p}=$ Young's modulus of the pile; $B=$ pile diameter.

Figure 3.7 compares the values of normalized pile head stiffness versus normalized pile length of ideal end-bearing piles (piles with zero base settlement) obtained from this study with those from previous studies for two different pile-soil modulus ratios $\left(E_{p} / G_{s}\right)$. The pile base is assumed to rest on a rigid layer; the soil above the rigid layer is homogeneous with $E_{s}$ as its Young's modulus and $v_{s}=0.5$ as its Poisson's ratio. It should be noted that, although we plotted the results obtained from the analysis of Fleming et al. (1992) in Figure 3.7, they did not specifically address the case of ideal end-bearing piles in their analysis. However, by allowing the shear modulus below the pile base to tend to infinity in the equation of the magical radius $r_{m}$ (Randolph and Wroth 1978), the results shown in Figure 3.7 (corresponding to Fleming et al. 1992) are obtained. 


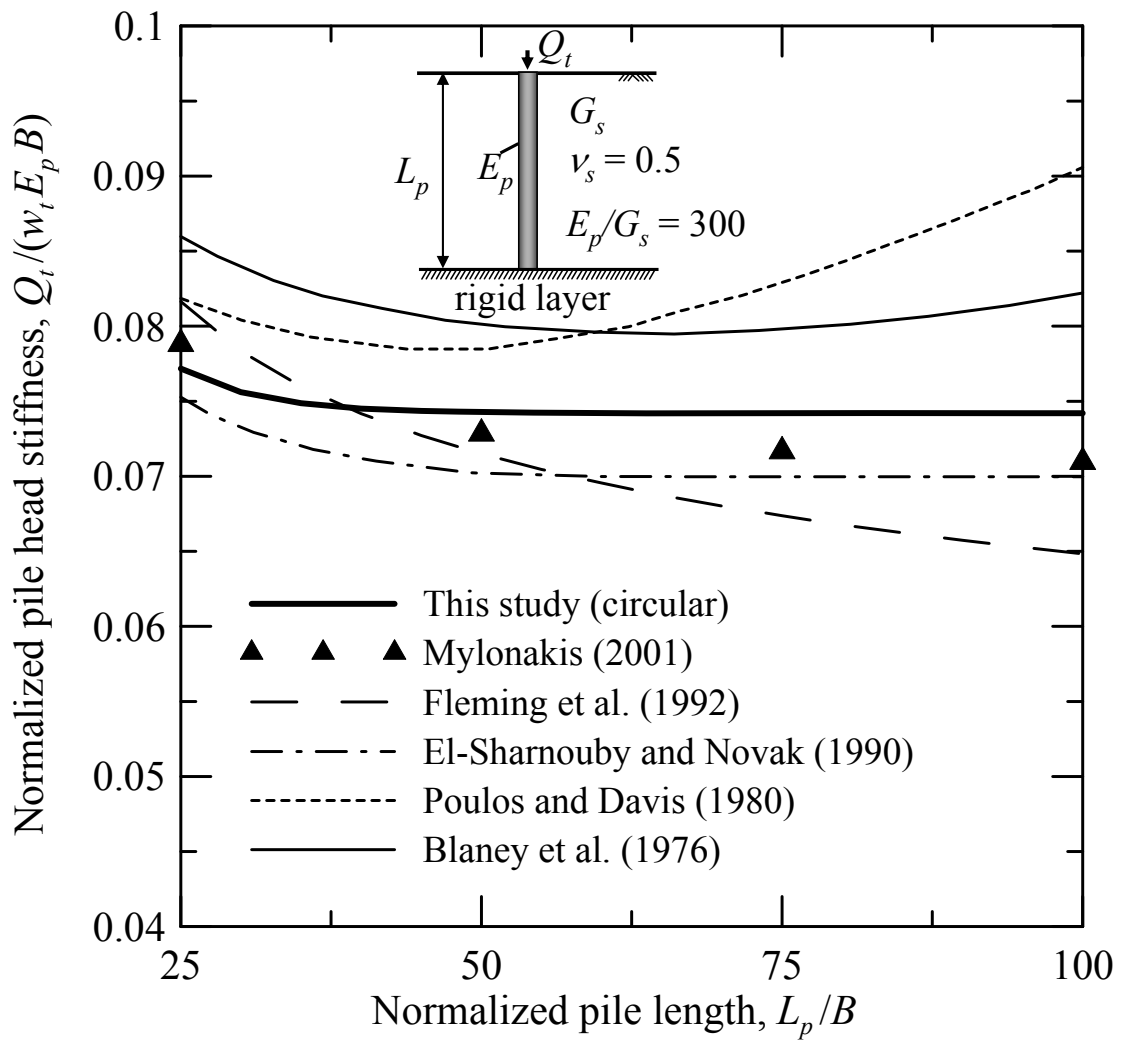

(a) 


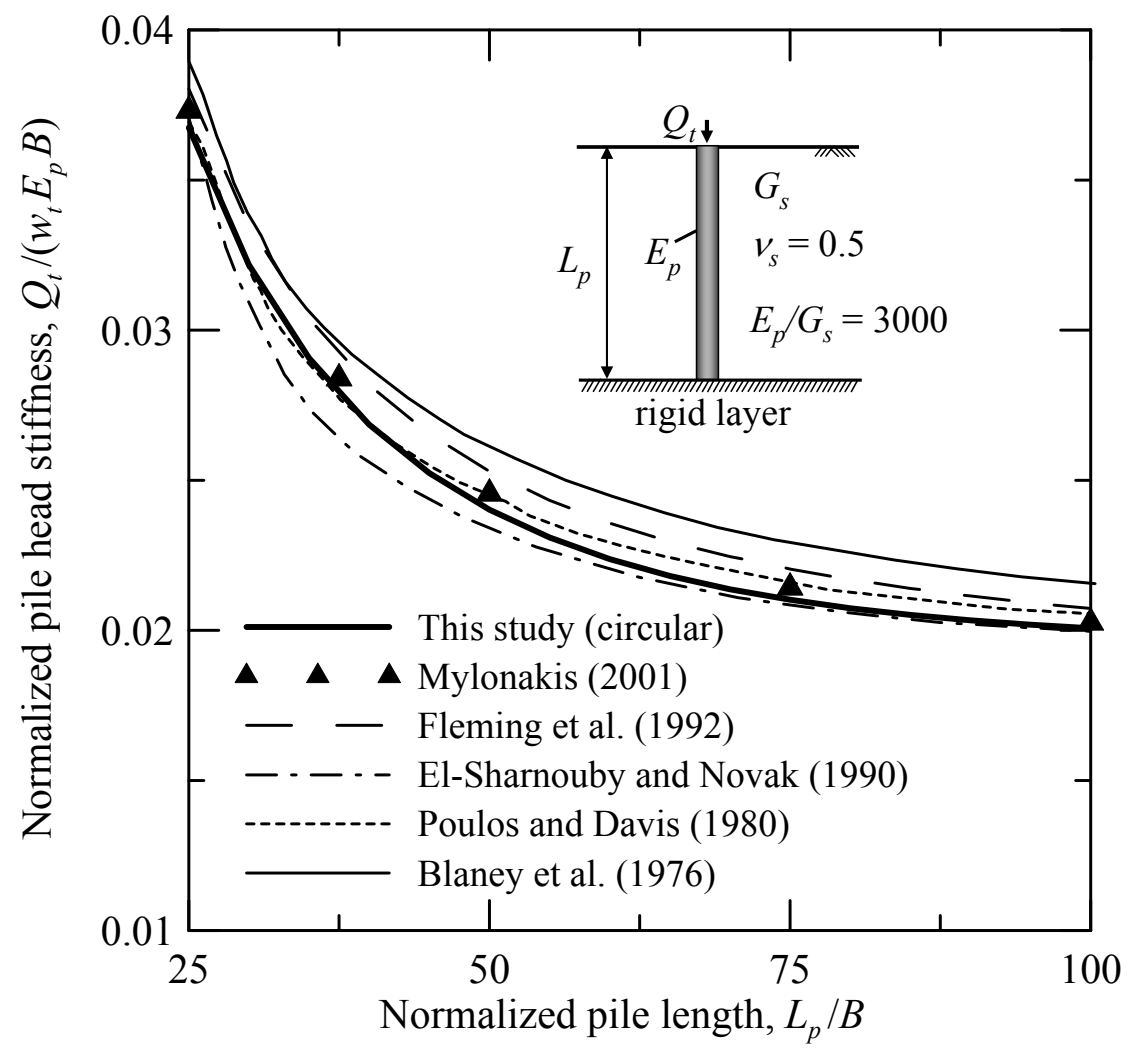

(b)

Figure 3.7 Comparison of normalized pile head stiffness versus normalized pile length of end-bearing piles: (a) $E_{p} / G_{s}=300$; (b) $E_{p} / G_{s}=3000$

For $E_{p} / G_{s}=300$, results from Blaney et al. (1976) and Poulos and Davis (1980) show that the pile head stiffness first decreases and then increases (Figure 3.7 (a)) as the pile slenderness ratio $L_{p} / B$ increases. As pointed out by El-Sharnouby and Novak (1990) and Mylonakis (2001), this trend cannot be true for ideal end-bearing piles because, no matter how much load is transferred to the pile base, it does not contribute to the head stiffness because the base is rigid. El-Sharnouby and Novak (1990), who used 50 discrete elements to discretize the pile in their analysis, reported that the small number of pile elements used in the analyses of Poulos and Davis (10 elements) and Blaney et al. (20 elements) led to the anomaly. The results from our analyses are free from this anomaly and are in good agreement with the more rigorous solutions of Mylonakis 
(2001) and El-Sharnouby and Novak (1990). In the case of $E_{p} / G_{\mathrm{s}}=3000$, the normalized pile head stiffness decreases with increasing $L_{p} / B$ for all cases, as seen in Figure 3.7 (b).

In order to further compare our analysis and its results to previous analyses of the same problem, we consider the analyses of Poulos (1979) and Lee (1991). Poulos (1979) analyzed the settlement of a single pile in non-homogeneous soil using the method of analysis employed by Mattes and Poulos (1969). In this analysis, the pile is divided into a number of equal cylindrical elements, with any element $j$ being acted upon by a shear stress $\tau_{j}$. The expressions for the pile displacements are obtained from the vertical equilibrium of a small cylindrical element of the pile assuming that the pile deforms in simple axial compression. The vertical displacements of the soil due to the shear stress along the pile shaft are obtained by double integration of the Mindlin equation for vertical displacement. To calculate the displacement of the soil at any element $i$ due to the shear stress $\tau_{j}$ on element $j$, the average of Young's modulus of soil element $i$ and $j$ was used for the analysis of nonhomogeneous soils. By imposing a no slippage condition at the pile-soil interface, the shear stresses and the displacements along the pile can then be calculated. The solutions obtained were compared with those from finite element analysis for three idealized cases, shown in Figure 3.8. The solutions were given in terms of a settlement influence factor $I_{w}$ defined by:

$$
I_{w}=\frac{E_{s, r e f} B w_{t}}{Q_{t}}
$$

where $E_{s, r e f}=$ reference Young's modulus of soil; $B=$ pile diameter; $w_{t}=$ settlement at the pile head; and $Q_{t}=$ applied load at the pile head.

Lee (1991) expanded the approach of Randolph and Wroth (1978) to layered soil. The analysis of Lee (1991) accounts for the effect of the change of the shear stress in the radial direction. Like the analysis of Randolph and Wroth (1978), it relies on the concept of the magical radius $r_{m}$, a radius at which the displacement becomes negligible. 


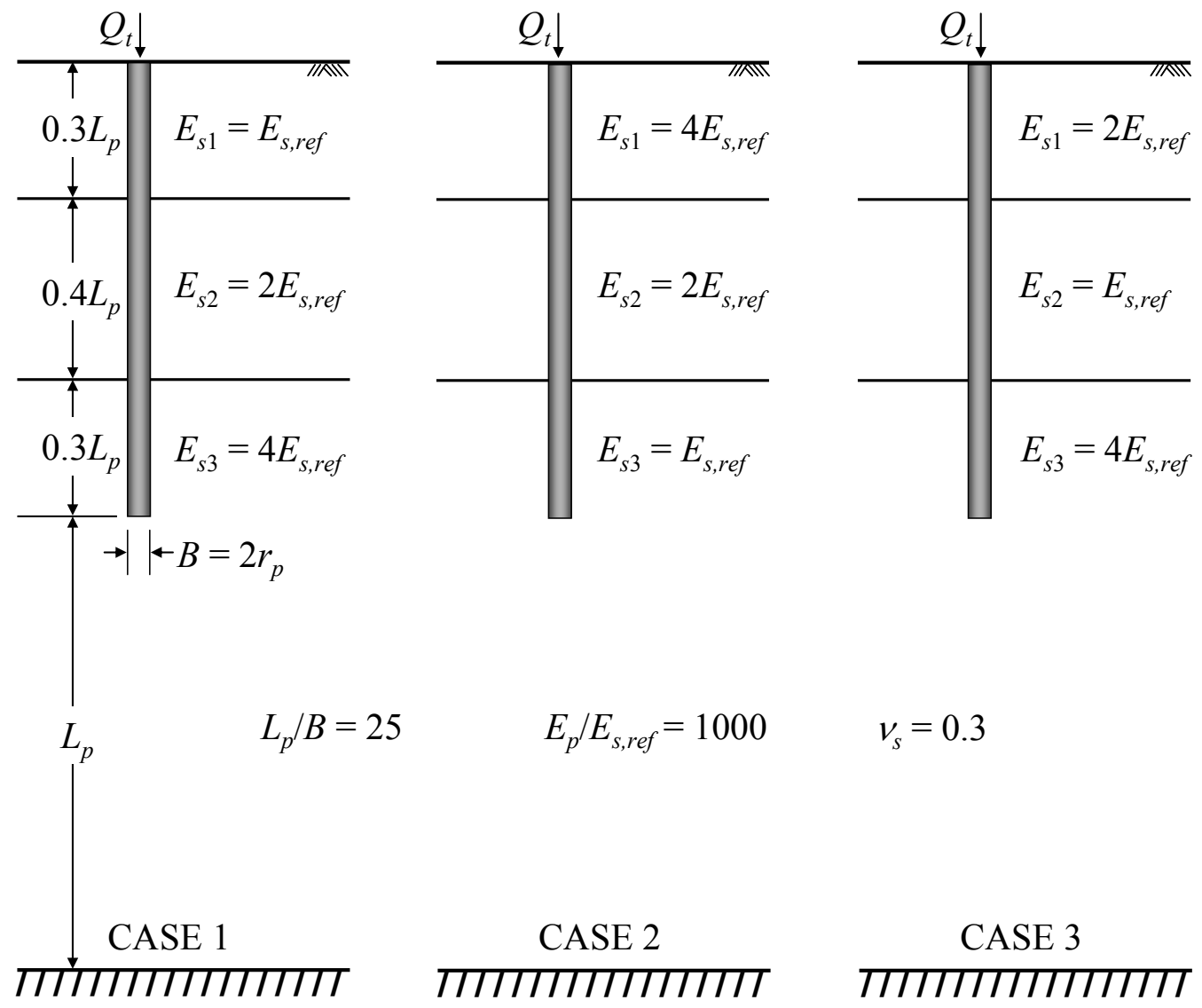

Figure 3.8 Layered soil profiles for settlement analyses (modified after Poulos 1979)

To consider the differences between the three analyses, we perform calculations for the same cases proposed by Poulos (1979) and used also by Lee (1991) for validation of their analysis. To use our analysis for these cases, we divide the soil profile into five layers, with the bottom of the third layer flush with the base of the pile. The $4^{\text {th }}$ layer extends from a depth of $L$ to $2 L$, and the $5^{\text {th }}$ layer extends from $2 L$ to infinity. The same value for the Young's modulus of the soil was used for the $3^{\text {rd }}$ and $4^{\text {th }}$ layers. For the rigid base ( $5^{\text {th }}$ layer $), E_{s 5}=10^{10} E_{p}$ was used.

The results from our analyses are given together with those of Poulos (1979) and Lee (1991) in Table 3.1. For Case I, the analysis of Poulos (1979) produces an settlement influence factor very similar to the one obtained with our analysis. On the other hand, in Case II, the result of our analysis is closest to that of Lee (1991). In Case III, our analysis 
produces almost the same value for the settlement influence factor as the finite element analysis of Poulos (1979). Overall, the results from our analyses are in reasonably good agreement with those from the previous studies.

Table 3.1 Comparison between solutions in layered soil

\begin{tabular}{|c|c|c|c|c|}
\hline \multirow{2}{*}{ Case } & \multicolumn{4}{|c|}{ Settlement influence factor $I_{w}=\frac{E_{s, r e f} B w_{t}}{Q_{t}}$} \\
\cline { 2 - 5 } & Poulos (1979) & Poulos (1979) - FEA & Lee (1991) & Present solution \\
\hline 1 & 0.0386 & 0.0377 & 0.0361 & 0.0394 \\
\hline 2 & 0.0330 & 0.0430 & 0.0372 & 0.0385 \\
\hline 3 & 0.0366 & 0.0382 & 0.0358 & 0.0383 \\
\hline
\end{tabular}

\subsection{Parametric Studies}

To investigate the effects of the soil layering on the response of piles with different pile slenderness ratio $\left(L_{p} / B\right)$ and pile-to-soil modulus ratio $\left(E_{p} / G_{s}\right)$, parametric studies were carried out. All figures present the results with respect to the modified shear modulus $G_{s}^{*}$ to avoid including additional charts for different Poisson's ratios (the effect of Poisson's ratio is already incorporated in the expressions for $G_{s}^{*}$ ).

\subsubsection{Effect of bearing layer}

If weak soil layers overly a stiff soil layer, depending on the depth of the stiff layer, it is often advantageous to extend the pile length to the stiff layer in order to capitalize on the end bearing resistance available there. We consider the case of a weak soil layer with equivalent shear modulus $G_{s}^{*}$ lying above a stiff layer with equivalent shear modulus $G_{s b}{ }^{*}$. The pile base is assumed to lie on the interface of the weak and the strong layer. In practice, we would embed the pile at least two diameters into the stiff layer so as to guarantee proper development of base resistance. In our analysis, there is no such 
requirement, as the base resistance will directly reflect the modulus of the soil underlying the pile base.

Figure 3.9 shows the normalized pile head stiffness as a function of the modulus ratio $G_{s b}{ }^{*} / G_{s}{ }^{*}$ of the two soil layers, for different values of $E_{p} / G_{s}{ }^{*}$ and $L_{\mathrm{p}} / B^{*}$. Irrespective of the pile slenderness ratio, the pile head stiffness increases as $E_{p} / G_{s}{ }^{*}$ decreases (i.e., as the stiffness of the weaker soil increases). When the soil layer surrounding the pile shaft becomes very stiff $\left(E_{p} / G_{s}{ }^{*}=100\right)$ or the pile slenderness ratio is large $\left(L_{\mathrm{p}} / B^{*}=100\right)$, as is the case for micropiles, the normalized pile head stiffness is practically independent of the soil properties below the pile base. If the soil below the pile base is only slightly stiffer than the soil surrounding the shaft (i.e., for low values of $G_{s b}{ }^{*} / G_{s}{ }^{*}$ ), the longer piles show a stiffer response, but if the base soil is much stiffer than the soil surrounding the shaft (i.e., for large values of $G_{s b}{ }^{*} / G_{s}{ }^{*}$ ), then the shorter piles have a normalized pile head stiffness that is greater than that of the longer piles.

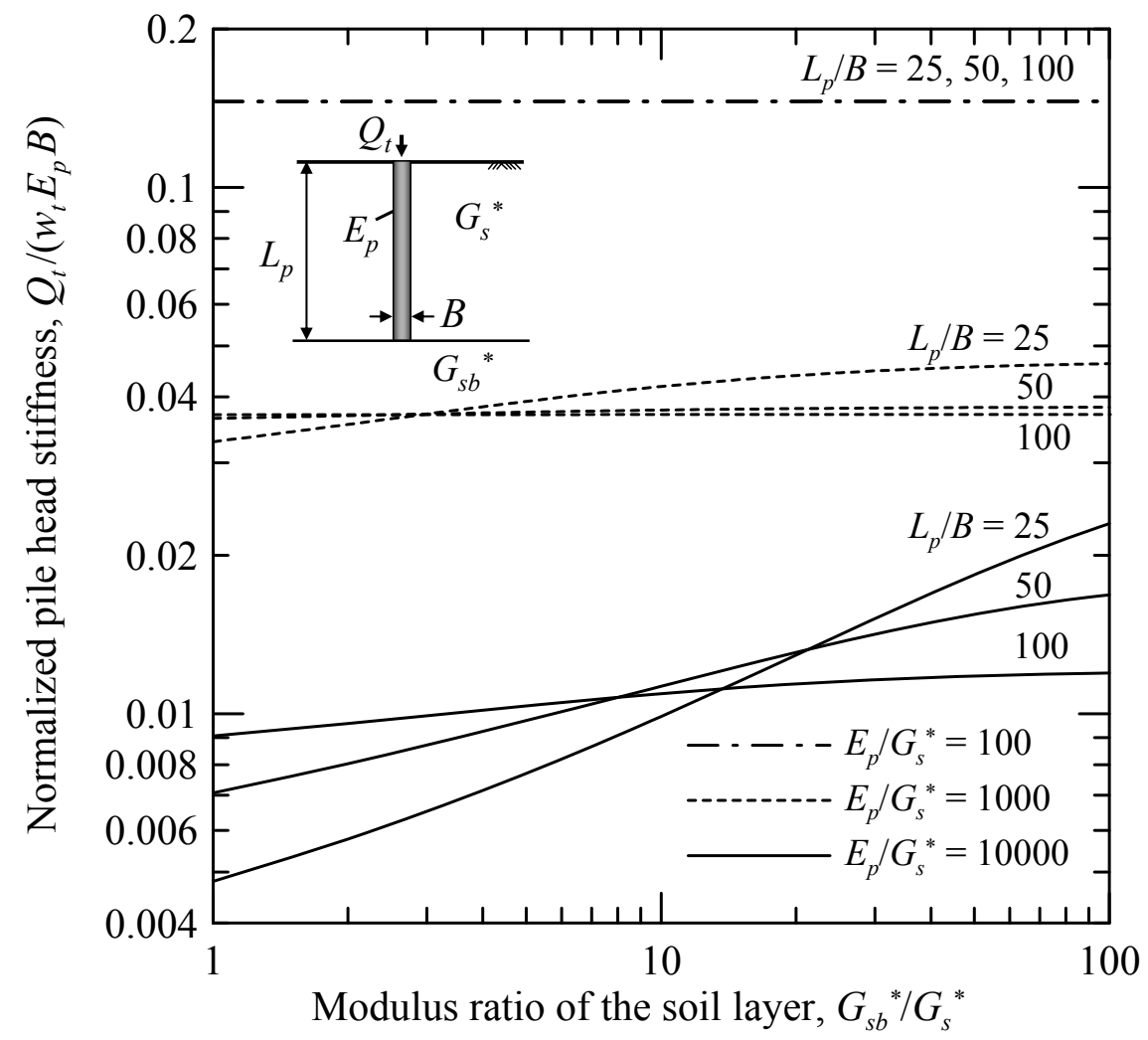

Figure 3.9 Normalized pile head stiffness versus modulus ratio of the base soil to shaft soil $G_{s b}{ }^{*} / G_{s}^{*}$ 


\subsubsection{Piles in two-layer soil}

We performed a parametric study for cases with two soil layers present along the pile shaft. Figure 3.10(a) shows the results for five different soil modulus ratios $G_{S 1}{ }^{*} / G_{s 2}{ }^{*}=$ $0.2,0.5,1,2$, and 5, with $L_{p} / B^{*}=25$ and $E_{p} / G_{s 2}{ }^{*}=1000$. The thickness $h$ of the top layer varies from 0 to $L_{p}$. Figure $3.10(\mathrm{~b})$ shows the variation of the normalized pile head stiffness as a function of $E_{p} / G_{s 2}{ }^{*}$ when the two layers have the same thickness. The curves shown in this figure may be used as design charts in early stages of pile design when similar soil profiles are encountered.

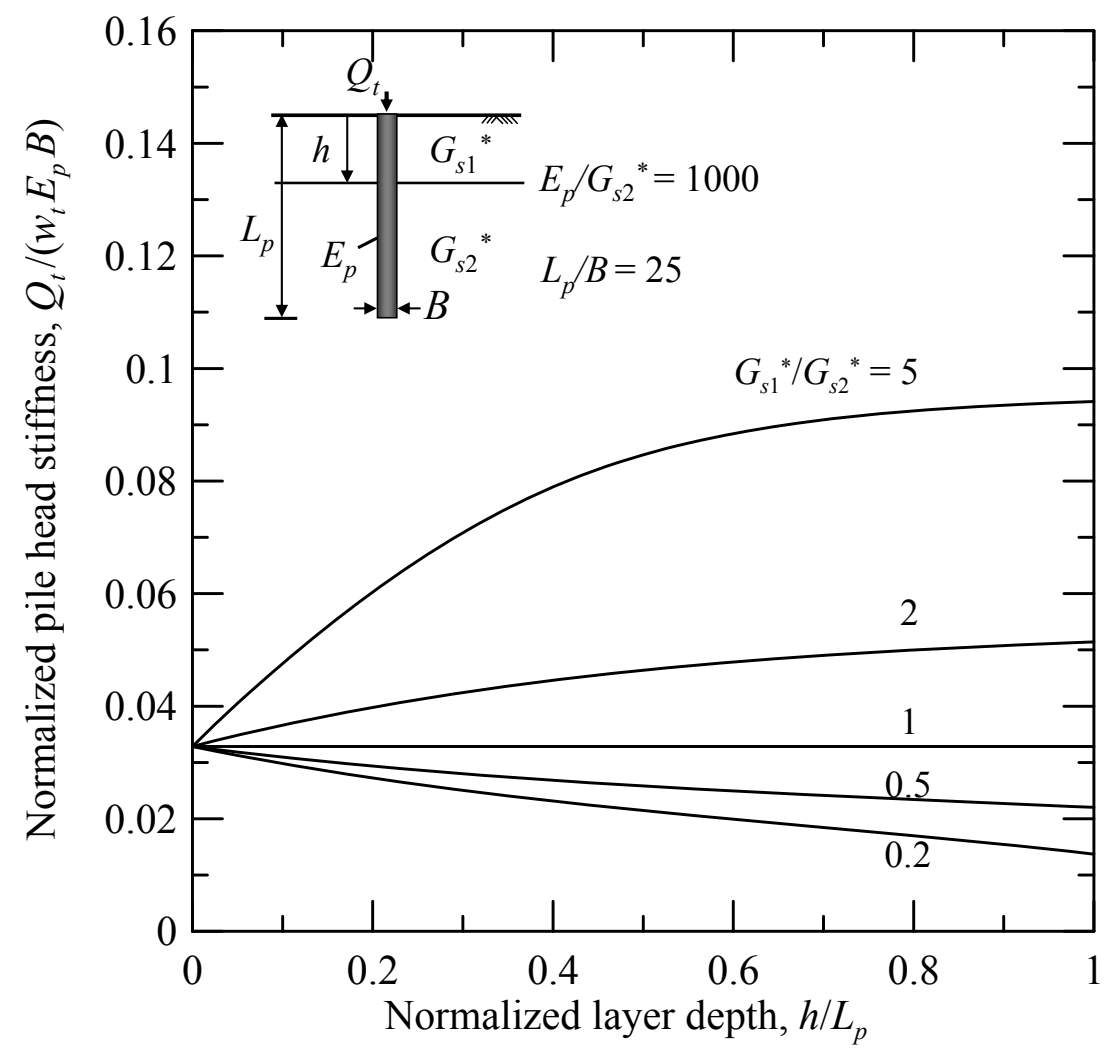

(a) 


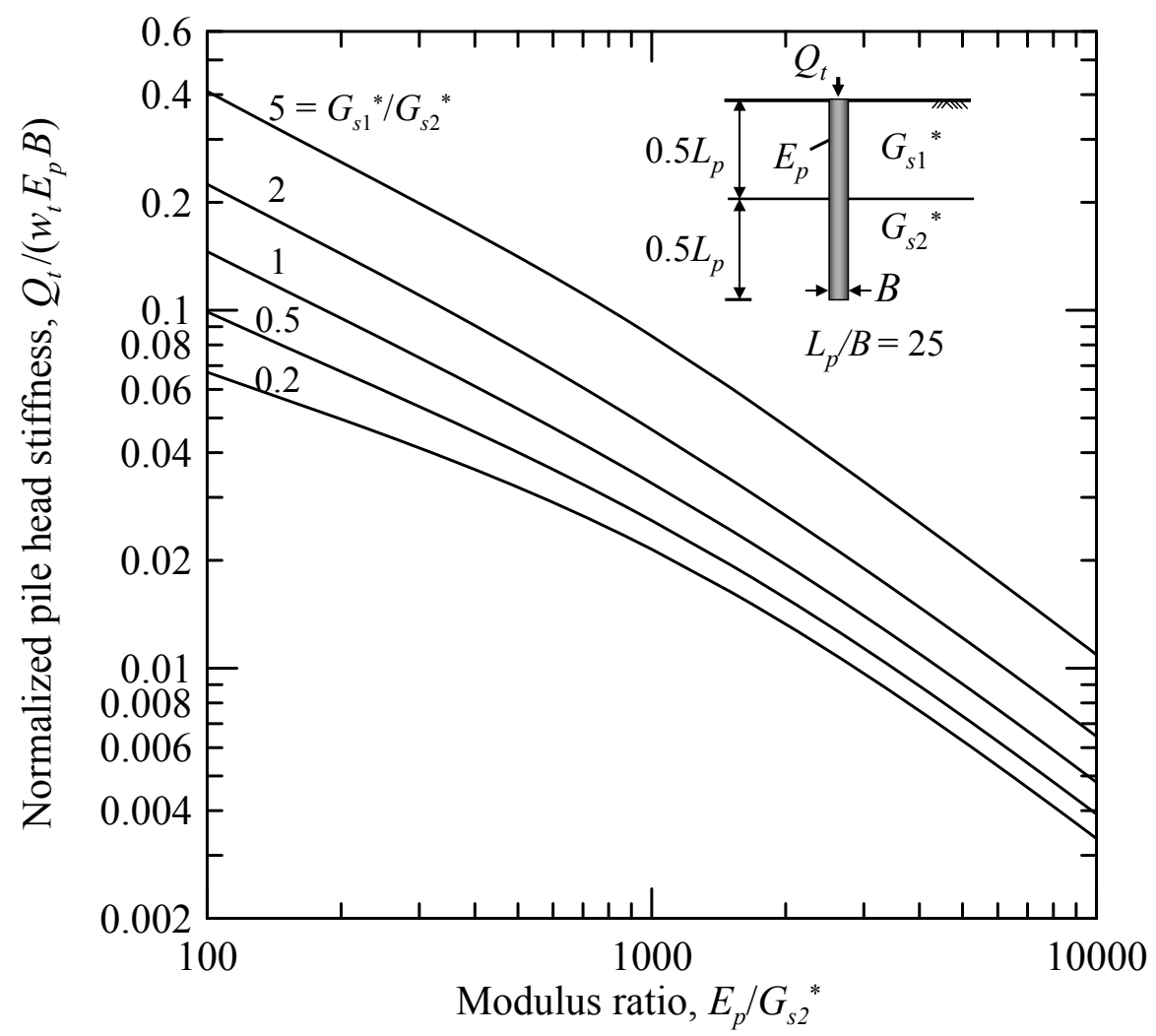

Figure 3.10 Normalized pile head stiffness in two-layer soil versus (a) $h / L_{p}$ and (b) $E_{p} / G_{s 2}{ }^{*}$ with $h=0.5 L_{p}$

\subsubsection{Piles in three-layer soil}

We also consider the case with three-layer soil deposits. It is assumed that each soil layer has the same thickness, but has different equivalent shear modulus $G_{s}{ }^{*}$ such that the average value $G_{s, a v g}^{*}\left[=\left(G_{s 1}{ }^{*}+G_{s 2}{ }^{*}+G_{s 3}{ }^{*}\right) / 3\right]$ remains the same for the cases (I, II and III) considered. In case I, the soil modulus increases with depth, with the smallest soil modulus observed for the uppermost layer. In case III, the soil modulus decreases with depth, with the largest soil modulus observed for the uppermost layer. Case II represents a profile with an intermediate weak layer.

Figure 3.11(a) shows the normalized pile head stiffness versus $E_{p} / G_{s}{ }^{*}$, with $L_{p} / B=$ 25 for all the three cases (I, II and III). Case III shows the stiffest behavior but the difference in the observed normalized pile head stiffness for the three cases becomes smaller as the soil becomes weaker (i.e., as $E_{p} / G_{s}{ }^{*}$ becomes larger). When the soil 
deposit is very weak (i.e., for $E_{p} / G_{s}{ }^{*}=10000$ ), there is no practical difference in the normalized pile head stiffness for the three cases. Figure 3.11(b) shows the normalized pile head stiffness as a function of pile slenderness ratio $L_{p} / B^{*}$, with $E_{p} / G_{s}{ }^{*}=1000$ for all the three cases considered. The normalized pile head stiffness decreases with $L_{p} / B^{*}$ for end-bearing piles (case I) and increases for floating piles (case III). These results imply that analyses considering a single layer with a simple arithmetic average of the soil modulus of different soil layers will not produce correct pile head stiffness values.

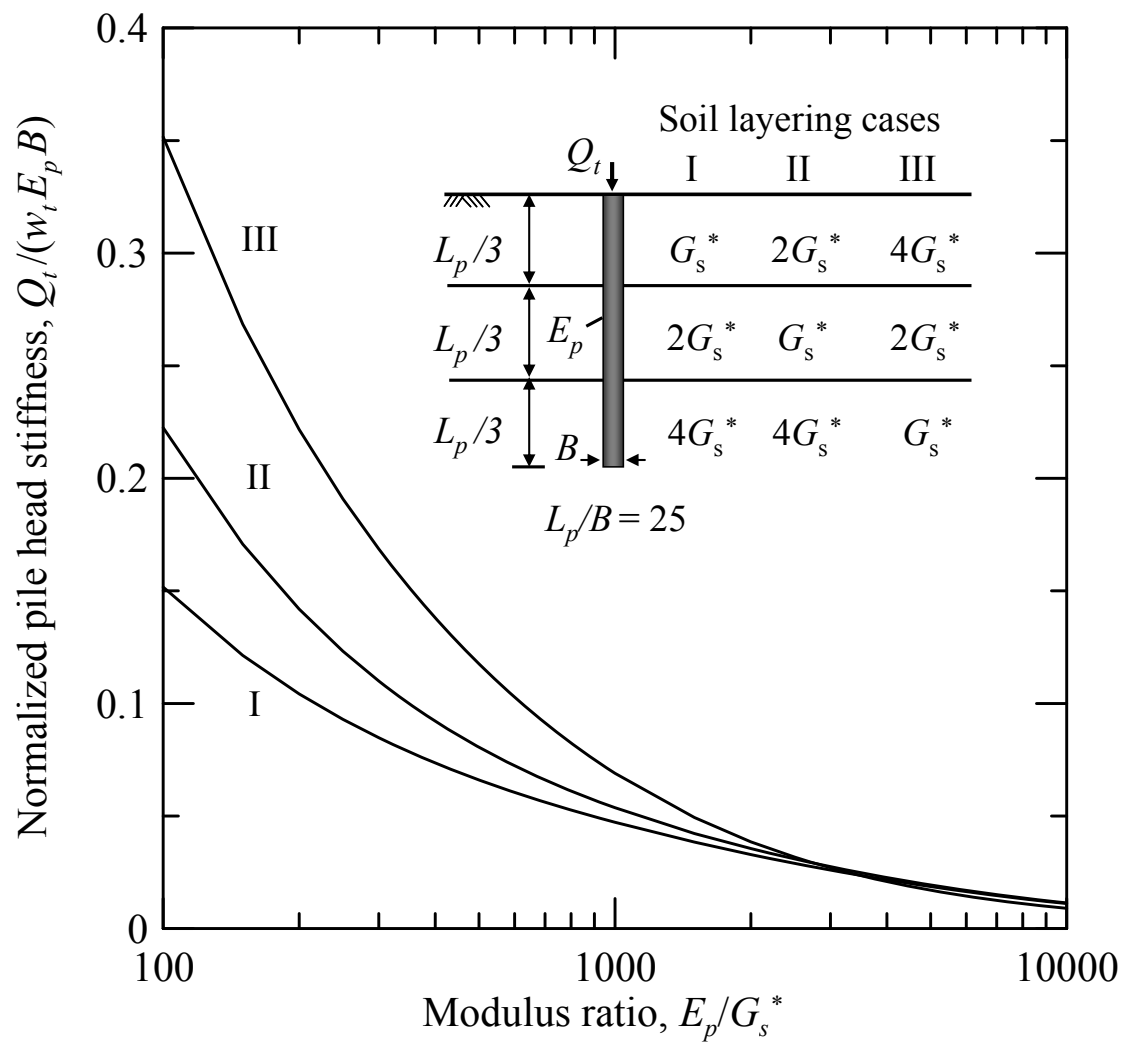

(a) 


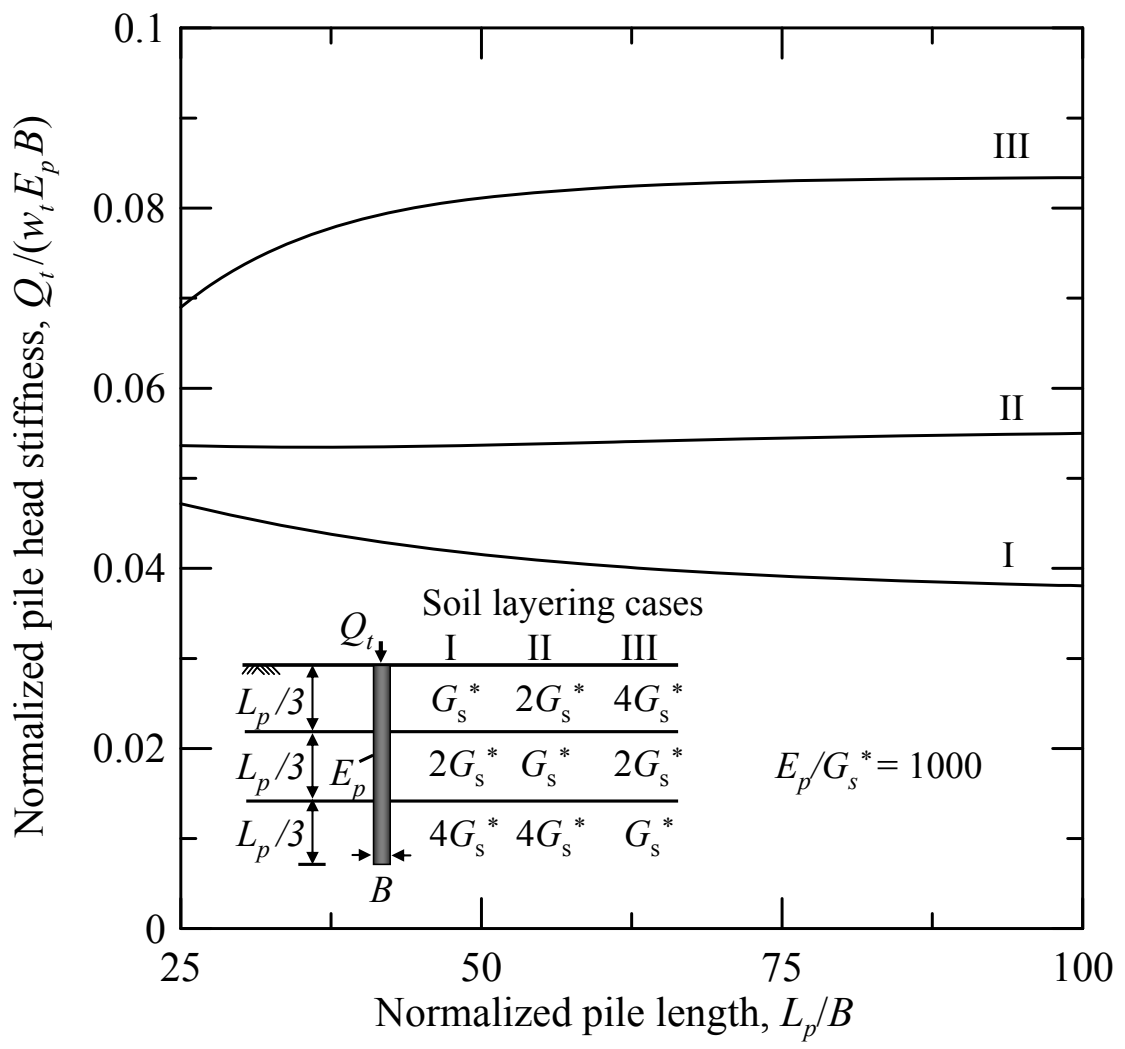

(b)

Figure 3.11 Normalized pile head stiffness in three-layer soil versus (a) $E_{p} / G_{s}{ }^{*}$ and (b) $L_{p} / B$

\subsection{Case Studies}

\subsubsection{Micropile (Italy)}

Russo (2004) presented a case history on micropiles used for underpinning a historical building in Naples, Italy. The micropiles were installed in a complex soil profile (there are thick layers of man-made materials accumulated over millennia at the site). The soil profile and representative values of cone resistance $q_{c}$ for each soil layer are shown in Figure 3.12. 


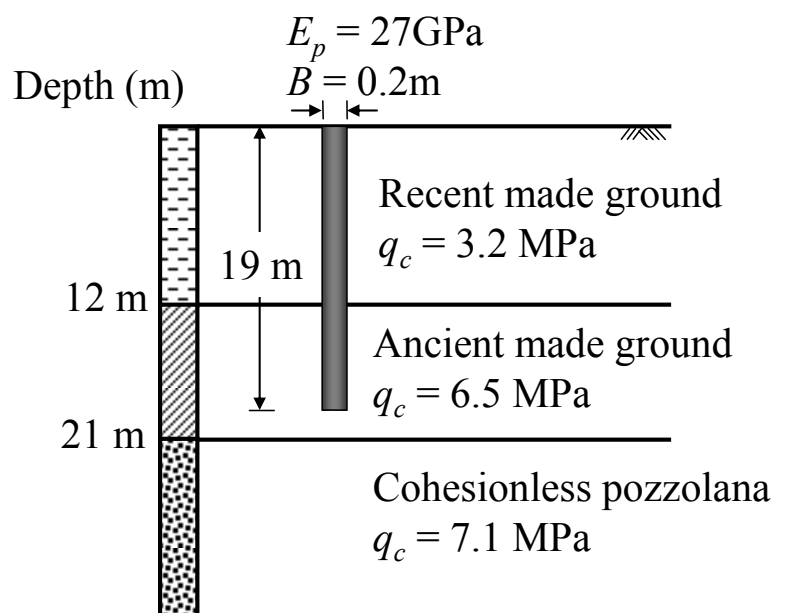

Figure 3.12 Soil profile at the micropile test site

According to Russo (2004), the micropile installation steps were: 1) drilling of a 200-mm-diameter hole using a continuous-flight auger, 2) inserting a steel pipe equipped with injection valves, 3) filling the annular space between the pipe and the soil with grout, 4) grouting the pile shaft through each valve using a double packer, and 5) filling the steel pipe with grout. This micropile $(0.2 \mathrm{~m}$ in diameter and $19 \mathrm{~m}$ in length) was loadtested. Two anchor piles were used to provide reaction to the loading frame, and the compressive load was applied on the test pile with a hydraulic jack. The vertical displacement of the pile head was measured by LVDT's, and the axial strain along the shaft was measured by vibrating-wire strain gages.

Russo (2004) compared the pile load test results with those obtained from finite element analysis. The Young's moduli of each soil layer were back-calculated from the FEA. Although Russo (2004) did not provide information on the geometry and properties of the steel pipe left inside the micropile, its outer diameter and inner diameter were assumed to be $33.4 \mathrm{~mm}$ and $25.4 \mathrm{~mm}$, respectively. Accordingly, assuming that the Young's moduli of the steel and grout are 200GPa and 25GPa, the equivalent Young's modulus of the composite steel-grout cross section is calculated to be approximately 27GPa. Table 3.2 shows the input values used in the analysis. We used four soil layers in the analysis with the bottom of the second layer flush with the base of the pile. The Poisson's ratio was assumed to be 0.3 for all the soil layers. 
Table 3.2 Input values for the analysis of the microplile load-tested in Italy $\left(B=0.2 \mathrm{~m} ; L_{p}\right.$ $\left.=19 \mathrm{~m} ; E_{p}=27 \mathrm{GPa}\right)$

\begin{tabular}{|l|l|l|l|}
\hline Layer & $H_{i}(\mathrm{~m})$ & $E_{s i}(\mathrm{MPa})$ & $v_{s i}$ \\
\hline 1 & 12 & 50 & 0.3 \\
\hline 2 & 19 & 117 & 0.3 \\
\hline 3 & 21 & 117 & 0.3 \\
\hline 4 & 50 & 138 & 0.3 \\
\hline
\end{tabular}

Figure 3.13(a) shows both the measured and calculated load versus settlement curves. Figure 3.13(b) shows measured and calculated load-transfer curves for applied loads equal to 51,253 , and $542 \mathrm{kN}$. These figures show that there is very good agreement between the calculated and measured values, although the calculated values for the pile head settlement become smaller than the measured values for loads greater than about $400 \mathrm{kN}$.

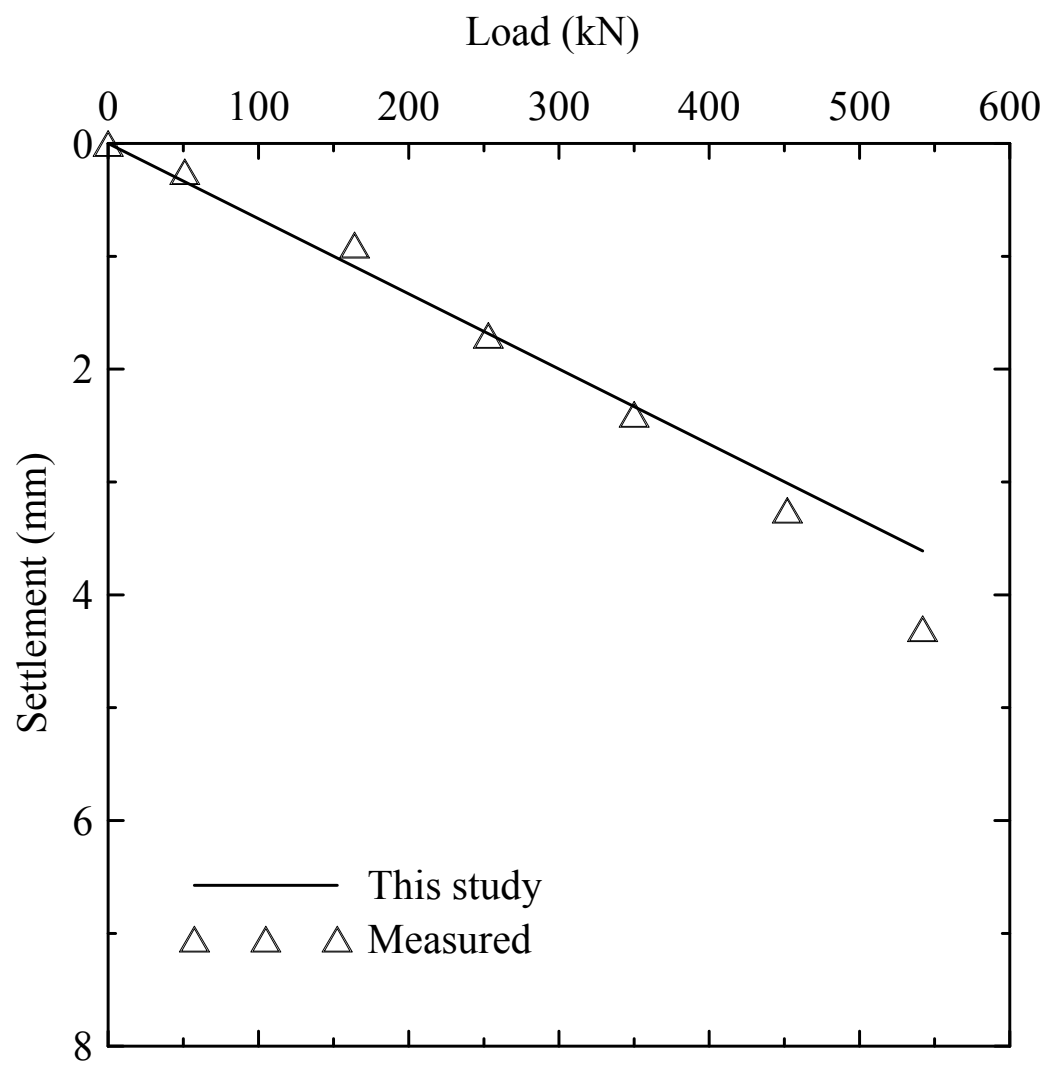

(a) 


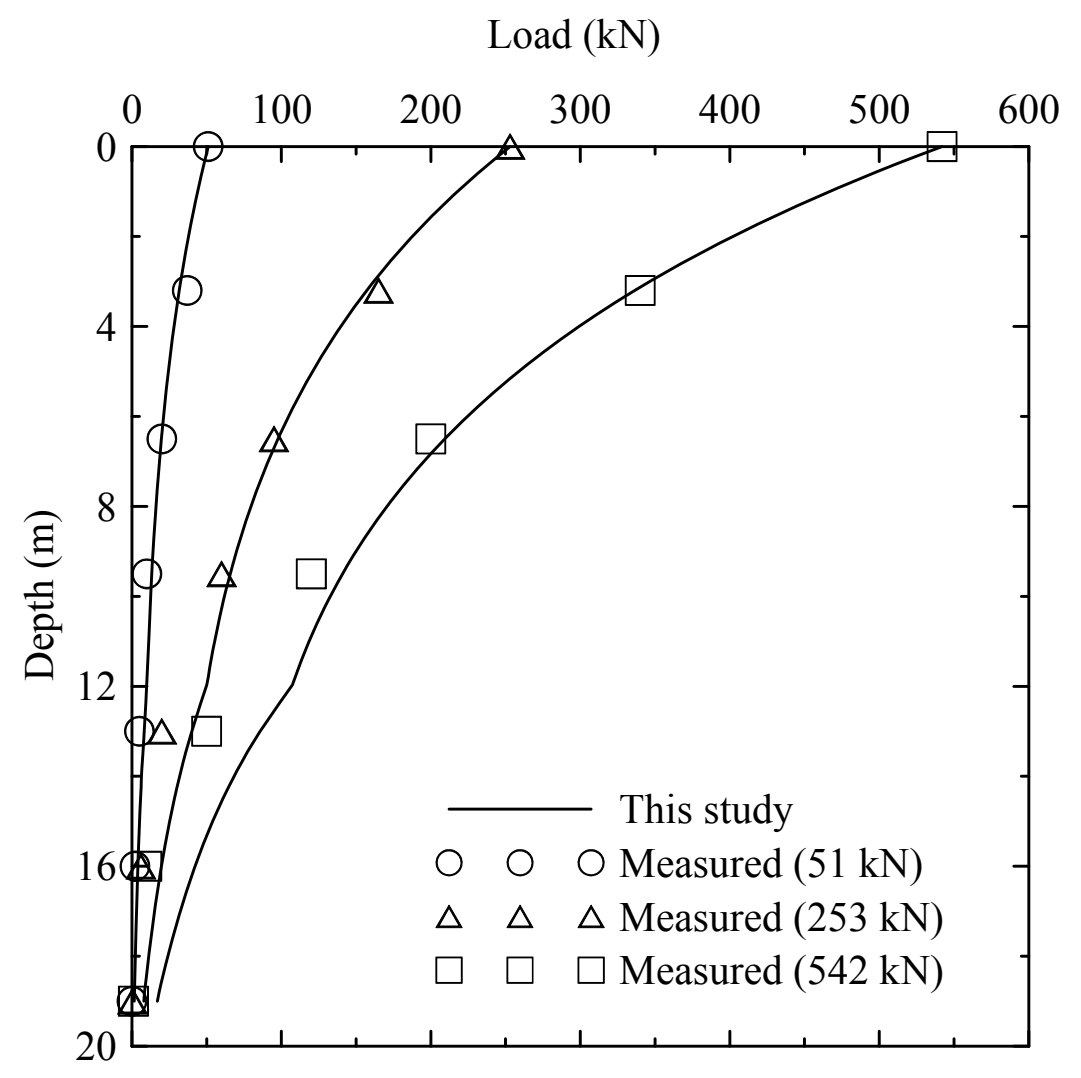

(b)

Figure 3.13 Comparison between the results from the present analysis and measured data (Italy case): (a) load-pile head settlement curves; (b) load-transfer curves

\subsubsection{Drilled shaft in rock (Singapore)}

Chang and Wong (1987) reported the results of instrumented load tests on drilled shafts installed in weathered sedimentary rocks of the Jurong Formation in Singapore. The top 11 meters of the soil profile consists of medium stiff to hard silty clay $\left(N_{\mathrm{SPT}}=7-36\right.$, where $N_{\mathrm{SPT}}=\mathrm{SPT}$ blow counts); underneath this layer there is a layer of highly weathered siltstone $\left(N_{\mathrm{SPT}}=50-145\right)$, with an undrained shear strength $s_{u}$ ranging from 40 to $200 \mathrm{kPa}$. The test pile, which was embedded $13 \mathrm{~m}$ into the siltstone layer, was $0.9 \mathrm{~m}$ in diameter and $24 \mathrm{~m}$ in length. It was instrumented with five vibrating-wire strain gages at $7.5,11.0,15.5,20.5$ and $24.0 \mathrm{~m}$ below the ground surface. The representative Young's modulus of the pile was $31 \mathrm{GPa}$. The pile was designed to carry an axial load of $2500 \mathrm{kN}$ 
and tested to 4 times the design load one month after its installation using the slow maintained-load test method.

The elastic properties of the soil and rock layers were not available in the original paper by Chang and Wong (1987). For the rock layer, input values for the Young's modulus was obtained from Kim et al. (1999) since they reanalyzed the pile load test results reported by Chang and Wong (1987) to develop load-transfer functions for drilled shafts installed in weathered rock. The Young's modulus of the weathered siltstone used in the analysis of Kim et al. (1999) was $1000 \mathrm{MPa}$. For the silty clay layer, the Young's modulus was estimated from the undrained shear strength $s_{u}$. According to Calanan and Kulhawy (1985), values for the $E_{s} / s_{u}$ ratio generally ranges between 200 and 900, with an average value of 500. Using $E_{s} / s_{u}=500, E_{s}$ values for the clay layer range from 20 to $100 \mathrm{MPa}$; an average value $E_{s, \text { avg }}=60 \mathrm{MPa}$ was used in the analysis. The Poisson's ratio was assumed to be 0.5 for the clay layer and 0.15 for the rock layer. The input values used in the analysis are summarized in Table 3.3.

Table 3.3 Input values for the analysis of the drilled shaft load-tested in Singapore $\left(L_{p}=\right.$ $\left.24 \mathrm{~m} ; E_{p}=31 \mathrm{GPa}\right)$

\begin{tabular}{|l|l|l|l|}
\hline Layer & $H_{i}(\mathrm{~m})$ & $E_{s i}(\mathrm{MPa})$ & $v_{s i}$ \\
\hline 1 & 11 & 60 & 0.5 \\
\hline 2 & 24 & 1000 & 0.15 \\
\hline 3 & 50 & 1000 & 0.15 \\
\hline
\end{tabular}

The results from our analysis are compared with measured data for up to 2 times the design load because our analysis is elastic and is valid only for the initial stages of loading. Figure 3.14(a) shows the predicted and measured load-settlement curves for the test pile and the predicted load-settlement curve for the barrette. The results from our analysis are in good agreement with the measured data. In particular, the calculated settlement showed very good agreement with the measured values up to the design load level $\left(Q_{t}=2500 \mathrm{kN}\right)$. The reason for a sudden jump in the measured load-settlement curve at $3000 \mathrm{kN}$ is not mentioned in the original paper. Figure 3.14(b) shows the predicted and measured load-transfer curves for the test pile. The results from both the 
load test and our analysis indicate that most of the applied load was carried by shaft friction, in particular along the pile-rock interface.

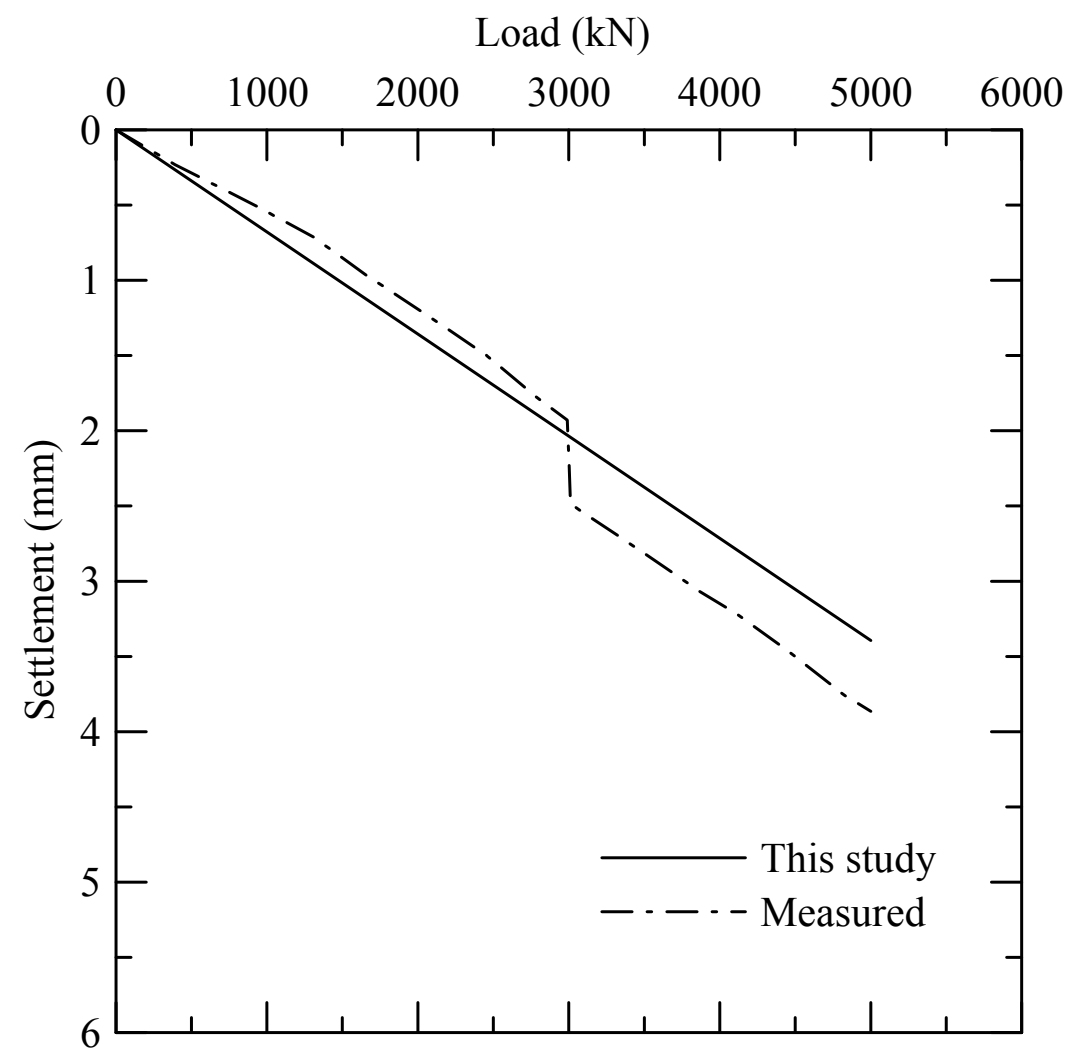

(a) 


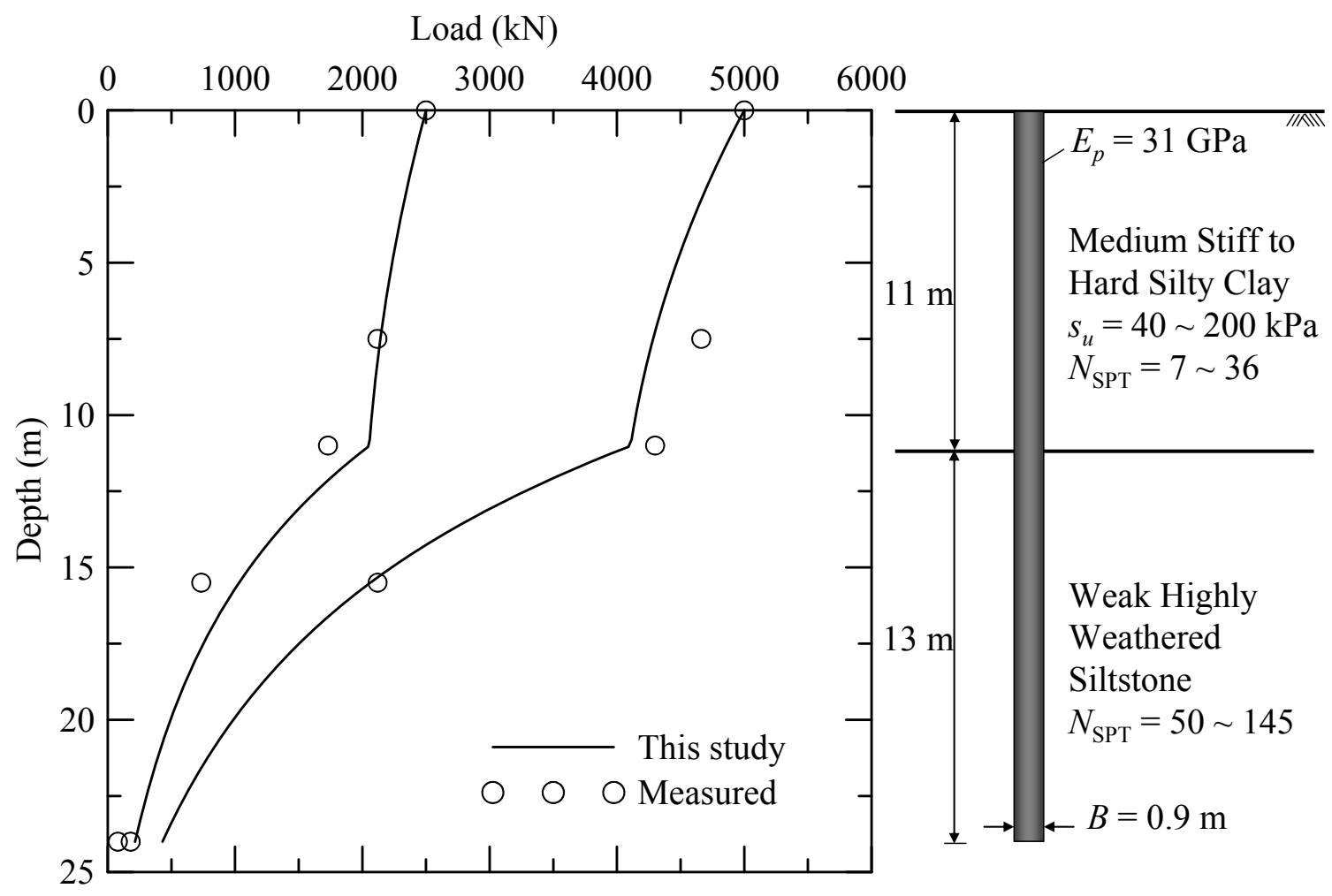

(b)

Figure 3.14 Comparison between the results from the present analysis and measured data (Singapore case): (a) load-pile head settlement curves; (b) load-transfer curves 


\section{CHAPTER 4. ANALYSIS OF ROCK-SOCKETED PILES}

\subsection{Introduction}

Micropiles have been successfully used as underpinning foundation elements throughout the world because they can be installed under low headroom and restricted access conditions with minimal disturbance of existing structures. Furthermore, they have been increasingly used as foundations of new structures as well. Even though micropiles may be installed in almost all ground conditions, they are particularly advantageous for conditions in which rock is near the ground surface because of the large load-carrying capacity that can be obtained.

In many situations, rock-socketed micropiles are expected to behave linear elastically under design loads. Therefore, use of the elastic solutions presented in CHAPTER 3 may be sufficient to evaluate the load-settlement response of rock-socketed piles. In order to use the elastic solutions presented in CHAPTER 3 for the case of rocksocketed piles, we need the elastic properties of rock masses. We briefly review the available methods for estimation of deformation properties of rock masses. We then perform extensive parametric studies for rock-socketed piles.

\subsection{Estimation of deformation modulus of rock mass}

In situ rock masses usually include joints or discontinuities. Therefore, their behavior is quite different from that of intact rocks. The Young's modulus or elastic modulus of intact rock $E_{r}$ can not be considered representative of the corresponding in situ rock mass. We use the term deformation modulus $E_{m}$ to describe the deformation properties of rock masses. According to the International Society for Rock Mechanics (ISRM 1975), the 
rock mass deformation modulus is defined as 'the ratio of the stress to the corresponding strain during loading of a rock mass including elastic and inelastic behavior'.

4.2.1. Correlation with unconfined compressive strength of intact rock

Rowe and Armitage (1987) have correlated $E_{m}$ with average unconfined compressive strength of intact rock core. They deduced the following equation from a large number of field load tests for drilled shafts founded in weak rock deposits:

$$
\frac{E_{m}}{p_{A}}=680 \sqrt{\frac{q_{u}}{p_{A}}}
$$

where $p_{A}=$ reference stress $=100 \mathrm{kPa}=0.1 \mathrm{MPa} \approx 1 \mathrm{tsf}=2000 \mathrm{psf}$

\subsubsection{Correlation with in situ rock mass quality}

A number of attempts have been made to correlate various rock mass quality designators to rock mass deformation modulus. Among others, the most common correlations use $R M R$ (rock mass rating) or $R Q D$ (rock quality designation) to estimate rock mass deformation modulus. The $R M R$ is a rock quality index that provides a general rock mass rating from 0 to 100 based on strength of the intact rock, drill core quality, groundwater conditions, discontinuity spacing, and discontinuity characteristics (see 
Table 4.1). The $R Q D$ is the percentage of the total length of the core drill run with rock core pieces longer than $100 \mathrm{~mm}$. The $R Q D$ is related to the drill core quality. Low $R Q D$ values are an indication of very fractured rock; high $R Q D$ values, on the other hand, indicate that the rock mass is fairly continuous. 
Table 4.1 RMR (rock mass rating) for jointed rock (modified after Bieniawski 1989)

A. Classification parameters and their ratings

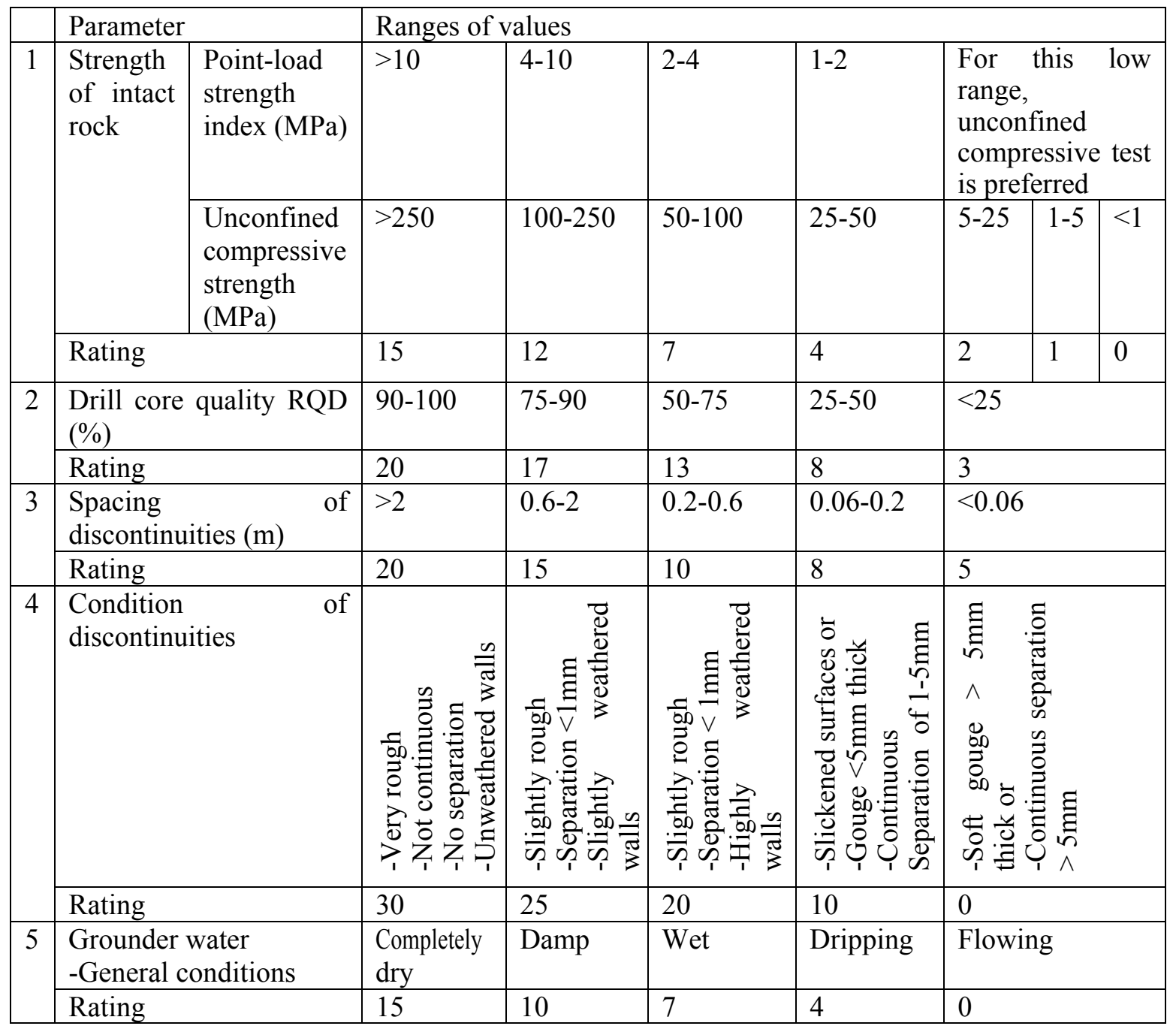

\section{B. Rating adjustment for joint orientations}

\begin{tabular}{|c|c|c|c|c|c|}
\hline $\begin{array}{c}\text { Strike and dip orientation } \\
\text { of discontinuities }\end{array}$ & $\begin{array}{c}\text { Very } \\
\text { favorable }\end{array}$ & Favorable & Fair & $\begin{array}{c}\text { Unfavora } \\
\text { ble }\end{array}$ & $\begin{array}{c}\text { Very } \\
\text { unfavorable }\end{array}$ \\
\hline Adjustment for foundations & 0 & -2 & -7 & -15 & -25 \\
\hline
\end{tabular}


Bieniawski (1978) suggested the following equation to predict $E_{m}$ from $R M R$ :

$$
E_{m}(\mathrm{GPa})=20 R M R-100
$$

Eq. (4.2) is not defined for $R M R$ values less than 50. For the rock mass whose $R M R$ value is less than $50, E_{m}$ can be estimated from (Serafim and Pereira 1983):

$$
E_{m}(\mathrm{GPa})=10^{(R M R-10) / 40}
$$

Although the $R M R$ has been widely used as a rock quality index for large underground construction projects, it may not be available for routine foundation projects. The $R Q D$ is often the rock quality index used in practice. Gardner (1987) proposed the following equation, later adopted by American Association of State Highway and Transportation Officials in Standard Specification for Highway Bridges (AASHTO 1989), for estimating $E_{m}$ from $R Q D$ :

$$
\frac{E_{m}}{E_{r}}=0.0231 R Q D-1.32 \geq 0.15
$$

where $E_{r}=$ Young's modulus of intact rock. Eq. (4.4) gives $E_{m} / E_{r}=0.15$ for $R Q D$ less than 64\%. To overcome this limitation, Zhang and Einstein (2004) collected additional data and proposed the following equation as an average relation for the collected data set:

$$
\frac{E_{m}}{E_{r}}=10^{0.0186 R Q D-1.91}
$$

The Young's modulus of intact rock can be determined from unconfined compression tests on rock core samples obtained from drilling using a diamond core barrel. Typical values of elastic modulus of intact rocks are given in Table 4.2. 
Table 4.2 Typical values of elastic modulus of intact rocks (modified after AASHTO, 1989)

\begin{tabular}{|c|c|c|c|c|}
\hline \multirow{2}{*}{ Rock type } & \multicolumn{3}{|c|}{ Elastic modulus (GPa) } & \multirow{2}{*}{$\begin{array}{c}\text { Standard } \\
\text { deviation }\end{array}$} \\
\cline { 2 - 4 } & Maximum & Minimum & Mean & \\
\hline Granite & 100 & 6.41 & 52.7 & 24.5 \\
\hline Diorite & 112 & 17.1 & 51.4 & 42.7 \\
\hline Gabbro & 84.1 & 67.6 & 75.8 & 6.69 \\
\hline Diabase & 104 & 69 & 88.3 & 12.3 \\
\hline Basalt & 84.1 & 29 & 56.1 & 17.9 \\
\hline Quartzite & 88.3 & 36.5 & 66.1 & 16 \\
\hline Marble & 73.8 & 4 & 42.6 & 17.2 \\
\hline Gneiss & 82.1 & 28.5 & 61.1 & 15.9 \\
\hline Slate & 26.1 & 2.41 & 9.58 & 6.62 \\
\hline Schist & 69 & 5.93 & 34.3 & 21.9 \\
\hline Phyllite & 17.3 & 8.62 & 11.8 & 3.93 \\
\hline Sandstone & 39.2 & 0.62 & 14.7 & 8.21 \\
\hline Siltstone & 32.8 & 2.62 & 16.5 & 11.4 \\
\hline Shale & 38.6 & 0.007 & 9.79 & 10 \\
\hline Limestone & 89.6 & 4.48 & 39.3 & 25.7 \\
\hline Dolostone & 78.6 & 5.72 & 29.1 & 23.7 \\
\hline & & & & \\
\hline
\end{tabular}

\subsection{Analysis of load-transfer behavior of rock-socketed piles}

In this section, we analyze the effect of rock socket geometry, rock mass deformation modulus, and quality of in situ rock mass on the load-transfer behavior of rock-socketed pile. In all the analyses, we assumed a rock mass Poisson's ratio of 0.2 . The results are given as percentage of applied load along the depth of the socket. 


\subsubsection{Effect of rock-socket geometry}

We considered several rock-socket geometries in the analysis. The rock-socket geometry is defined by the $L_{s} / B$ ratio, where $L_{s}$ and $B$ are the rock socket length and diameter, respectively. Two different ratios of rock-to-pile elastic modulus were assumed $\left(E_{m} / E_{p}=\right.$ 0.2 and 2) to represent weak and hard rock.

Figure 4.1 shows the distribution of axial load along the depth of a rock-socketed pile for $E_{m} / E_{p}=0.2$ and 2. As $L_{s} / B$ increases, less load is transferred to the pile base in both cases. For example, for $E_{m} / E_{p}=0.2$, about $57 \%$ of the applied load is transferred to the base of the rock-socketed pile with $L_{s} / B=1$, while only $11 \%$ of the applied load is transferred to the base of the rock-socketed pile with $L_{s} / B=5$. This implies that the loadsettlement response of shorter sockets will be largely affected by the stiffness of the rock at the base, whereas that of longer sockets will be less sensitive to the stiffness of the base rock. For the same socket geometry and, hence, the same $L_{S} / B$, the transfer of load to the base is less in hard rock $\left(E_{m} / E_{p}=2\right)$ than in weak rock $\left(E_{m} / E_{p}=0.2\right)$. For example, for $L_{s} / B=3$, about $25 \%$ of the applied load is transferred to the base for $E_{m} / E_{p}=0.2$, while only $1.4 \%$ is transferred to the base for $E_{m} / E_{p}=2$. This suggests that for very hard rock, even for relatively short socket lengths, the load-settlement response of rock-socketed piles will be controlled by the resistance developed along the shaft. 

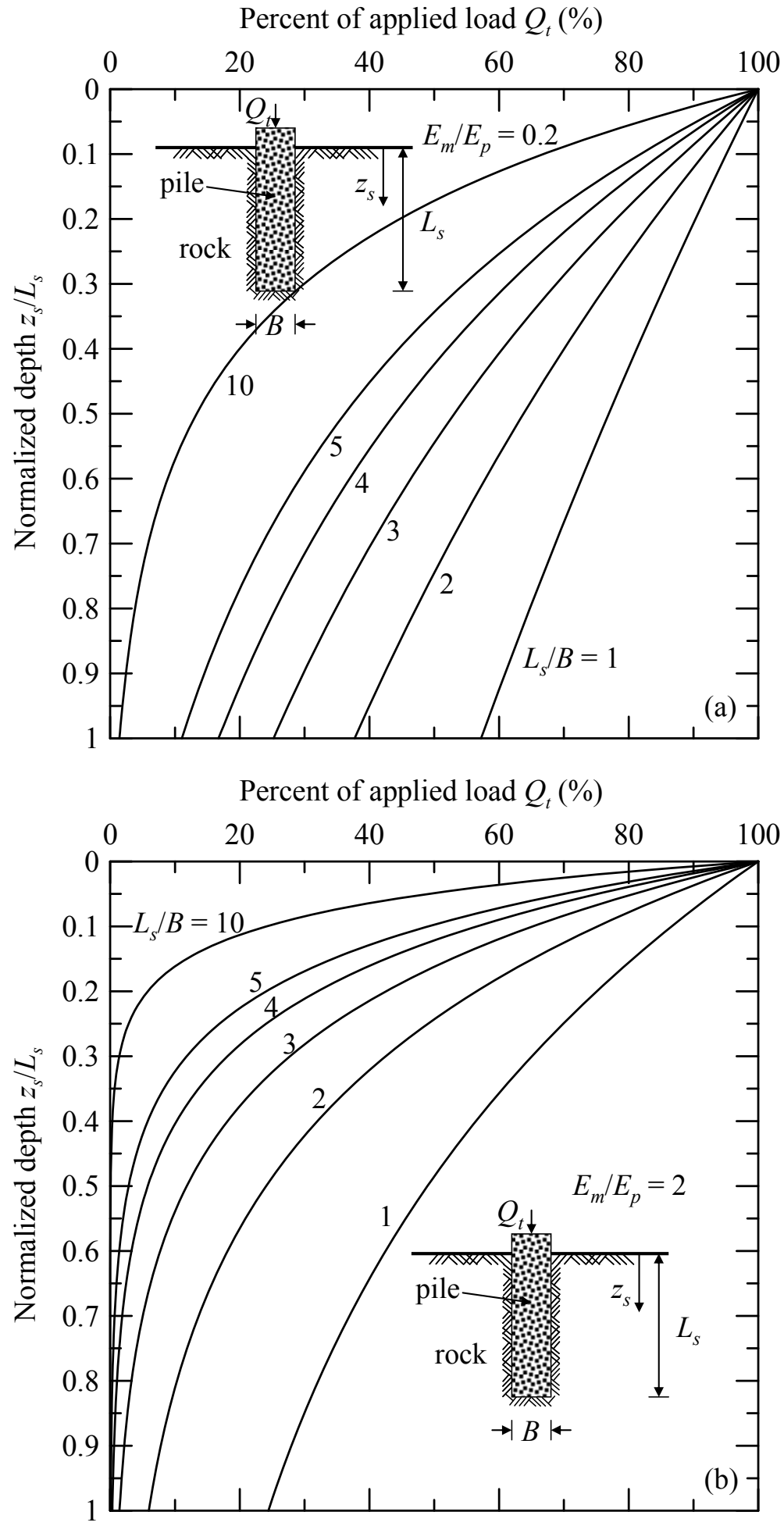

Figure 4.1 Distribution of axial load versus normalized depth for rock-socketed piles with: (a) $E_{m} / E_{p}=0.2$ and (b) $E_{m} / E_{p}=2$ 


\subsubsection{Effect of rock mass modulus}

We now consider different values of $E_{m} / E_{p}$ for the same $L_{s} / B$ ratio in order to investigate the effect of the rock mass deformation modulus. As rock becomes stiffer, $E_{m} / E_{p}$ increases, and a larger portion of the applied load is carried by the shaft. Almost all the applied load is carried by the shaft for very stiff rock $\left(E_{m} / E_{p}=5\right)$, while only half of the applied load is carried by the shaft for very soft rock $\left(E_{m} / E_{p}=0.02\right)$. These observations, together with the ones in the previous section on the effects of rock socket geometry, justify the usual decision often made in practice to ignore the base capacity of micropiles installed in hard rock because, as our analysis results show, there will be no load transferred to the base for high values of $E_{m} / E_{p}$ and $L_{s} / B$.

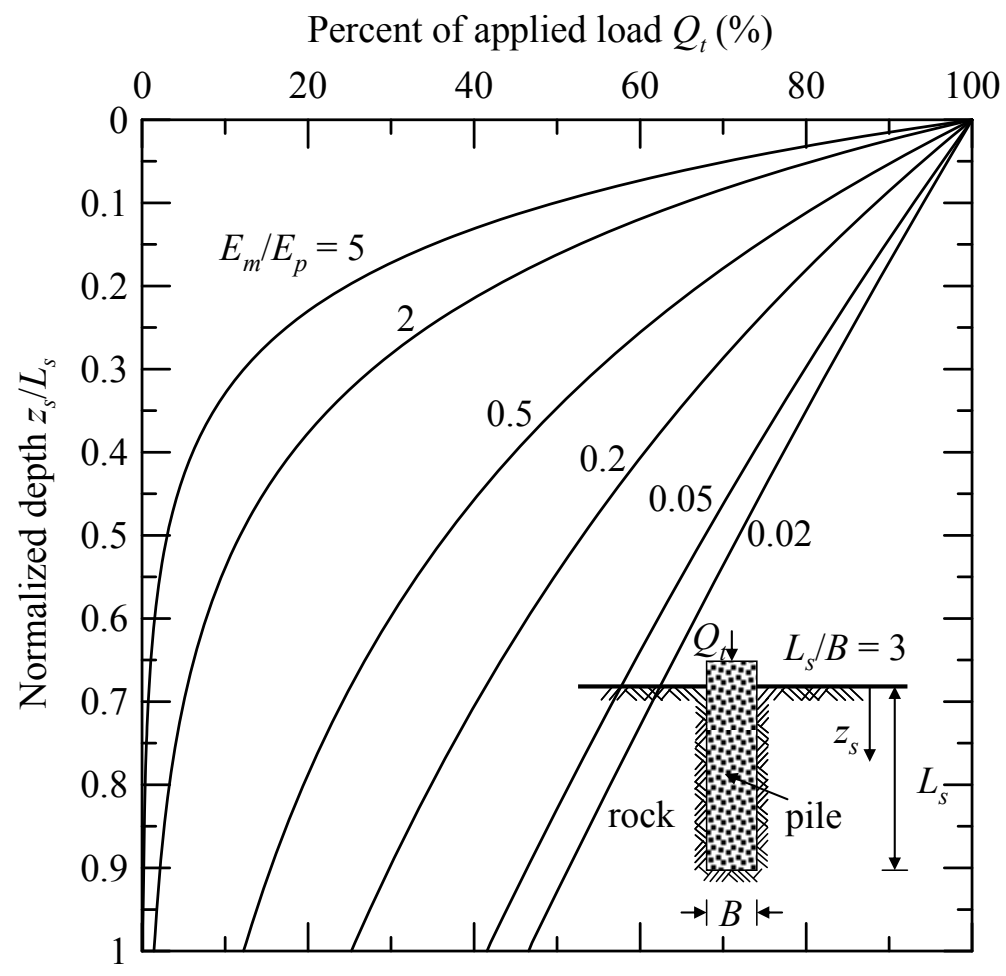

Figure 4.2 Distribution of axial load versus normalized depth for a rock-socketed pile with $L_{p} / B=3$ 


\subsubsection{Effect of rock mass quality}

In this section, we study the effects of in situ rock mass quality on the load-transfer behavior of rock-socketed piles. We considered a single value for the elastic modulus of intact rock $E_{r}$ and varied the $R Q D$ from 0 to $100 \%$. A Young's modulus $E_{p}$ of $30 \mathrm{GPa}$ was assumed for the pile. Two different values of intact rock elastic modulus $E_{r}$ were assumed: 10 and $90 \mathrm{GPa} . E_{r}=10 \mathrm{GPa}$ represents typical properties of weak rocks, such as slate or shale (see Table 4.2); $E_{r}=90 \mathrm{GPa}$ represents typical properties of hard rocks, such as granite or diabase. We fixed the socket geometry to $L_{s} / B=3$. The rock mass deformation modulus was estimated from the $R Q D$ values using Eq. (4.5).

Figure 4.3 shows the load-transfer behavior of a rock-socketed pile with $L_{s} / B=3$ for various values of $R Q D$. For weak rocks $\left(E_{r} / E_{p}=1 / 3\right)$, the rock mass quality does not affect significantly the load-transfer response of the pile (see Figure 4.3(a)). Almost the same load-transfer response is observed for highly fractured rocks $(R Q D=0-40 \%)$. It is interesting to note that Eq. (4.1), proposed by Rowe and Armitage (1984) based on a large number of field load tests for drilled shafts installed in weak rock deposits, correlates the rock mass deformation modulus to the unconfined compressive strength of intact rock, regardless of in situ rock mass quality. On the other hand, in hard rock $\left(E_{r} / E_{p}\right.$ $=3$ ), the $R Q D$ has a much more pronounced effect in the load-transfer response of rocksocketed piles than in weak rock; as the $R Q D$ increases, less load is transferred to the pile base. 

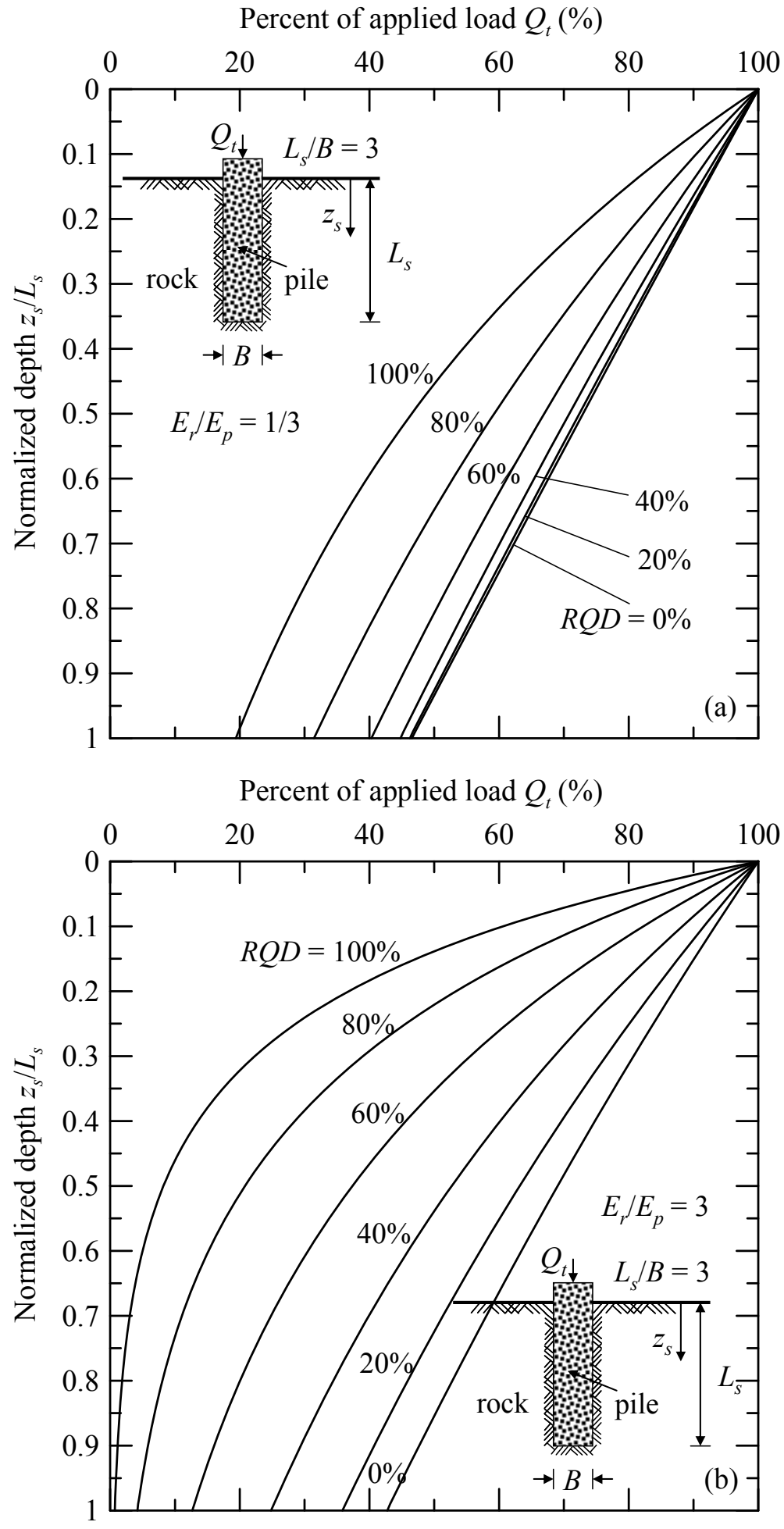

Figure 4.3 Distribution of axial load versus normalized depth for a rock-socketed pile: (a) $E_{r} / E_{p}=1 / 3$ and (b) $E_{r} / E_{p}=3$ 


\subsection{Analysis of the load-settlement response of rock-socketed piles}

In this section, we investigate the effect of socket geometry, rock mass deformation modulus, and in situ rock mass quality on the load-settlement response of rock-socketed piles. The results are presented in terms of normalized pile head stiffness $K_{N}\left(=Q_{t} / w_{t} E_{p} B\right)$, as seen in Eq. (3.54).

\subsubsection{Effect of socket geometry}

Figure 4.4 shows socket geometry versus normalized pile head stiffness. For soft rocks $\left(E_{m} / E_{p}=0.02\right.$ and 0.2$)$, normalized pile head stiffness increases slightly as $L_{s} / B$ increases. However, this trend is not observed for stiffer rock $\left(E_{m} / E_{p}=2\right)$. This means that the pile head stiffness remains the same regardless the pile length of piles in hard rock because most of the applied load is carried by the top portion of the shaft (see Figure 4.1(b)).

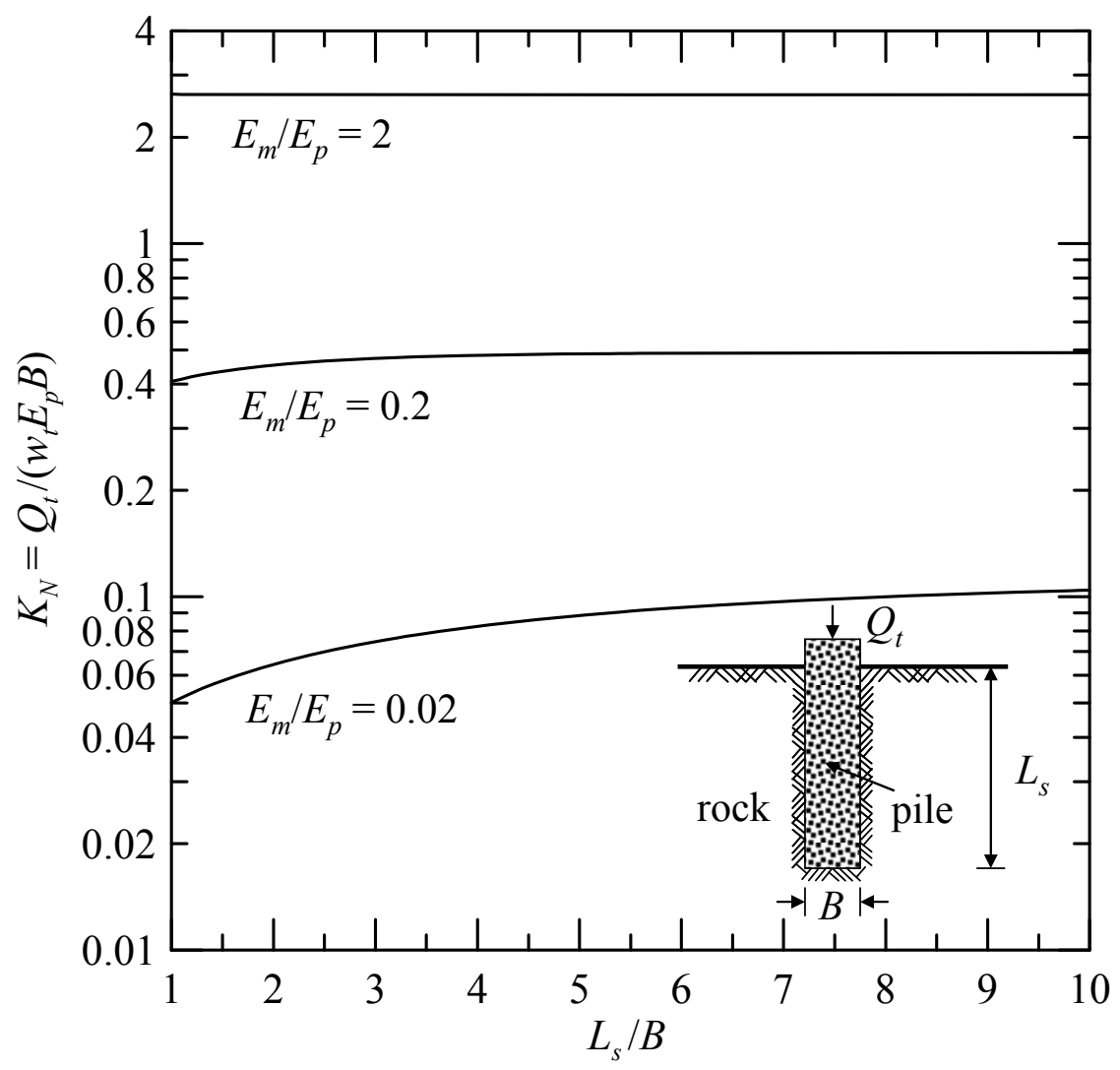

Figure 4.4 Normalized pile head stiffness $K_{N}$ versus $L_{s} / B$ for $E_{m} / E_{p}=0.02,0.2$, and 3 


\subsubsection{Effect of rock mass deformation modulus}

Figure 4.5 shows normalized pile head stiffness versus normalized rock mass deformation modulus on log-log scale. Pile head stiffness increases with increasing rock mass deformation modulus, irrespective of socket geometry. When the rock mass deformation modulus is larger than the elastic modulus of the pile $\left(E_{m} / E_{p}>1\right)$, socket geometry no longer affects pile head stiffness as all curves for different $L_{s} / B$ values merge on a single line (see Figure 4.5).

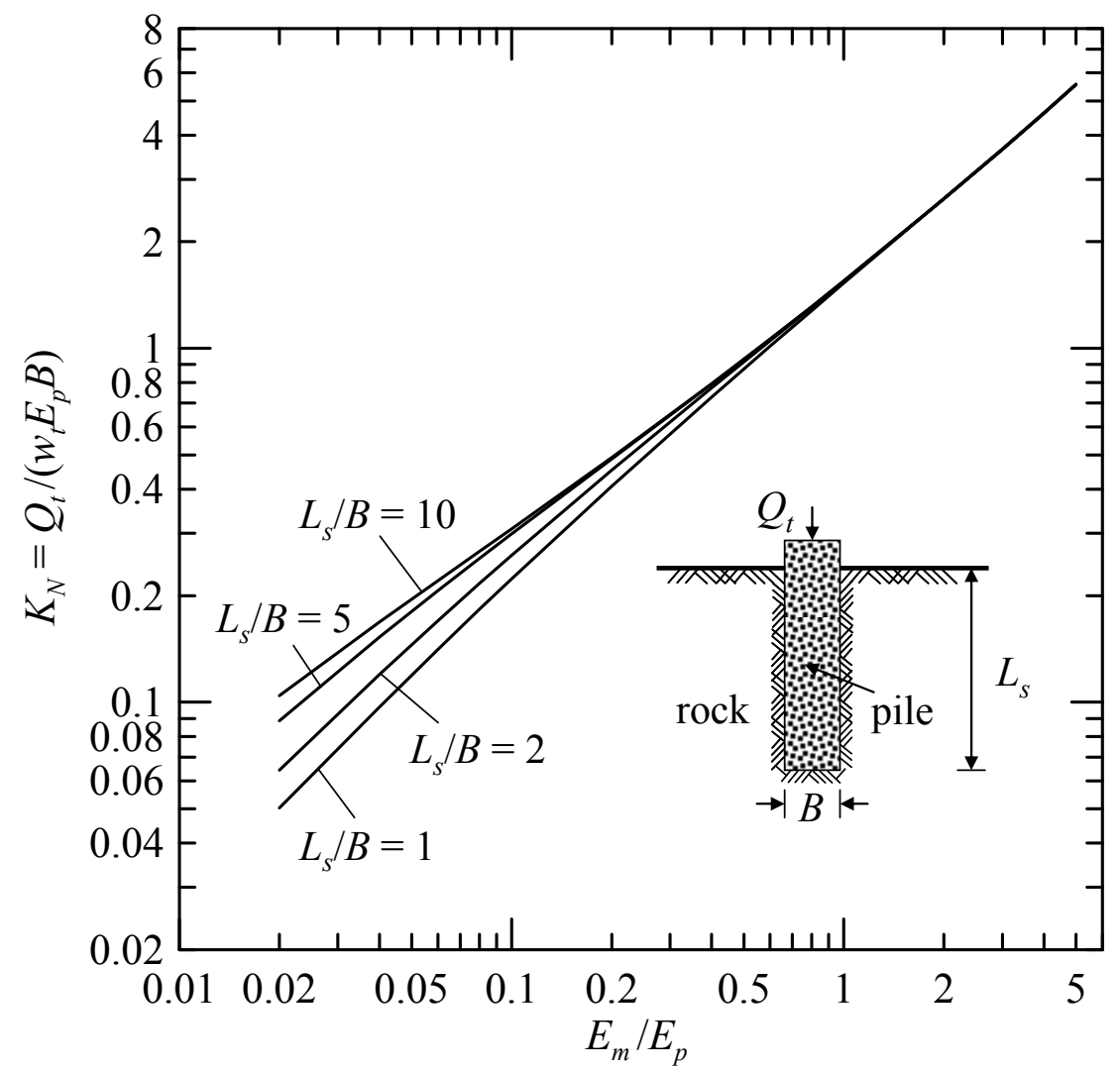

Figure 4.5 Normalized pile head stiffness $K_{N}$ versus $E_{m} / E_{p}$ for $L_{s} / B=1,2,5$, and 10

\subsubsection{Effect of rock mass quality}

Figure 4.6 shows normalized pile head stiffness versus $R Q D$ of rock mass. As we did in an earlier section, we fix the socket geometry to $L_{s} / B=3$ and estimate the rock mass deformation modulus for different $R Q D$ values using Eq. (4.5). Pile head stiffness 
increases as the $R Q D$ increases. In fact, the effect of $R Q D$ on pile head stiffness is more pronounced for stronger than weak rock. This is in agreement with the finding that $R Q D$ has a larger effect on the load-transfer behavior of rock-socketed piles in hard rock than in weak rock (see Section 4.3.3).

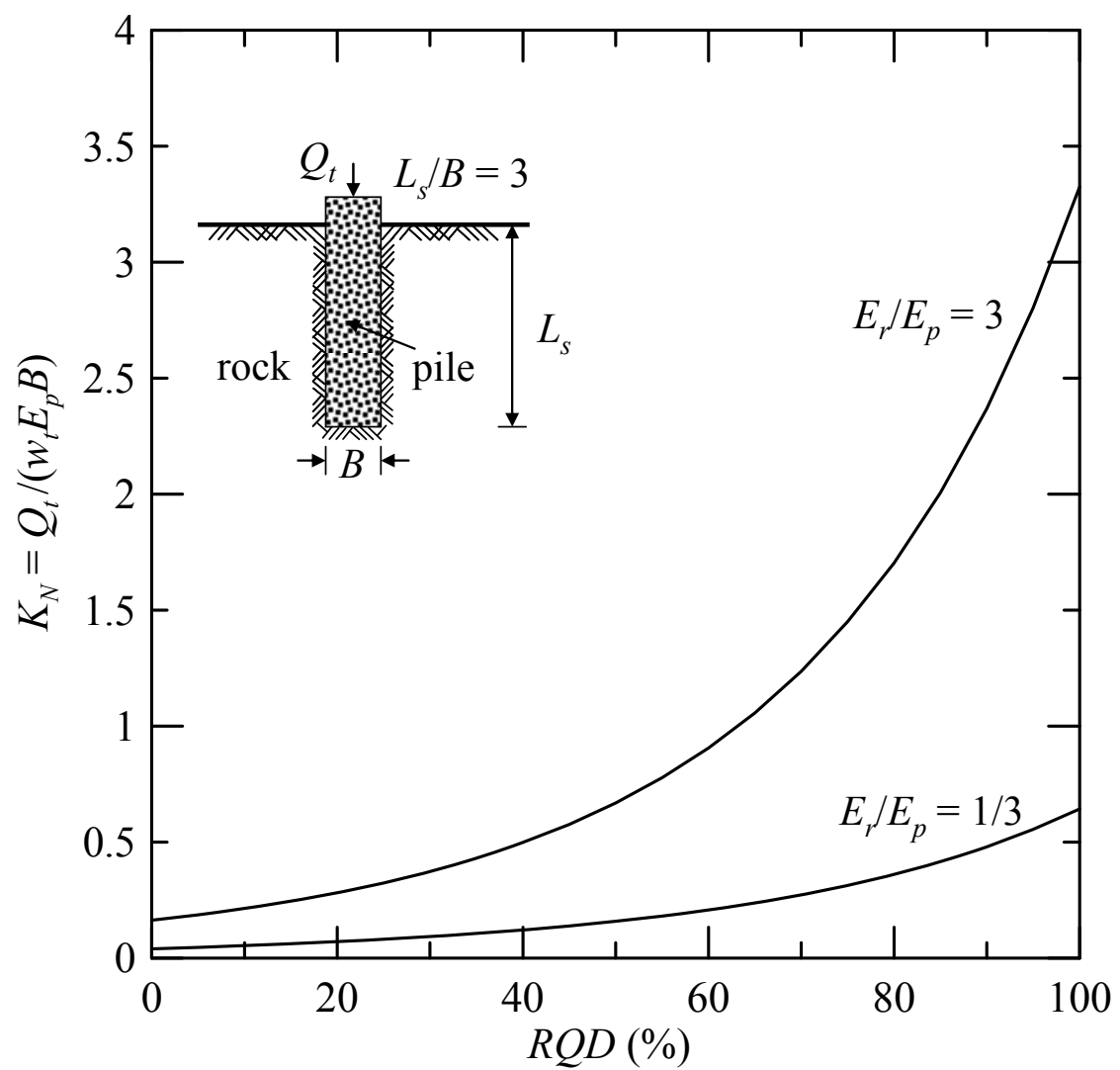

Figure 4.6 Normalized pile head stiffness $K_{N}$ versus $R Q D$ for $E_{m} / E_{p}=1 / 3$ and 3 


\section{CHAPTER 5. DEVELOPMENT OF A USER-FRIENDLY SPREADSHEET PROGRAM ALPAXL}

\subsection{Introduction}

In CHAPTER 3, we obtained elastic solutions for the load-settlement response of axially loaded piles. These solutions were successfully used in the analysis of rock-socketed piles in CHAPTER 4. However, in order to facilitate the use of the analysis in cases where the profile consists of many soil or rock layers, we developed a user-friendly spreadsheet program called ALPAXL (Axially Loaded Pile Analysis). This program is based on the solution scheme presented in CHAPTER 3 and uses built-in functions of Microsoft Excel. ALPAXL provides the results of the analysis, the deformed configuration of the pile-soil system and the load-settlement curve in seconds. It can be downloaded at http://cobweb.ecn.purdue.edu/ mprezzi. In this Chapter, we show how to use ALPAXL and perform a few analyses using ALPAXL.

\subsection{How to use ALPAXL}

Depending on the user's settings of Microsoft Excel, Bessel's function, which is used for the solution of the soil displacement decay function $\phi$, may not be available. In order to have Bessel's function available, the Analysis ToolPak must be installed first. The installation procedures for the Analysis ToolPak are as follows:

1. On the Tools menu, click Add-Ins. 


\begin{tabular}{|c|c|c|c|c|c|c|}
\hline \multicolumn{7}{|c|}{$\mathbb{\Omega}$ Microsoft Excel - Book1 } \\
\hline \multicolumn{4}{|c|}{ iㅣㄹ File Edit View Insert } & Iools & Data $\underline{\text { Wind }}$ & \\
\hline \multicolumn{4}{|c|}{ 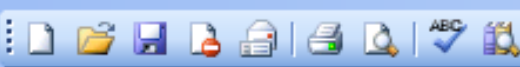 } & \multirow{3}{*}{\multicolumn{3}{|c|}{$\begin{array}{l}\text { Erotection } \\
\text { Goal Seek... } \\
\text { Solver... }\end{array}$}} \\
\hline \multicolumn{2}{|c|}{$\mathrm{A} 2$} & \multicolumn{2}{|c|}{$f_{x}$} & & & \\
\hline & A & B & $\mathrm{C}$ & & & \\
\hline $\begin{array}{l}1 \\
2\end{array}$ & & & & & Macro & , \\
\hline 3 & & & & & Add-In $n s . .$. & \\
\hline 4 & & & & & Customize... & \\
\hline 5 & & & & & 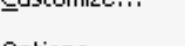 & \\
\hline 6 & & & & & Options... & \\
\hline 7 & & & & & Data Analysis... & \\
\hline 8 & & & & & $\approx$ & \\
\hline
\end{tabular}

2. In the Add-Ins available list, select the Analysis ToolPak box, and then click OK.

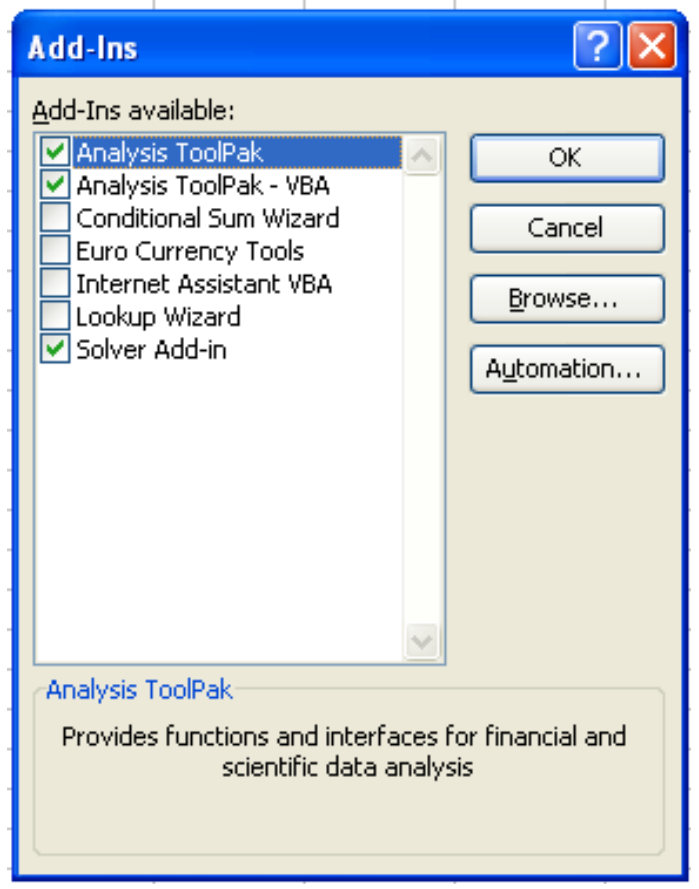

\section{Restart Microsoft Excel.}

Now we need to set the Macro security level. In order to run ALPAXL properly, the security level should be set to 'Medium'. This can be done as follows: 
1. On the Tools menu, place mouse over Macro and click Security.

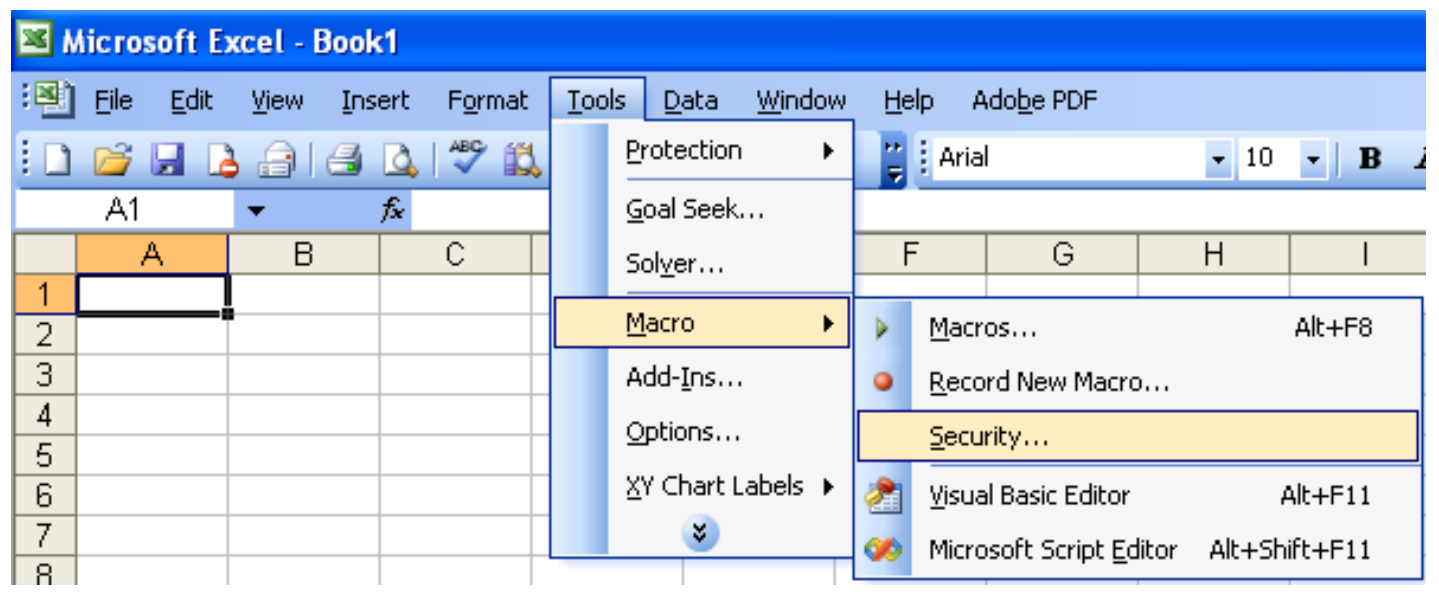

2. In the Security Level tab, select the Medium button, and then click OK.

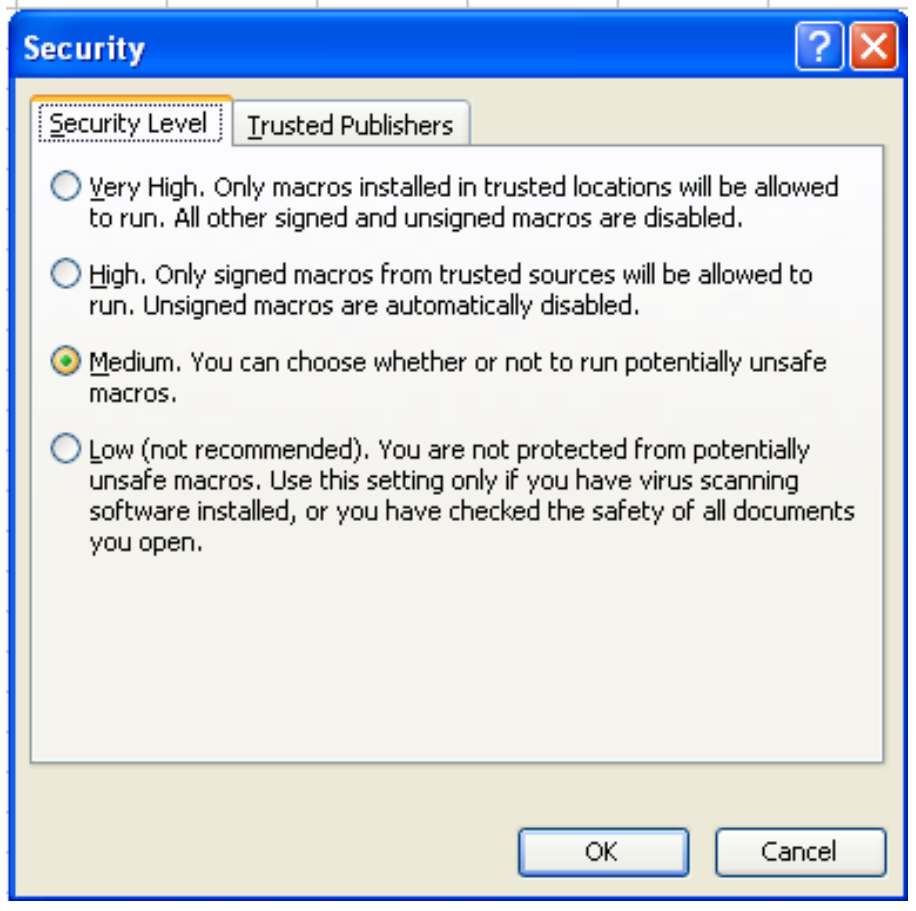

3. After running ALPAXL, click Enable Macros in the security warning message box. 


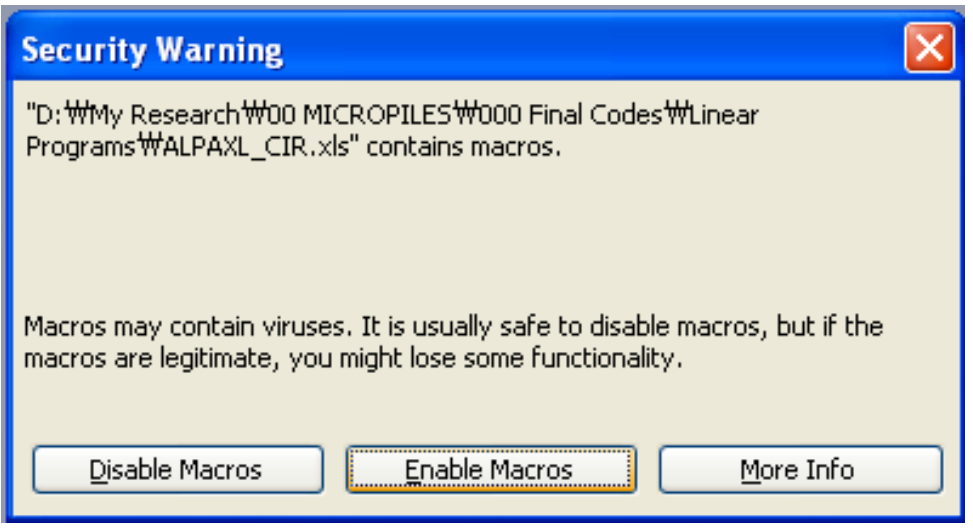

Figure 5.1 shows a screenshot of the 'Main' tab of ALPAXL. In the 'Main' tab, there are four input sections: pile geometry, number of soil layers, load information, and soil properties. All the input parameters should be in SI units. Since the level of the last layer within the pile is flush with the base of the pile in our analysis, the depth to the last layer within the pile must be the same as the length of the pile. Mathematically, the depth of the last layer below the pile base is infinite, but two times the pile length is sufficient for most cases (no difference is observed in the output results unless the pile is very short).

After inputting all the values and selecting whether to use the original shear modulus or the modified shear modulus in the calculations, click the 'Run' button. The pile head settlement appears in the output section. We recommend the use of the modified shear modulus in the analysis to minimize the artificial stiffness resulting from the assumption of zero lateral displacement for high Poisson's ratios (see section 3.6). The 'Plot' tab shows the original and deformed configurations of the pile-soil system. The 'Graphs' tab gives the load-settlement and load-transfer curves, as well as soil displacement fields at the level of the pile head and base. 


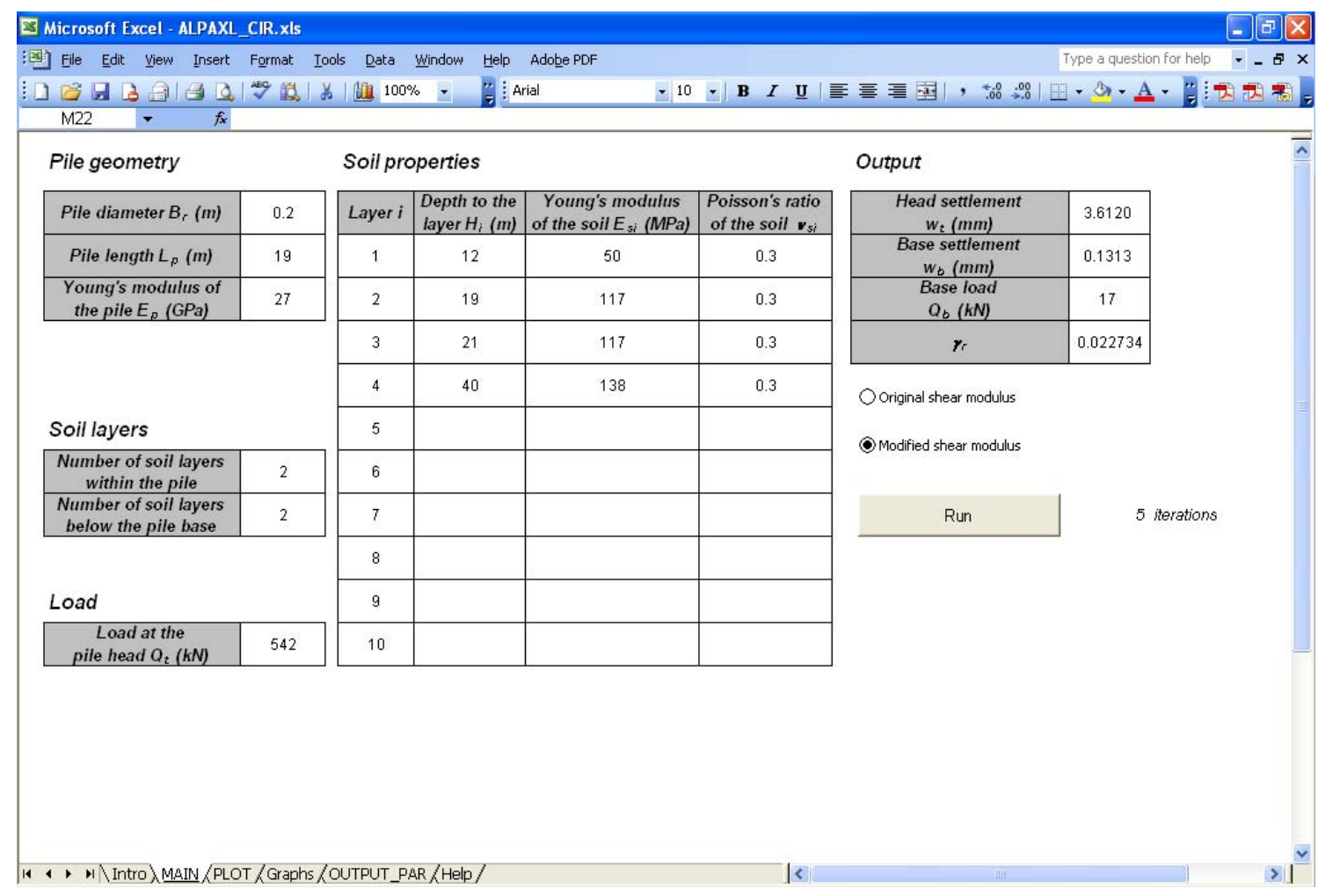

Figure 5.1 Screenshot of the 'Main' tab of ALPAXL

\subsection{Examples}

In this section, we choose two examples to illustrate the use of our analysis with ALPAXL.

\subsubsection{Example 1: Micropile in a four-layer soil}

Let us consider a $15-\mathrm{m}$-long micropile with $0.2 \mathrm{~m}$ in diameter embedded in a four-layer soil. The axial force $Q_{t}$ at the head of the pile is $300 \mathrm{kN}$. The Young's modulus $E_{p}$ of the pile is equal to $25 \mathrm{GPa}$. The pile is embedded in a four-layer deposit with $H_{1}=3 \mathrm{~m}, H_{2}$ $=7 \mathrm{~m}$ and $H_{3}=12 \mathrm{~m}$ (the pile base rests in the fourth layer); $E_{s 1}=10 \mathrm{MPa}, E_{s 2}=70 \mathrm{MPa}$, 
$E_{s 3}=120 \mathrm{MPa}$ and $E_{s 4}=250 \mathrm{MPa} ; v_{\mathrm{s} 1}=0.45, v_{s 2}=0.3, v_{s 3}=0.3$ and $v_{s 4}=0.2$. Figure 5.2 shows the soil profile and the pile.

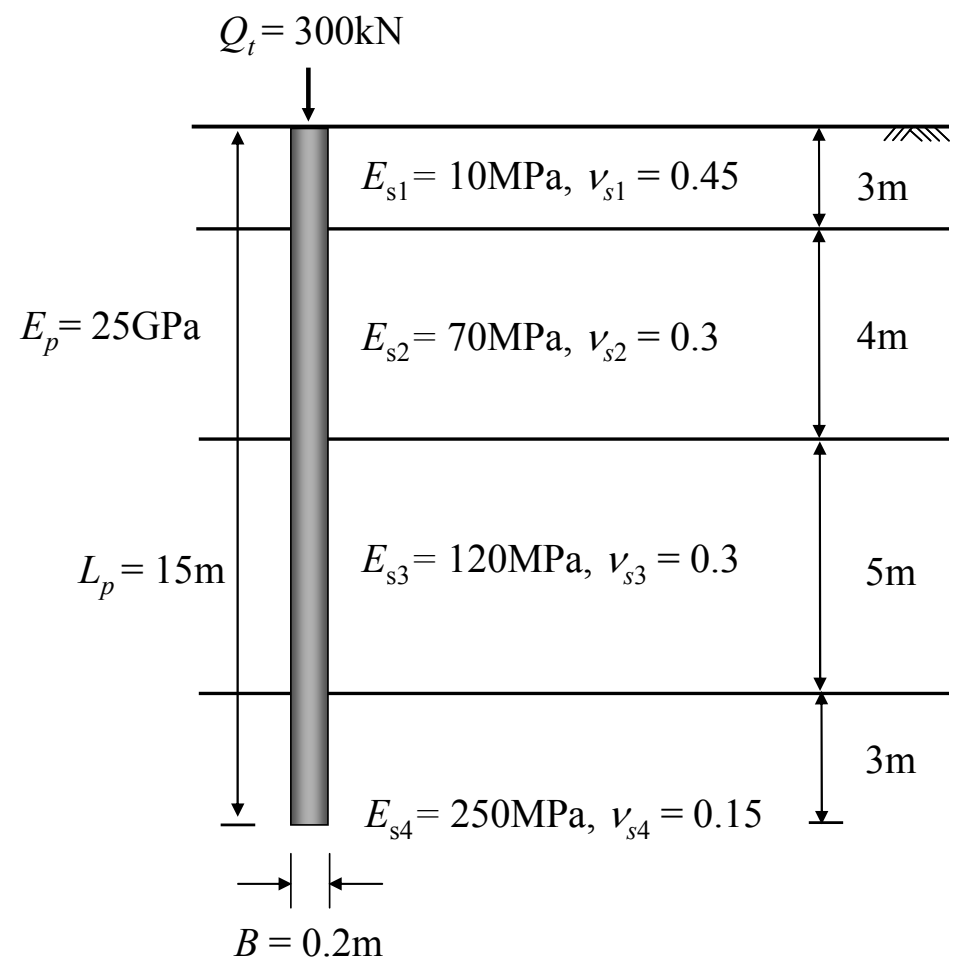

Figure 5.2 Soil profile for Example 1

Figure 5.3 shows the input parameters for Example 1. Note that the last layer is subdivided into two layers, with the fourth layer flush with the pile base. The analysis gives us $2.5 \mathrm{~mm}$ settlement of the pile head for a load of $300 \mathrm{kN}$. Figure 5.4 shows the load-settlement and load-transfer curves, pile displacement along the pile length, and soil displacement in the radial direction at the level of the pile head and base that are obtained in the 'Graphs' tab. Figure 5.5 shows the magnified deformed configuration of the pilesoil system obtained in the 'Plot' tab. 


Pile geometry
\begin{tabular}{|c|c|}
\hline Pile diameter $B_{r}(m)$ & 0.2 \\
\hline Pile length $L_{p}(m)$ & 15 \\
\hline $\begin{array}{c}\text { Young's modulus of } \\
\text { the pile } E_{p} \text { (GPa) }\end{array}$ & 25 \\
\hline
\end{tabular}

Soil properties

\begin{tabular}{|c|c|c|c|c|c|}
\hline & & & & \\
\hline \multirow{3}{*}{\multicolumn{2}{|c|}{ Soil layers }} & 3 & 12 & 120 & 0.3 \\
\hline & & 4 & 15 & 250 & 0.2 \\
\hline & & 5 & 30 & 250 & 0.2 \\
\hline $\begin{array}{c}\text { Number of soil layers } \\
\text { within the pile }\end{array}$ & 4 & 6 & & & \\
\hline $\begin{array}{c}\text { Number of soil layers } \\
\text { below the pile base }\end{array}$ & 1 & 7 & & & \\
\hline \multirow{2}{*}{\multicolumn{2}{|c|}{ Load }} & 8 & & & \\
\hline & & 9 & & & \\
\hline $\begin{array}{c}\text { Load at the } \\
\text { pile head } Q_{t}(k N)\end{array}$ & 300 & 10 & & & \\
\hline
\end{tabular}

Figure 5.3 Input parameters for Example 1 


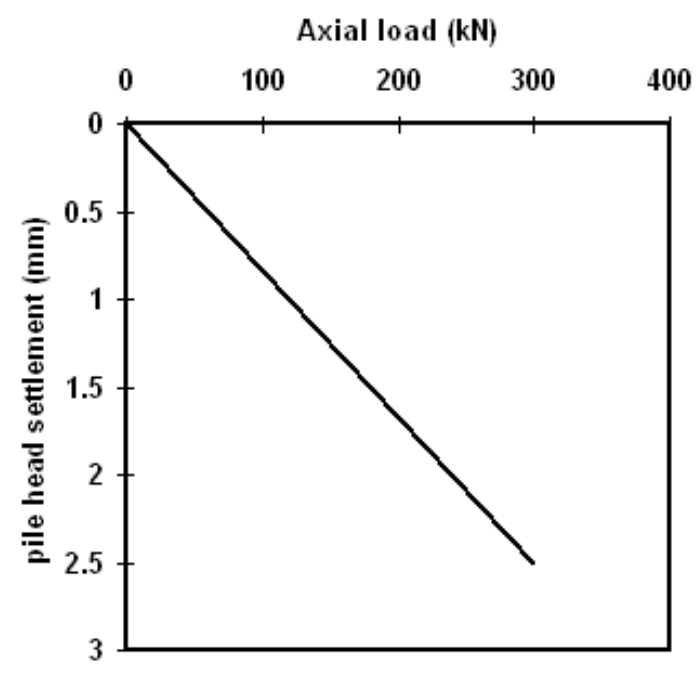

(a)

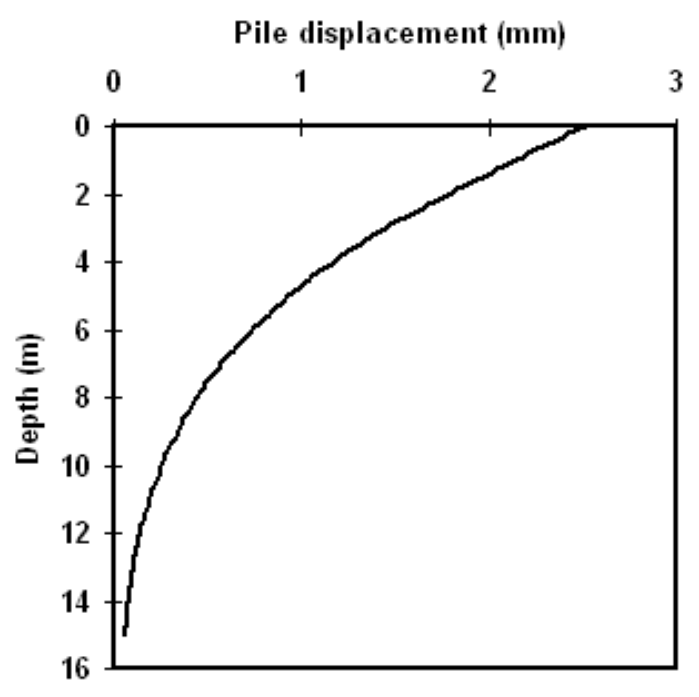

(c)

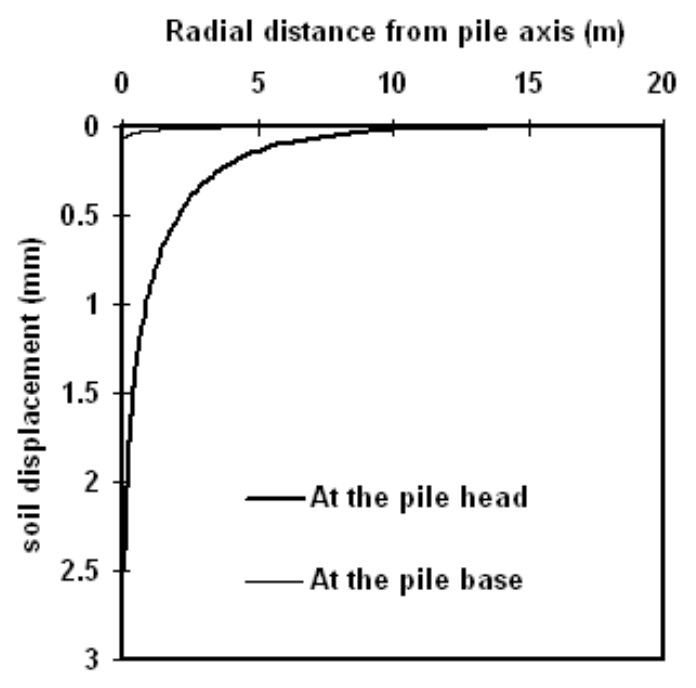

(b)

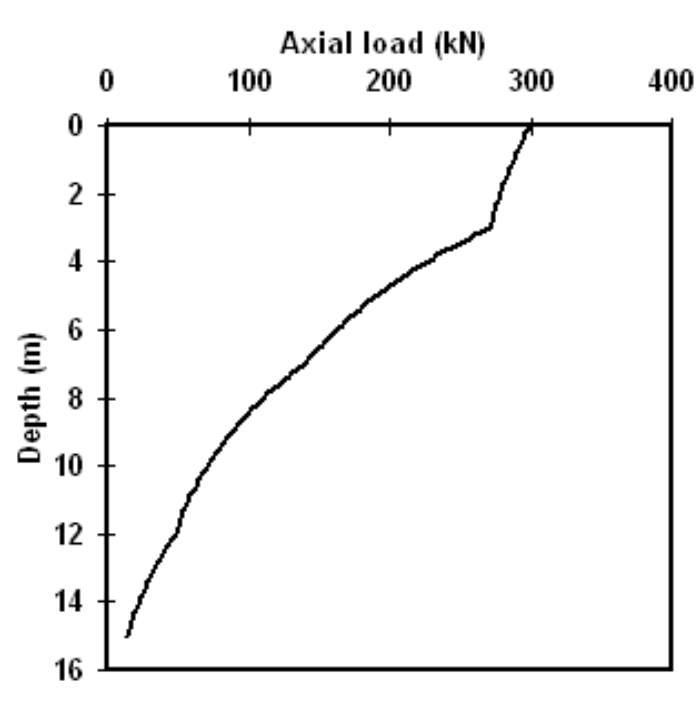

(d)

Figure 5.4 Results from ALPAXL (Example 1): (a) load-settlement curve; (b) soil displacement in the radial direction at the level of the pile head and base; (c) pile displacement along the pile length; and (d) load-transfer curve 


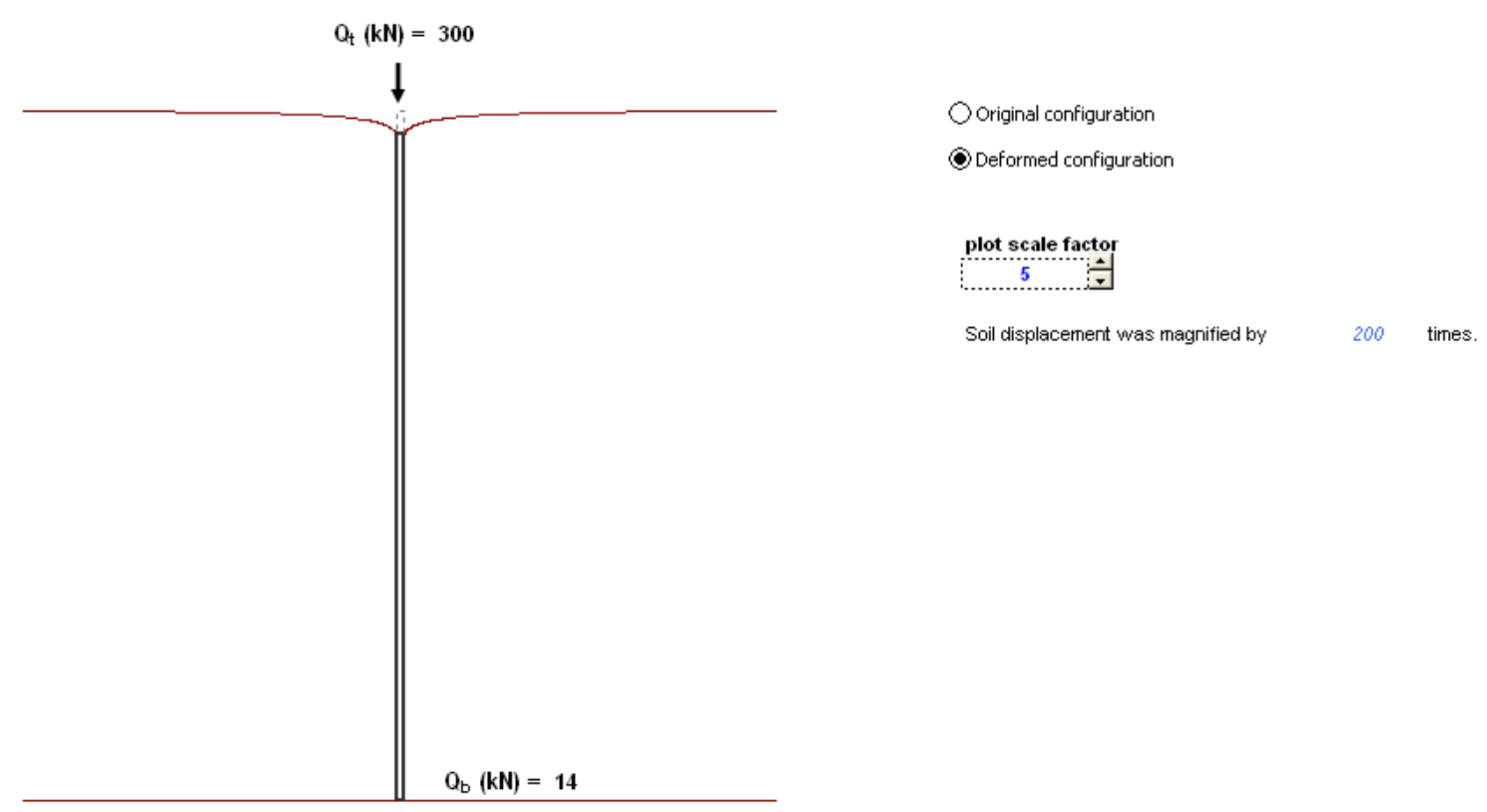

Figure 5.5 Deformed configuration of pile-soil system after loading for Example 1

\subsubsection{Example 2: Rock-socketed micropile}

Let us consider a 7 -m-long micropile with $0.2 \mathrm{~m}$ in diameter embedded in a hard rock underlain by soft soil. The axial force $Q_{t}$ at the head of the pile is $400 \mathrm{kN}$. The Young's modulus $E_{p}$ of the pile is equal to $30 \mathrm{GPa}$. From the ground level to $2 \mathrm{~m}$, there is a very soft clay with $E_{s 1}=10 \mathrm{MPa}$ and $v_{\mathrm{s} 1}=0.5$. Below this layer, there is a medium dense sand layer with $E_{s 2}=100 \mathrm{MPa}$ and $v_{\mathrm{s} 2}=0.2$ extending down to the bedrock at a depth of $5.5 \mathrm{~m}$. The deformation modulus $E_{m}$ of the rock layer is equal to $2500 \mathrm{MPa}$ and the Poisson's ratio of the rock mass is 0.2 . Figure 5.6 shows the soil profile and the pile. 


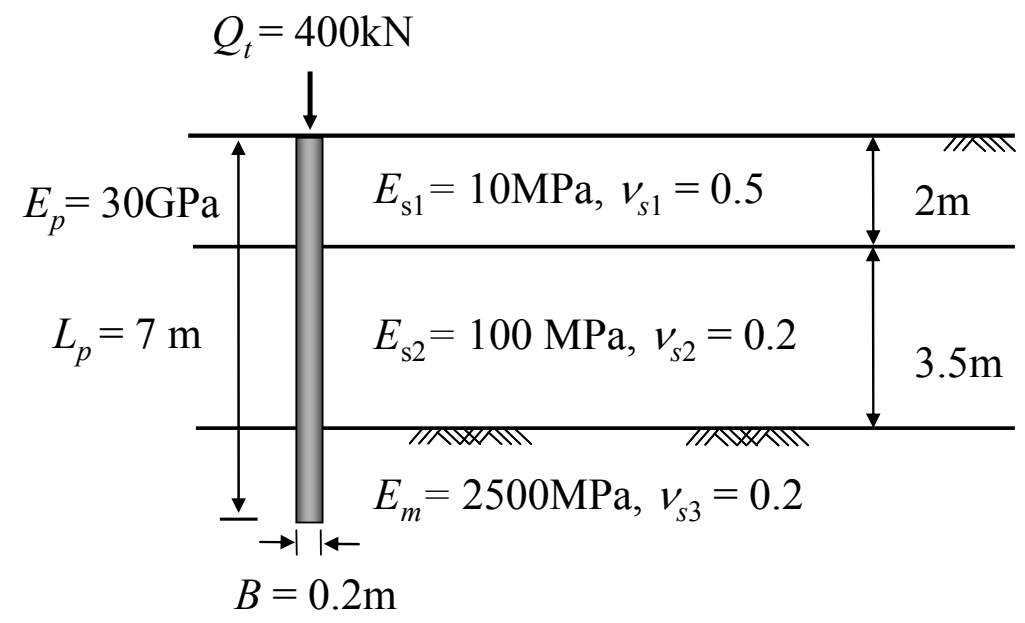

Figure 5.6 Soil profile and pile of Example 2

Figure 5.7 shows the input and output sections for Example 2. For the applied load of $400 \mathrm{kN}$, the pile head settlement is $2 \mathrm{~mm}$. The pile base settlement and load are $0.046 \mathrm{~mm}$ and $68 \mathrm{kN}$, respectively. Figure 5.8 shows the pile displacement and axial load distribution with depth obtained from ALPAXL for Example 2.

\begin{tabular}{|c|c|c|c|c|c|c|c|}
\hline \multicolumn{2}{|l|}{ Pile geometry } & \multicolumn{4}{|c|}{ Soil properties } & \multicolumn{2}{|l|}{ Output } \\
\hline Pile diameter $B_{r}(m)$ & 0.2 & Layer i & $\begin{array}{l}\text { Depth to the } \\
\text { layer } H_{i}(m)\end{array}$ & $\begin{array}{l}\text { Young's modulus } \\
\text { of the soil } E_{s i}(\mathrm{MPa})\end{array}$ & $\begin{array}{l}\text { Poisson's ratio } \\
\text { of the soil } \boldsymbol{v}_{s i}\end{array}$ & $\begin{array}{c}\text { Head settlement } \\
w_{t}(\mathrm{~mm})\end{array}$ & 2.0027 \\
\hline Pile length $L_{p}(m)$ & 7 & 1 & 2 & 10 & 0.5 & $\begin{array}{c}\text { Base settlement } \\
w_{b}(\mathrm{~mm})\end{array}$ & 0.0457 \\
\hline $\begin{array}{l}\text { Young's modulus of } \\
\text { the pile } E_{p}(G P a)\end{array}$ & 30 & 2 & 5.5 & 100 & 0.2 & $\begin{array}{c}\text { Base load } \\
Q_{b}(k N)\end{array}$ & 68 \\
\hline \multirow{3}{*}{\multicolumn{2}{|c|}{ Soil layers }} & 3 & 7 & 2500 & 0.2 & $\boldsymbol{y}_{r}$ & 0.065591 \\
\hline & & 4 & 20 & 2500 & 0.2 & \multirow{3}{*}{$\begin{array}{l}\text { Original shear modulus } \\
\text { Modified shear modulus }\end{array}$} & \\
\hline & & 5 & & & & & \\
\hline $\begin{array}{c}\text { Number of soil layers } \\
\text { within the pile }\end{array}$ & 3 & 6 & & & & & \\
\hline $\begin{array}{c}\text { Number of soil layers } \\
\text { below the pile base }\end{array}$ & 1 & 7 & & & & Run & \\
\hline \multirow{2}{*}{\multicolumn{2}{|c|}{ Load }} & 8 & & & & & \\
\hline & & 9 & & & & & \\
\hline $\begin{array}{c}\text { Load at the } \\
\text { pile head } Q_{t}(k N)\end{array}$ & 400 & 10 & & & & & \\
\hline
\end{tabular}

Figure 5.7 Input and output sections for Example 2 

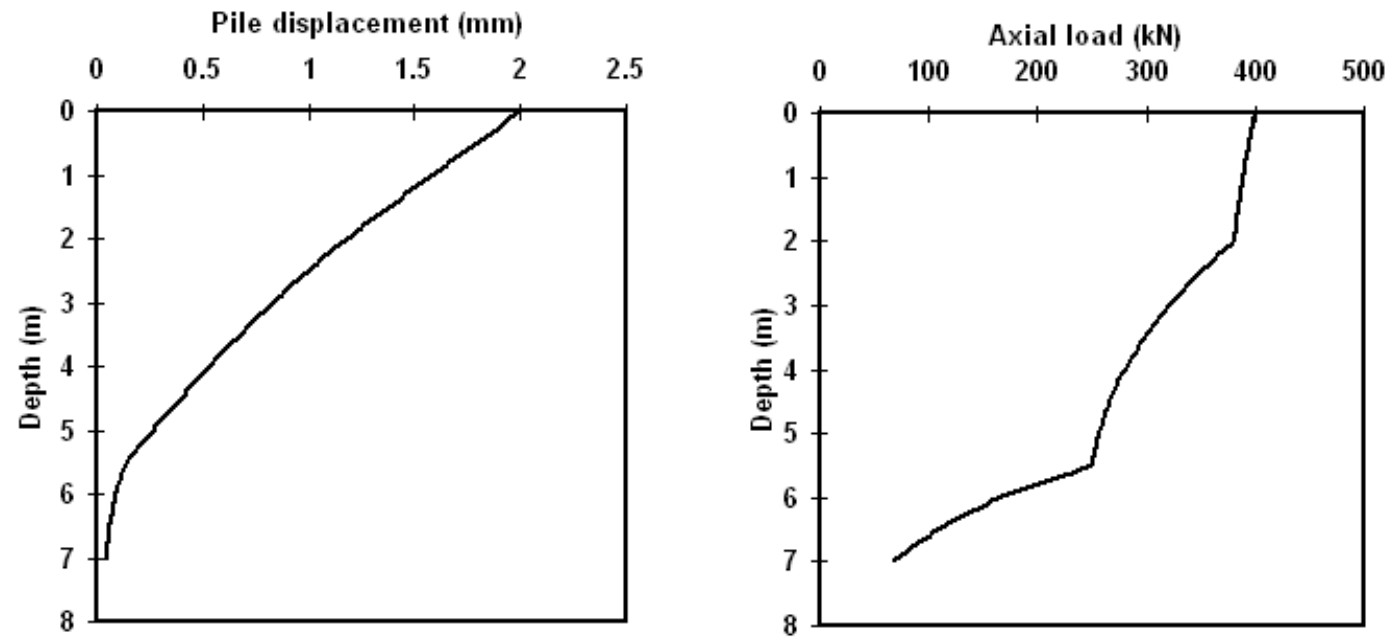

Figure 5.8 Pile displacement and axial load distribution with depth obtained from ALPAXL (Example 2) 


\section{CHAPTER 6. FIELD LOAD TEST ON A ROCK-SOCKETED MICROPILE}

\subsection{Introduction}

In this chapter, we present the results of a static load test performed on a rock-socketed micropile. The test pile was fully instrumented with vibrating-wire strain gages. We compare the results from the load test with those obtained from our analysis.

\subsection{Overview}

The test site is located on County Road 375W in Paoli, Indiana. As an old bridge over Lick Creek showed signs of collapse, there was the need to construct a new bridge to replace it. Micropiles were selected to support the new bridge and concrete retaining wall abutment. The pile load testing program was designed to evaluate the load-transfer characteristics of rock-socketed micropiles. The load test was performed up to the ultimate structural capacity of the micropile.

\subsection{Site description}

At the project area, limestone bedrock is found at relatively shallow depth. The subsurface profile of the test site consists of weak soil layers at shallow depths underlain by fractured to hard rock layers at greater depths. Five SPTs and rock core sampling were performed before installation of the piles. The groundwater level was found at a depth of $2.4-3 \mathrm{~m}$.

Figure 6.1 shows the geometry of the test pile and the subsurface profile at the location of the test pile. Results of SPTs near the test pile location are also presented in the figure. From the ground surface to $1.2 \mathrm{~m}$, there is a very soft silty soil layer. Underneath this layer to a depth of $2.4 \mathrm{~m}$ below the ground surface, there is a dense sandy 
loam layer, which overlies a very loose silty loam layer. From a depth of $4 \mathrm{~m}$ to $6.7 \mathrm{~m}$, there is a fractured limestone layer underlain by a very hard limestone layer. The unconfined compressive strength of the intact rock sample obtained from the fractured limestone layer was equal to $54 \mathrm{MPa}$. The rock quality designation $(R Q D)$ for this layer varied from 0 to $45 \%$. The unconfined compressive strength of the rock sample obtained from the hard limestone layer varied from 71 to $88 \mathrm{MPa}$; the $R Q D$ for this layer was in $50-88 \%$ range.

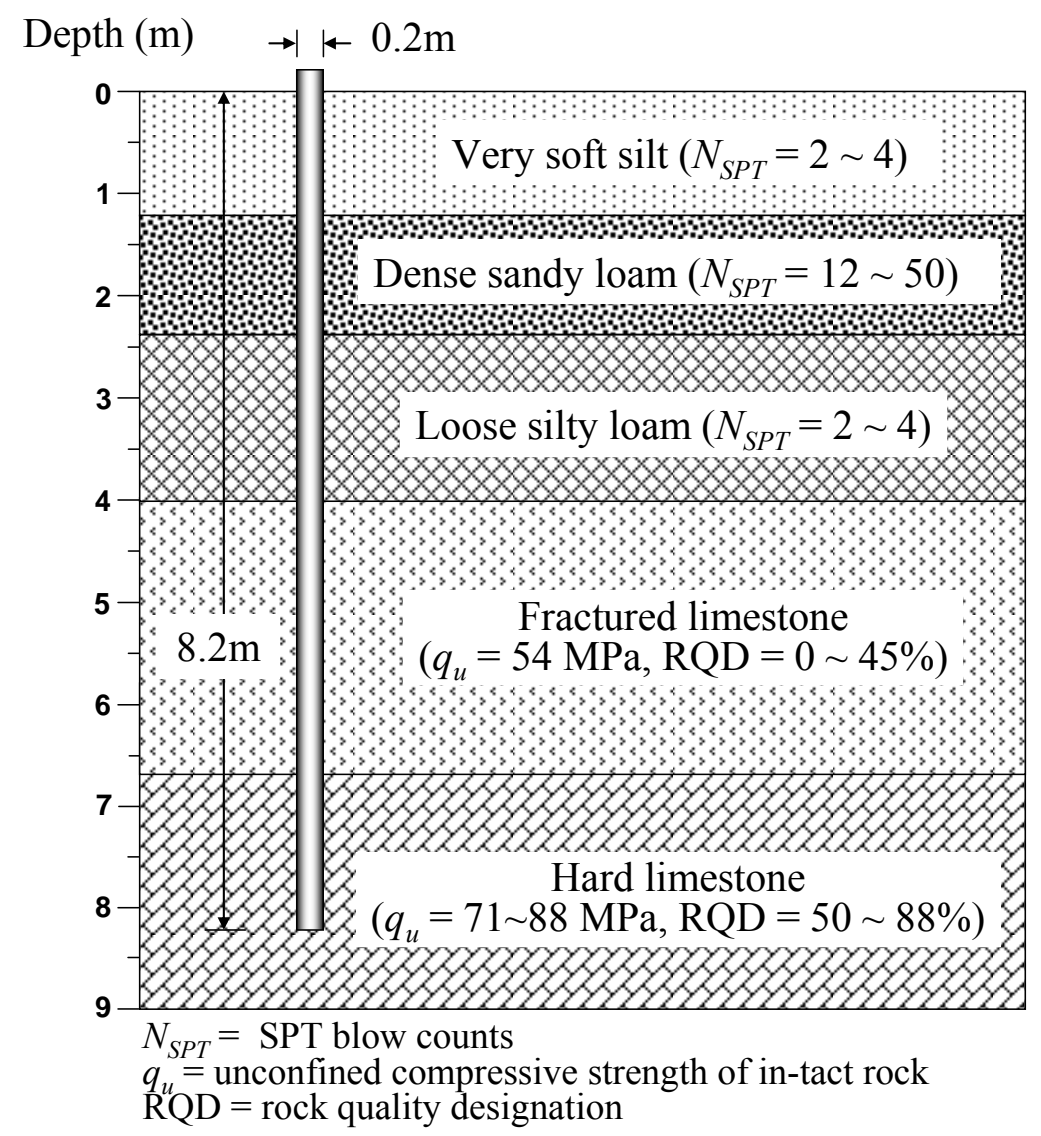

Figure 6.1 Subsurface profile and test pile

\subsection{Test pile installation}

A rotary duplex drilling technique was used to install the test pile and the production piles as well. First, a drilling rod with a drill bit on its end was inserted inside the drill 
casing. Then, the drilling rod and the casing were attached to the same rotary head, which rotates to advance the drilling into soil or rock. Figure 6.2 shows the outer drill casing and the inner rod with the drilling bit on its end. Figure 6.3 shows a view of the folded and expanded drilling bit. During drilling, the drilling bit was expanded to produce a diameter larger that of the casing. The drilling rod, equipped with the drilling bit, advanced ahead of the tip of the casing, carrying the casing forward with it. High pressure air and water was used to clear the cuttings as drilling advances. When drilling was completed, the drilling bit was folded and the inner rod was extracted from the ground.

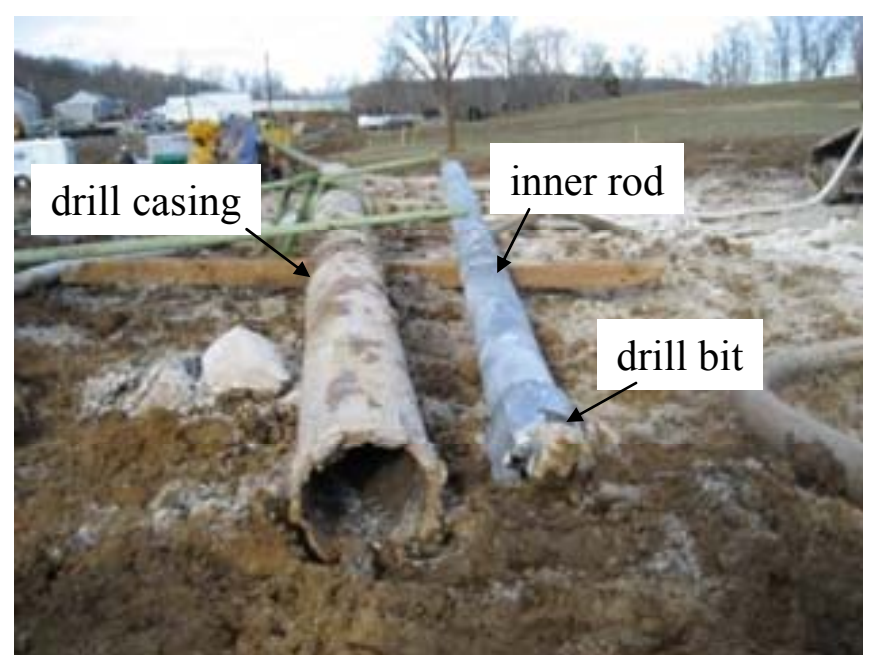

Figure 6.2 Drilling tools used to install test pile 


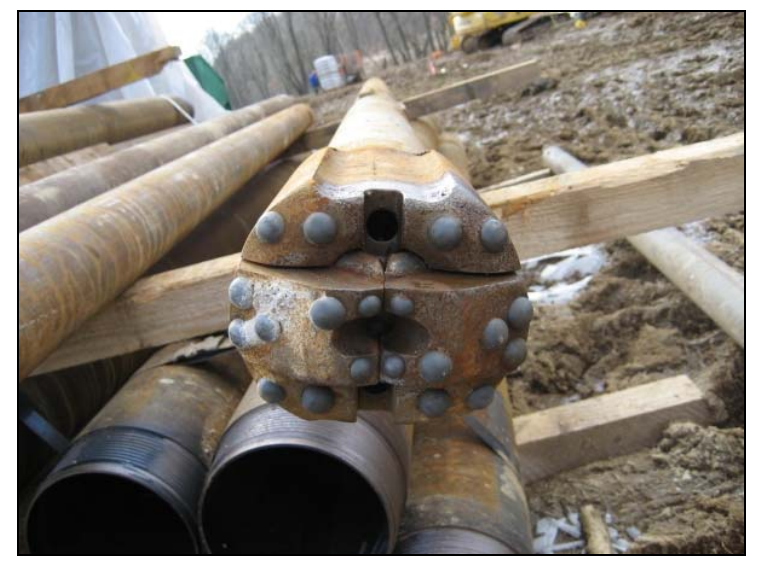

(a)

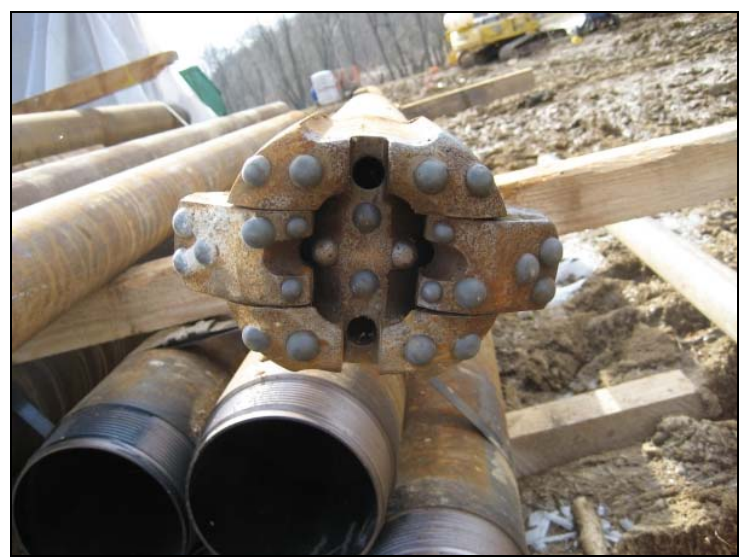

(b)

Figure 6.3 A view of (a) folded and (b) expanded drilling bit

After reaching the desired depth, the inner rod was removed, whereas the outer steel casing was left permanently in the ground. The casing was then filled with grout until grout was observed flowing through the annulus between the drilled hole and the outer casing. All the production piles were installed in this manner. In the case of the test pile, a rebar with instrumented pipe segments attached to it was inserted into the grout-filled casing. The strain gages cables were carefully inserted through a hole drilled at the top of the test pile (the instrumentation details are presented in the next section). Figure 6.4 shows the steps in the test pile installation.

The outer and inner diameters of the steel casing left in the ground are equal to $178 \mathrm{~mm}$ of and $152 \mathrm{~mm}$, respectively. The steel casing Young's modulus $E_{\text {casing }}$ and yield strength $f_{y, \text { casing }}$ are equal to $200 \mathrm{GPa}$ and $552 \mathrm{MPa}$, respectively. The nominal diameter of the test pile is $197 \mathrm{~mm}$. The test pile length is $8.2 \mathrm{~m}$ (the micropile was embedded $1.5 \mathrm{~m}$ into the hard limestone layer). 


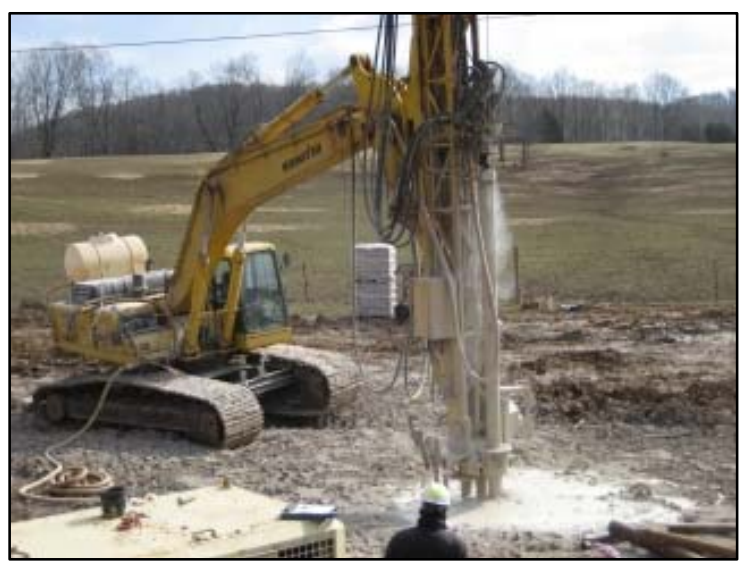

(a)

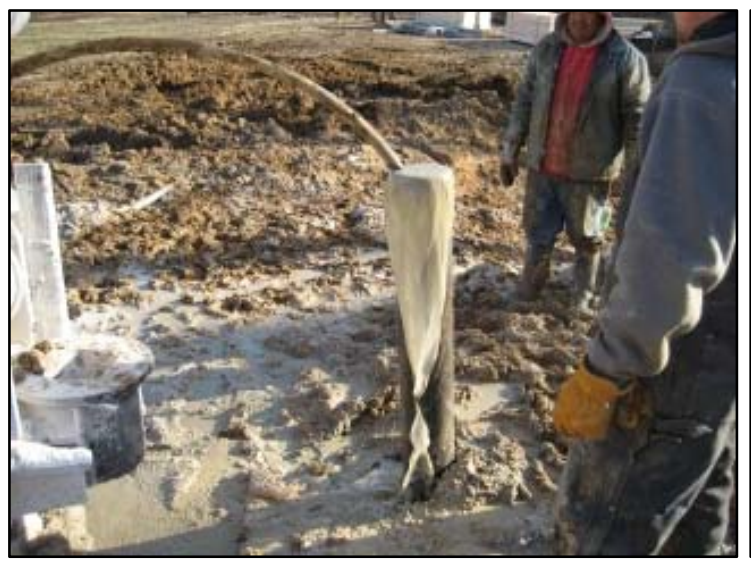

(c)

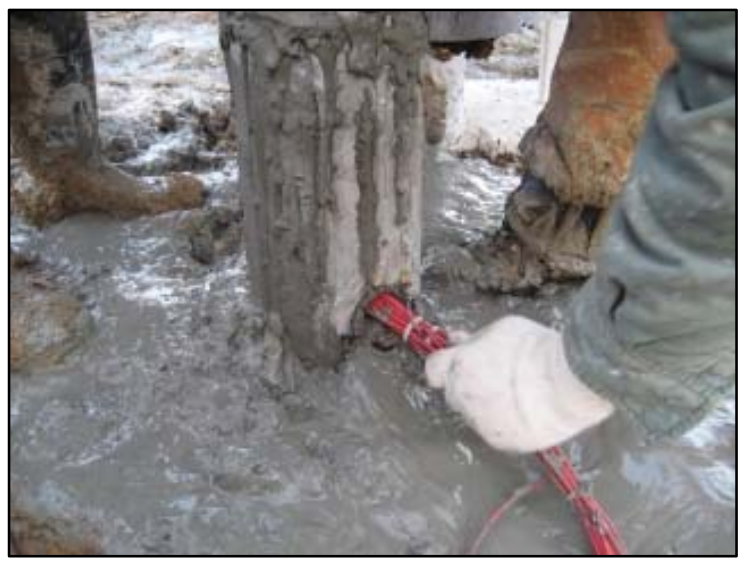

(e)

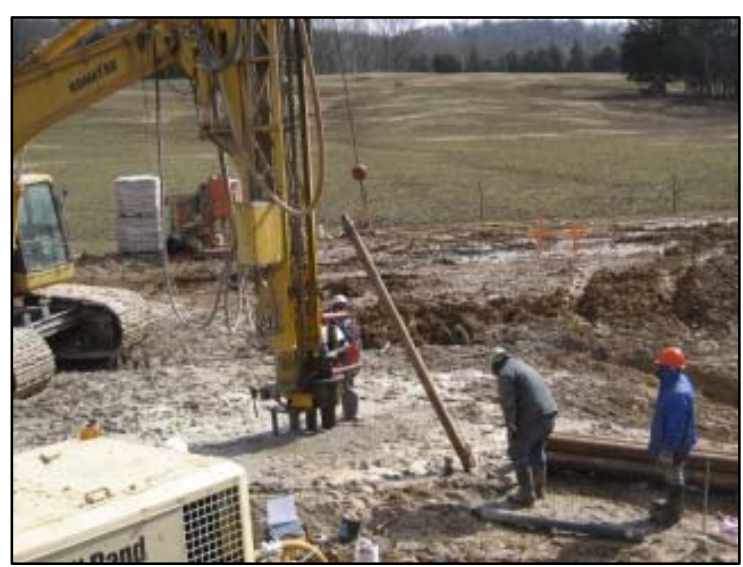

(b)

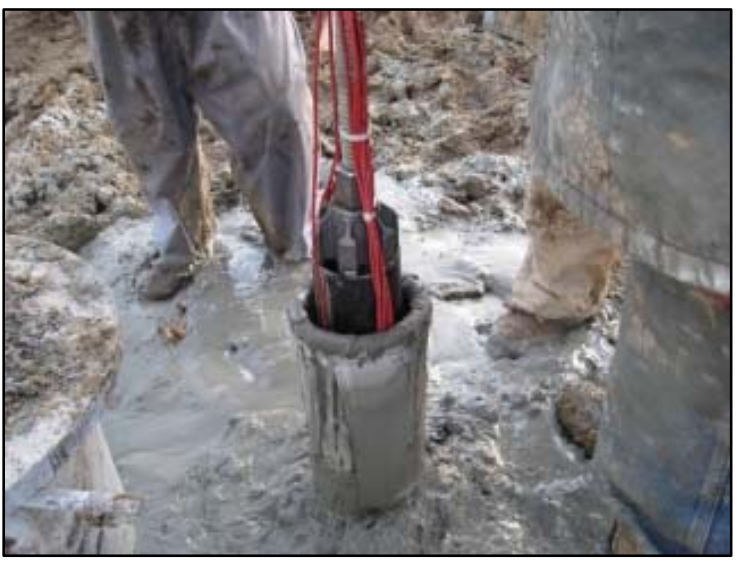

(d)

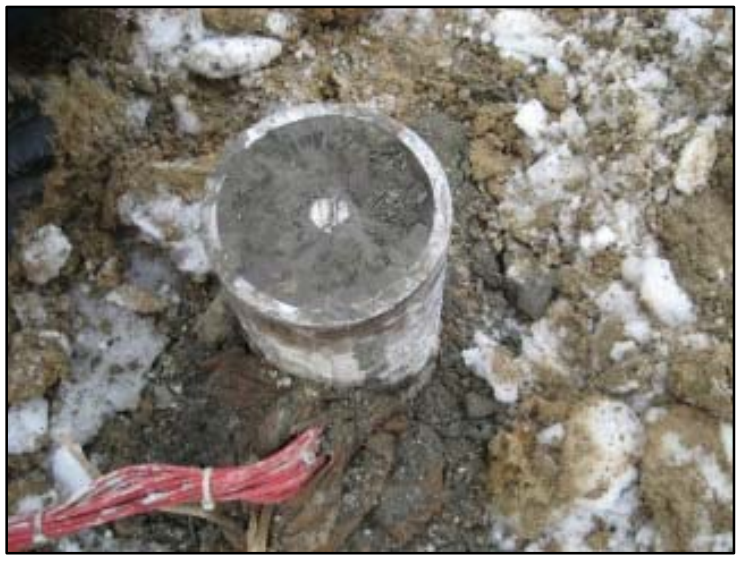

(f)

Figure 6.4 Installation of test pile: (a) drilling of the hole into the ground; (b) connecting the rod and casing; (c) grouting; (d) insertion of instrumented pipe; (e) positioning properly the instrumentation cables; (f) completed test pile 


\subsection{Instrumentation}

The instrumentation of the steel pipe was done in the laboratory. A total of 18 vibratingwire strain gages were attached outside the three steel pipe segments at 9 different levels. The outer and inner diameters of the steel pipe are equal to $114 \mathrm{~mm}$ and $102 \mathrm{~mm}$, respectively. The steel pipe Young's modulus $E_{\text {pipe }}$ and yield strength $f_{y \text {,pipe }}$ are equal to $200 \mathrm{GPa}$ and $290 \mathrm{MPa}$, respectively. The strain gages were installed in pairs, diametrically opposite to each other at each level. A total of 14 strain gages were attached to one of the three pile segments. These gages were planned to be installed in the rock layers to provide data for load-transfer behavior of rock-socketed piles. Other two gages were attached to another pile segment to be intalled in the soil layer to provide intermediate points in the load-transfer curves. The other two gages were attached to the other pile segment to be installed near the top of the pile; the data from these gages were used for calculation of the Young's modulus of the pile to be used to convert the strains measured at other levels to load in the pile. The cable-to-lead-wire junction was firmly secured to the steel surface, leaving some slack in the lead wires. A stainless steel semicircular cover was placed over the gages and secured with an epoxy bond. The installed gages were waterproofed with silicone rubber.

The instrumented pipes were later moved to the test site and connected to a threaded rebar $\left(E_{\text {rebar }}=200 \mathrm{GPa}\right.$ and $\left.f_{y \text {,rebar }}=517 \mathrm{MPa}\right)$. To connect the threaded rebar to the instrumented pipes, a specially manufactured connector was welded onto both ends of each pipe. The connector had openings so that grout could flow through the pipes. After completing drilling and identifying the exact depths of the soil and rock layers at the location of the test pile, the connection of each instrumented pipe segment to the threaded bar was adjusted such that the gages were located at the desired depths. Figure 6.5 shows this in detail. 


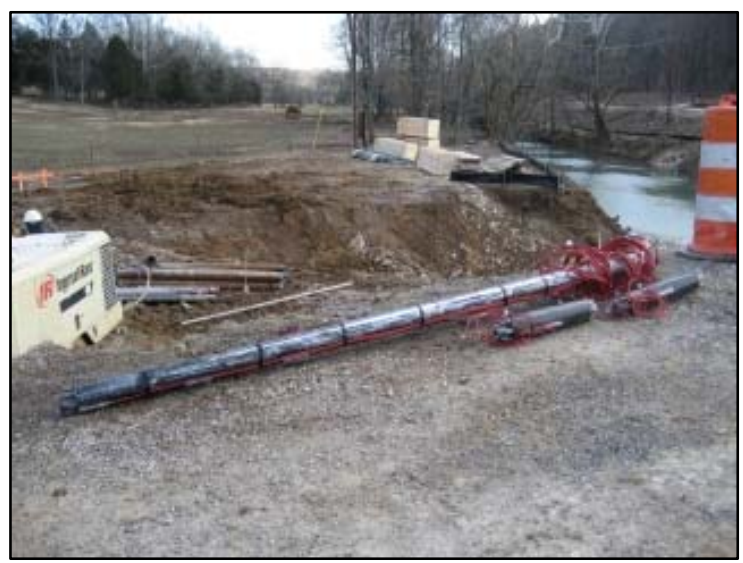

(a)

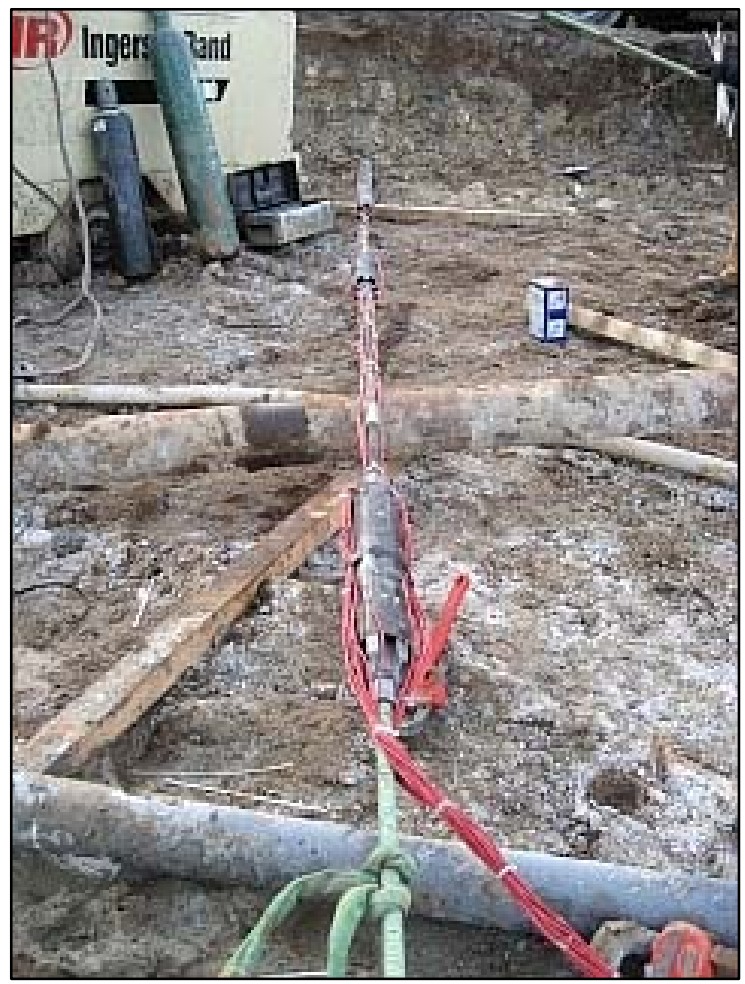

(c)

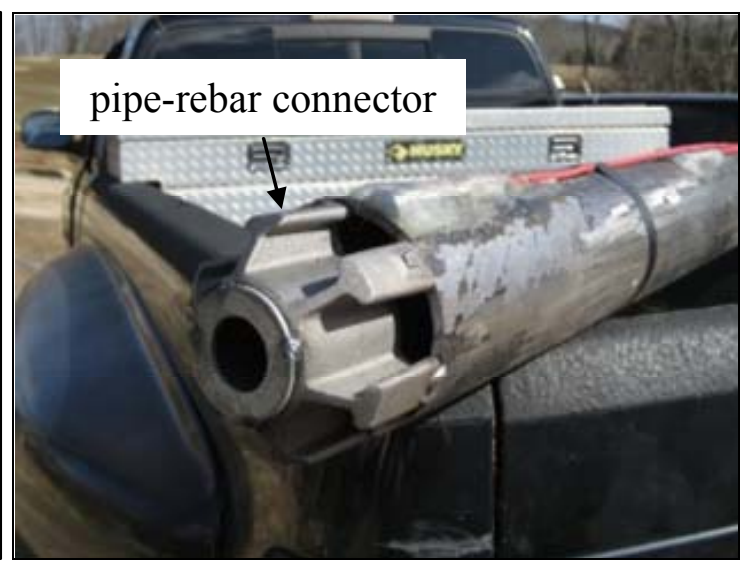

(b)

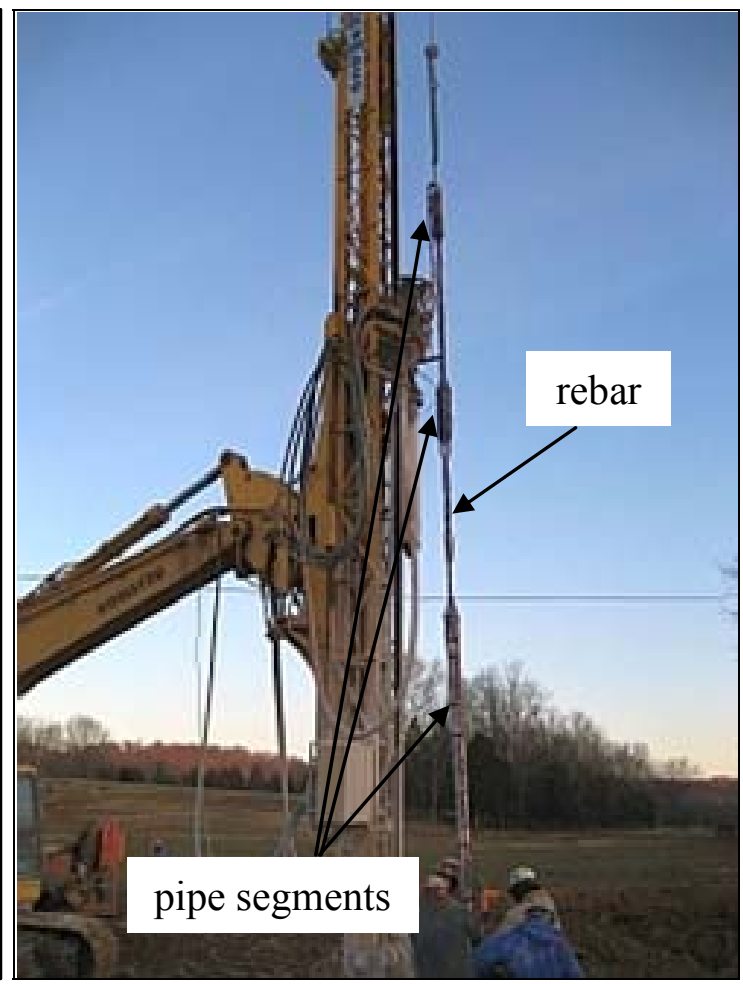

(d)

Figure 6.5 Test pile instrumentation: (a) three instrumented pipe segments; (b) manufactured pipe connector; (c) connection of pipe segments with threaded rebar; (d) positioning the instrumented pipes for insertion into the grout-filled casing

The instrumentation details are provided in Figure 6.6 and Table 6.1. The gages at levels 1 through 4 were located in the hard limestone layer. 


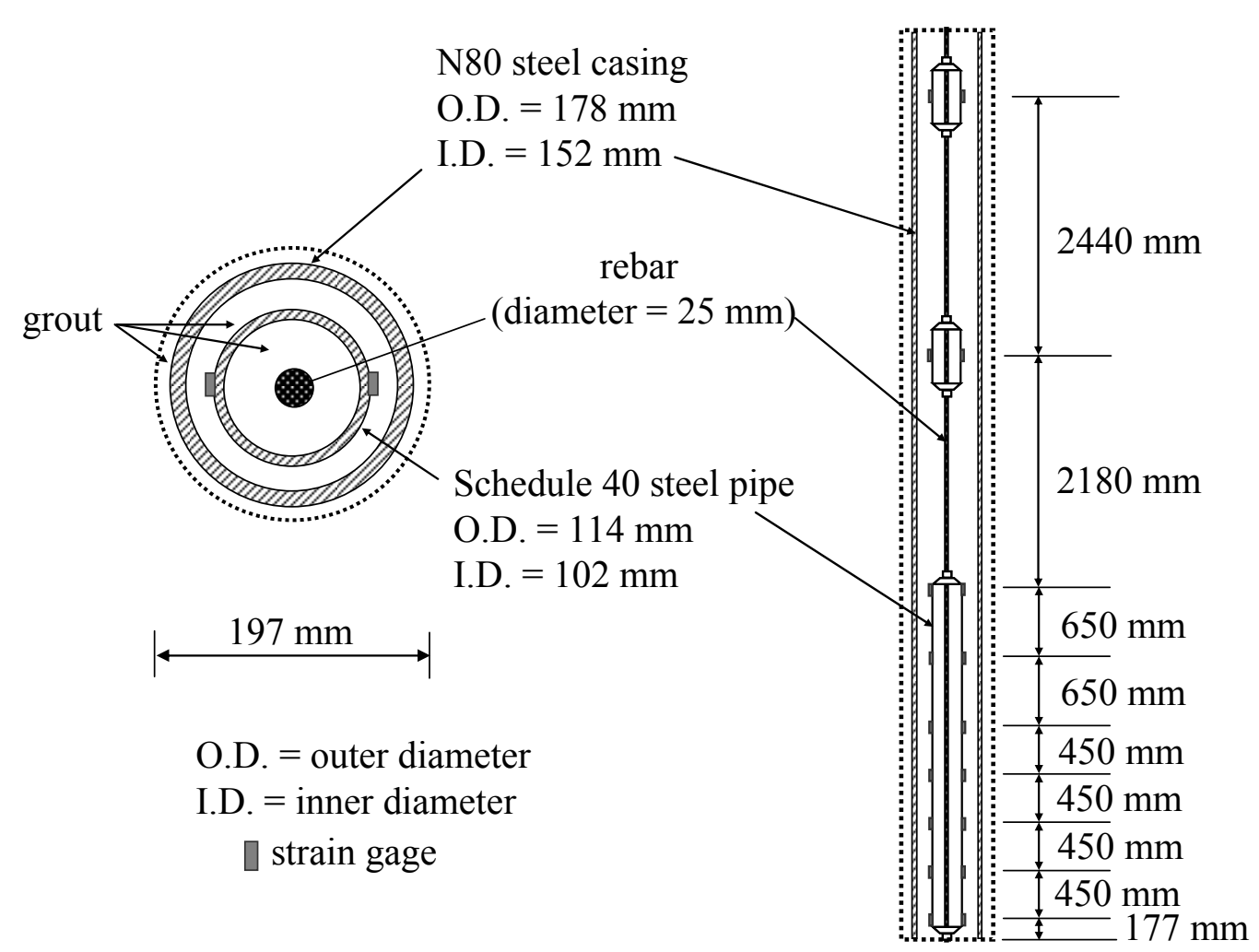

Figure 6.6 Instrumentation details

Table 6.1 Gage installation depths

\begin{tabular}{|c|c|c|c|c|c|c|c|c|c|}
\hline & \multicolumn{10}{|c|}{ Level } \\
\cline { 2 - 10 } & 9 & 8 & 7 & 6 & 5 & 4 & 3 & 2 & 1 \\
\hline Below ground (m) & 0.34 & 2.78 & 4.96 & 5.61 & 6.26 & 6.71 & 7.16 & 7.61 & 8.06 \\
\hline
\end{tabular}

\subsection{Testing procedures}

A static load test was performed on the test pile 7 days after installation. As shown in the test layout in Figure 6.7, four tension anchors were used as reaction for the load test. The total load applied to the pile head during the static load test was measured by a load cell with a capacity of $4450 \mathrm{kN}$. The vertical settlement of the pile head was measured by two dial gages (one on each side of the pile) attached to two reference beams. The load was applied in increments of $134 \mathrm{kN}$ and maintained until the settlement rate from two 
consecutive settlement readings at the pile head was less than $0.5 \mathrm{~mm} / \mathrm{hr}$. The load increment was reduced to $89 \mathrm{kN}$ as the load applied at the pile head approached the structural capacity of the pile $(=3620 \mathrm{kN})$. After reaching the maximum load, the pile was unloaded in 445-kN-load steps. The data acquisition system recorded the strains at every 2 minutes during the load test. The strains obtained from the two strain gages installed on opposite sides of the pile were averaged to determine the corresponding load carried by the pile at each level.

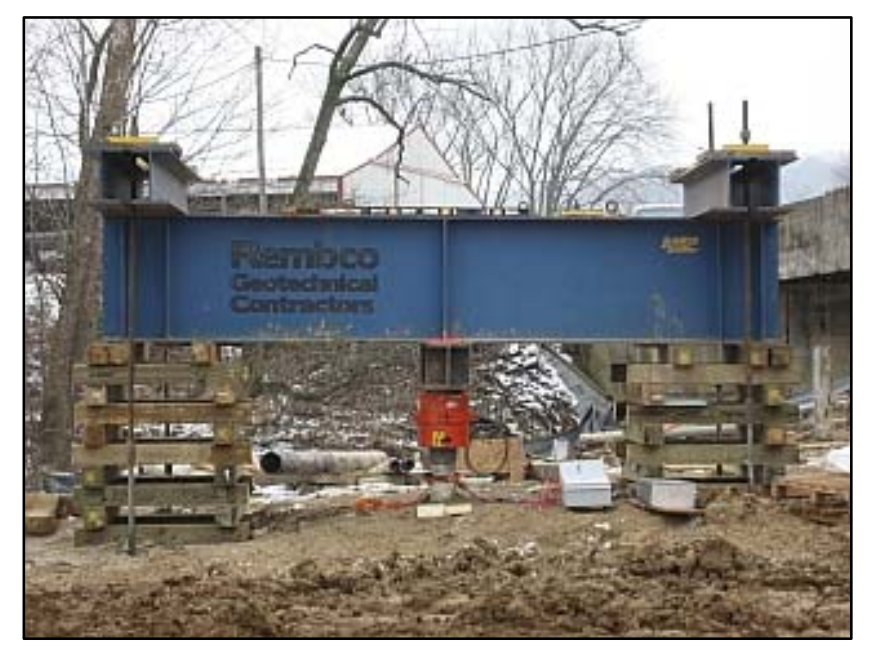

Figure 6.7 Axial load test layout

\subsection{Test results}

\subsubsection{Evaluation of Young's modulus of the micropile}

The strain values obtained from the gages at level $9(0.34 \mathrm{~m}$ below ground $)$ were used to calculate the Young's modulus of the test pile. We assumed that the load at this level was the same as the load applied at the pile head because the 0.34-m-thick very soft silt layer surrounding the pile would offer negligible shaft resistance. Therefore, the stress at this level was calculated by dividing the applied head load by the cross-sectional area of the pile. Figure 6.8 shows the stress-strain plot at level 9. As can be seen in this figure, a 
Young's modulus of $90 \mathrm{GPa}$ for the micropile is appropriate for the range of strains expected to develop during the load test.

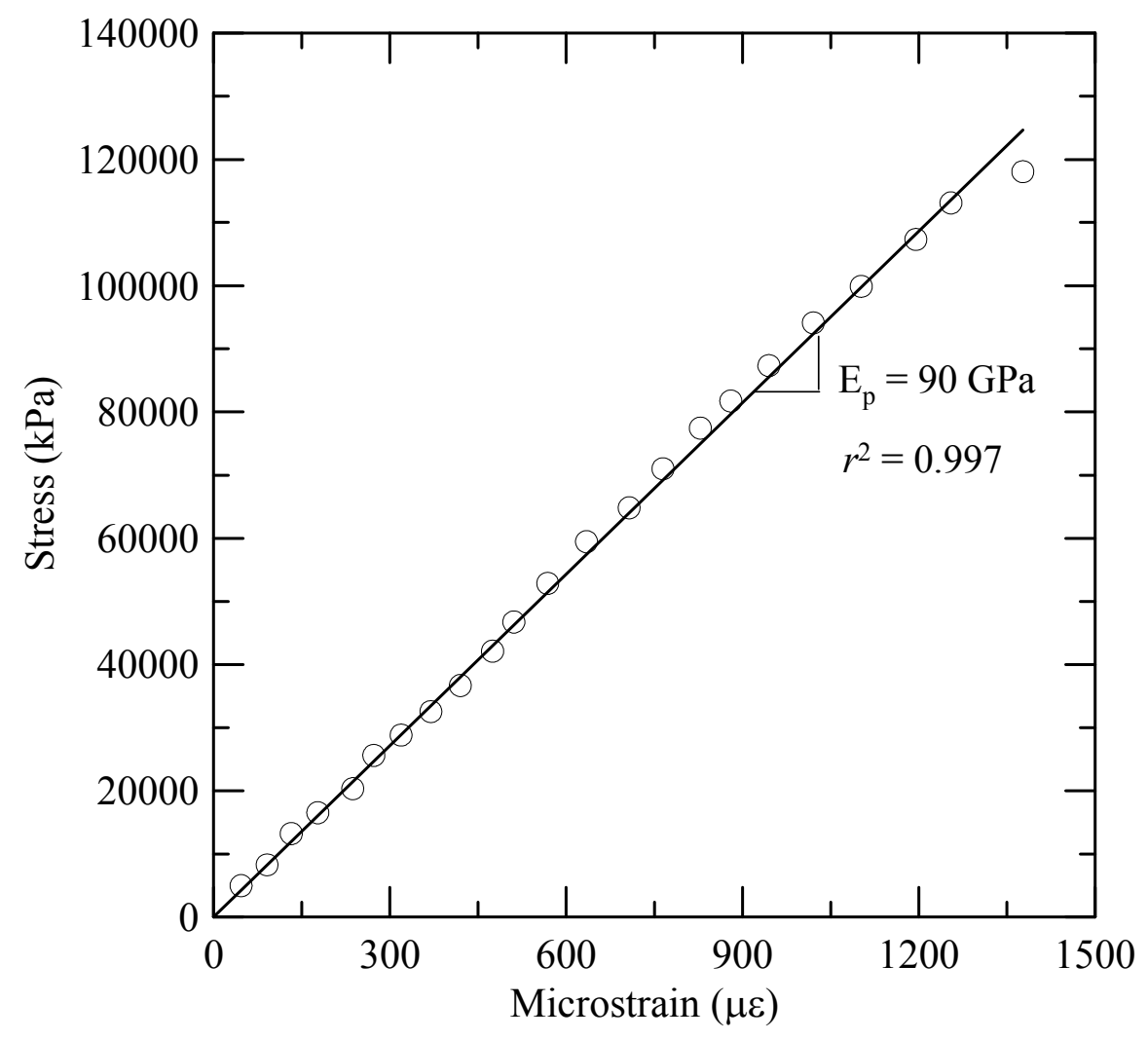

Figure 6.8 Determination of micropile Young's modulus $\left(r^{2}=\right.$ coefficient of correlation $)$

\subsubsection{Load-settlement response}

Figure 6.9 shows the applied load versus pile head settlement curves obtained from the static load test. At a design load of $486 \mathrm{kN}$, the pile head settlement was $0.8 \mathrm{~mm}$. At 2.5 times of design load $(=1215 \mathrm{kN})$, the settlement at the pile head increased to $3 \mathrm{~mm}$. At the final loading step, a pile head settlement of $13.97 \mathrm{~mm}(7 \%$ of the pile diameter) was recorded for an applied load of $3599 \mathrm{kN}$. Although the pile was loaded to up to 7.4 times the design load, which corresponds to the ultimate structural capacity of the micropile, the test pile did not show any sign of plunging into the ground. 


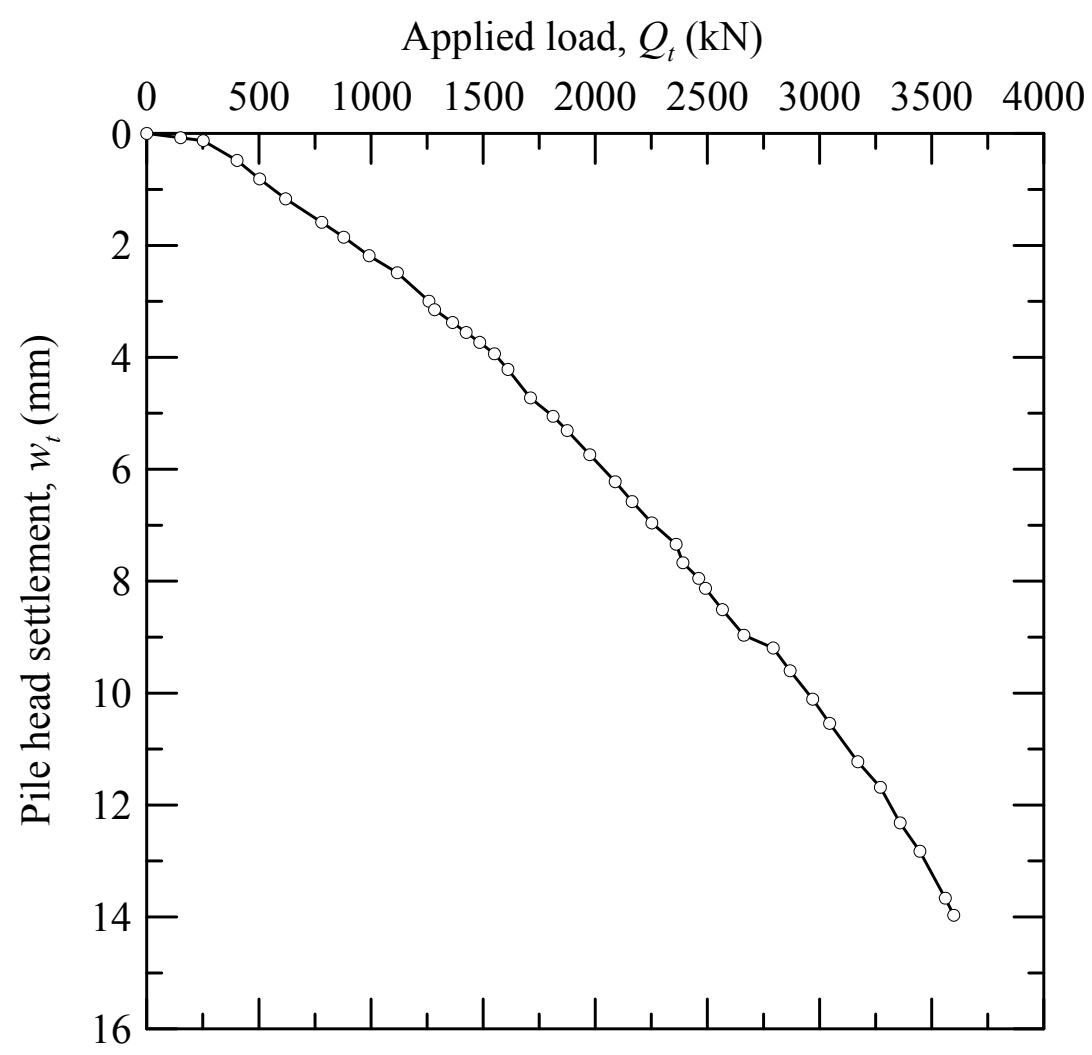

Figure 6.9 Load-settlement response of test pile

\subsubsection{Load-transfer response}

Figure 6.10 shows the load distribution profiles corresponding to each loading step of the load test. The strain gages at levels 5 and 6 were unstable throughout the test and, hence, the data obtained from them were ignored. Figure 6.10 shows that, even though there was some resistance mobilized in the dense sandy loam layer, almost all of the shaft capacity of the micropile is due to the shaft resistances provided by the rock layers, particularly, the hard limestone layer. Furthermore, practically, no load was transferred to the pile base (at the final loading step, the load at the pile base was $2.4 \%$ of the applied load). This is more evident in Figure 6.11, which shows pile head settlement versus applied pile head load, shaft load, and base load. The pile shaft load $Q_{s}$ was obtained by subtracting the pile base load $Q_{b}$, estimated using data from the strain gages at level 1, from the applied head load $Q_{t}$. As can be seen in this figure, almost all of the applied load is taken by the shaft (recall that the same trend was observed in CHAPTER 4 for sock geometries with 
high-slenderness ratios; $L_{S} / B=7.6$ for the test pile). The pile base started to carry load at approximately $Q_{t}=3000 \mathrm{kN}$.

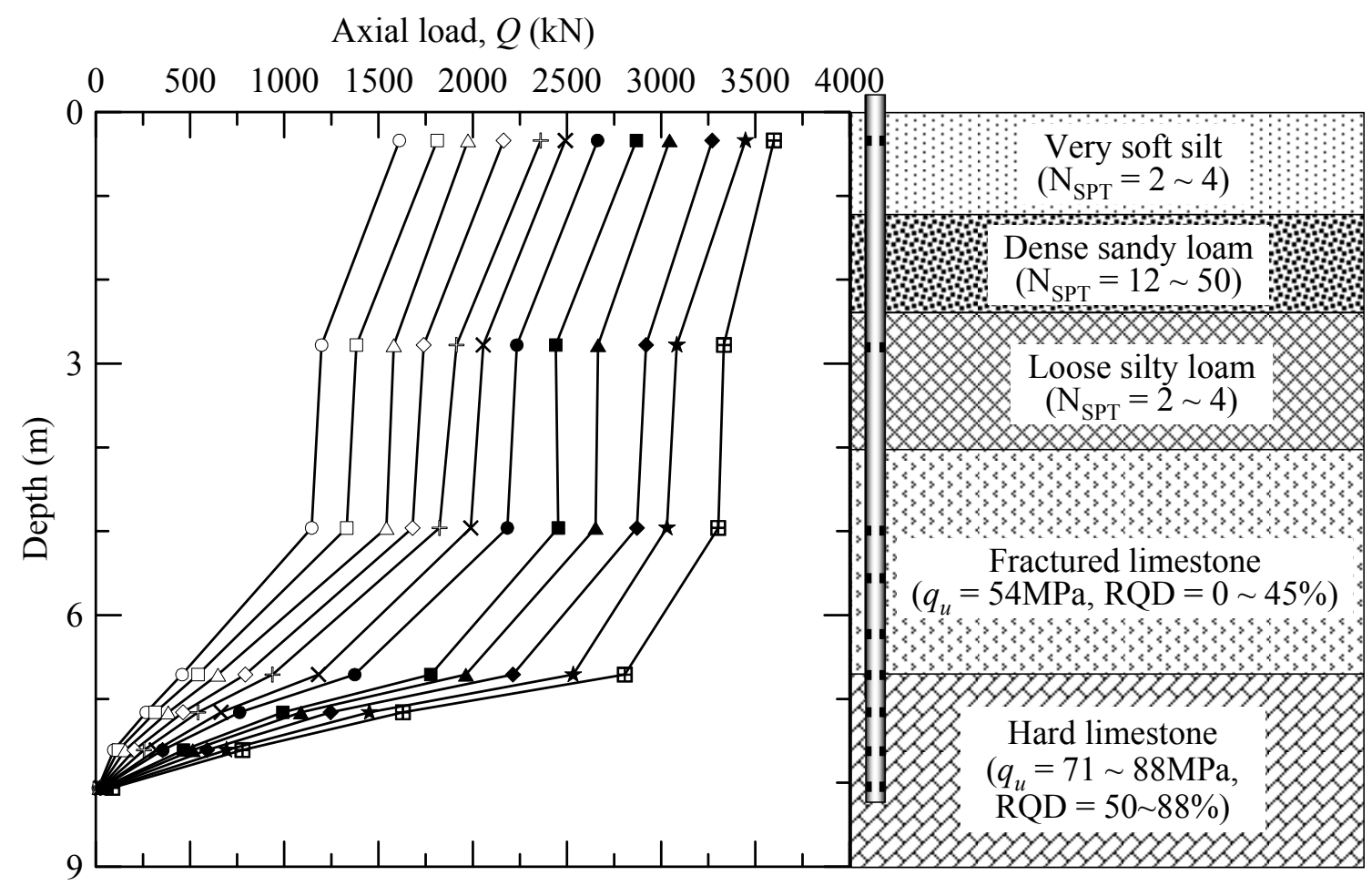

Figure 6.10 Distribution of axial load versus depth 


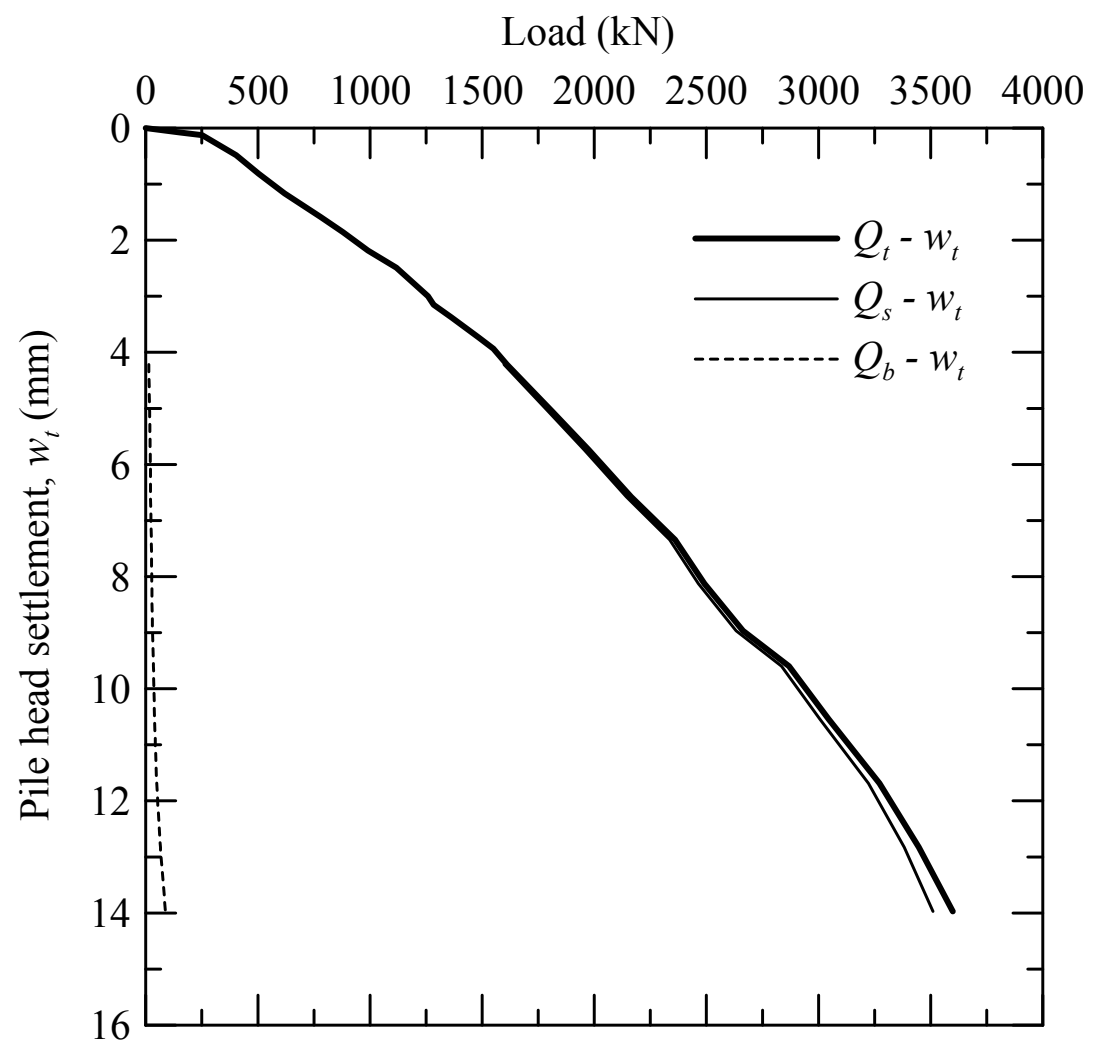

Figure 6.11 Pile head settlement versus applied head load, shaft load, and base load

Referring to Table 2.3, the shaft resistance of Type A micropiles installed in fresh to moderate limestone (FHWA 2000) is in the 1035 - $2070 \mathrm{kPa}$ range, with the higher value of the range corresponding to fresh rock. However, the FHWA manual does not provide specific guidance on which value to use in design. In fact, a $q_{s L}=1292 \mathrm{kPa}$, closer to lowest value, was used in the design of the micropiles at the test site. As discussed in CHAPTER 4, the quality of the rock mass plays an important role in the shaft resistance of hard rocks. Considering that the average $R Q D$ of the hard limestone layer is about $70 \%$, the shaft resistance of the hard limestone layer at the test site is expected to be closer to the higher value prescribed by FHWA. At the final loading step $\left(Q_{t}=3599 \mathrm{kN}\right)$, the measured base load was equal to $88 \mathrm{kN}$ and, hence, the shaft load $Q_{s}$ $=3511 \mathrm{kN}$. The shaft load carried by the hard limestone layer, determined by subtracting the base load from the load at level 4, was $2719 \mathrm{kN}$. This load corresponds to $77 \%$ of the 
shaft load at the final loading step. By dividing $2719 \mathrm{kN}$ by the lateral surface area of the hard limestone layer, we get a shaft resistance of $2950 \mathrm{kPa}$. The shaft resistance obtained from this study based on the final loading step of the load test is 1.4 times larger than the higher value suggested by FHWA.

\subsection{Analysis of the pile load test with ALPAXL}

\subsubsection{Estimation of input parameters}

In order to use ALPAXL, we need to determine the input parameters. The pile diameter is $0.2 \mathrm{~m}$, and the pile length is $8.2 \mathrm{~m}$. The Young's modulus of the pile is $90 \mathrm{GPa}$. We also need to estimate the Young's moduli of the soil and rock layers. We estimated the Young's modulus $E_{s}$ of the soil layers from the SPT blow counts using the correlation proposed by Lee and Xiao (1999):

$$
\frac{E_{s}}{p_{A}}=39.2 N_{S P T}
$$

where $p_{A}=$ reference stress $=100 \mathrm{kPa}=0.1 \mathrm{MPa} \approx 1 \mathrm{tsf}=2000$ psf. In order to estimate the deformation modulus $E_{m}$ of the rock layers, we used Eq. (4.5) proposed by Zhang and Einstein (2004). The Young's modulus of intact limestone was assumed to be $39 \mathrm{GPa}$, following the guidelines in Table 4.2.

Table 6.2 gives representative blow counts for the soil layers, $R Q D$ values for the rock layers and the estimated modulus values. Poisson's ratios for all the layers were assumed to be 0.2 . 
Table 6.2 Estimation of Young's modulus of soil or rock layer

\begin{tabular}{|c|c|c|c|}
\hline Depth (m) & Layer & $\begin{array}{c}\text { Representative } N_{S P T} \\
\text { or } R Q D\end{array}$ & $\begin{array}{c}\text { Estimated Young's } \\
\text { modulus of layer } \\
(\mathrm{MPa})\end{array}$ \\
\hline $0-1.2$ & Very soft silt & 3 & 12 \\
\hline $1.2-2.4$ & Dense sandy loam & 31 & 122 \\
\hline $2.4-4.0$ & Loose silty loam & 3 & 12 \\
\hline $4.0-6.7$ & Fractured limestone & $22 \%$ & 1230 \\
\hline $6.7-10.7$ & Hard limestone & $69 \%$ & 9210 \\
\hline
\end{tabular}

\subsubsection{Analysis results}

Figure 6.12 shows the results of ALPAXL for a design load of $480 \mathrm{kN}$. The predicted pile head settlement is $0.86 \mathrm{~mm}$, while the measured settlement for the same load is about $0.8 \mathrm{~mm}$. We further run the analysis for an applied load of $1610 \mathrm{kN}$.

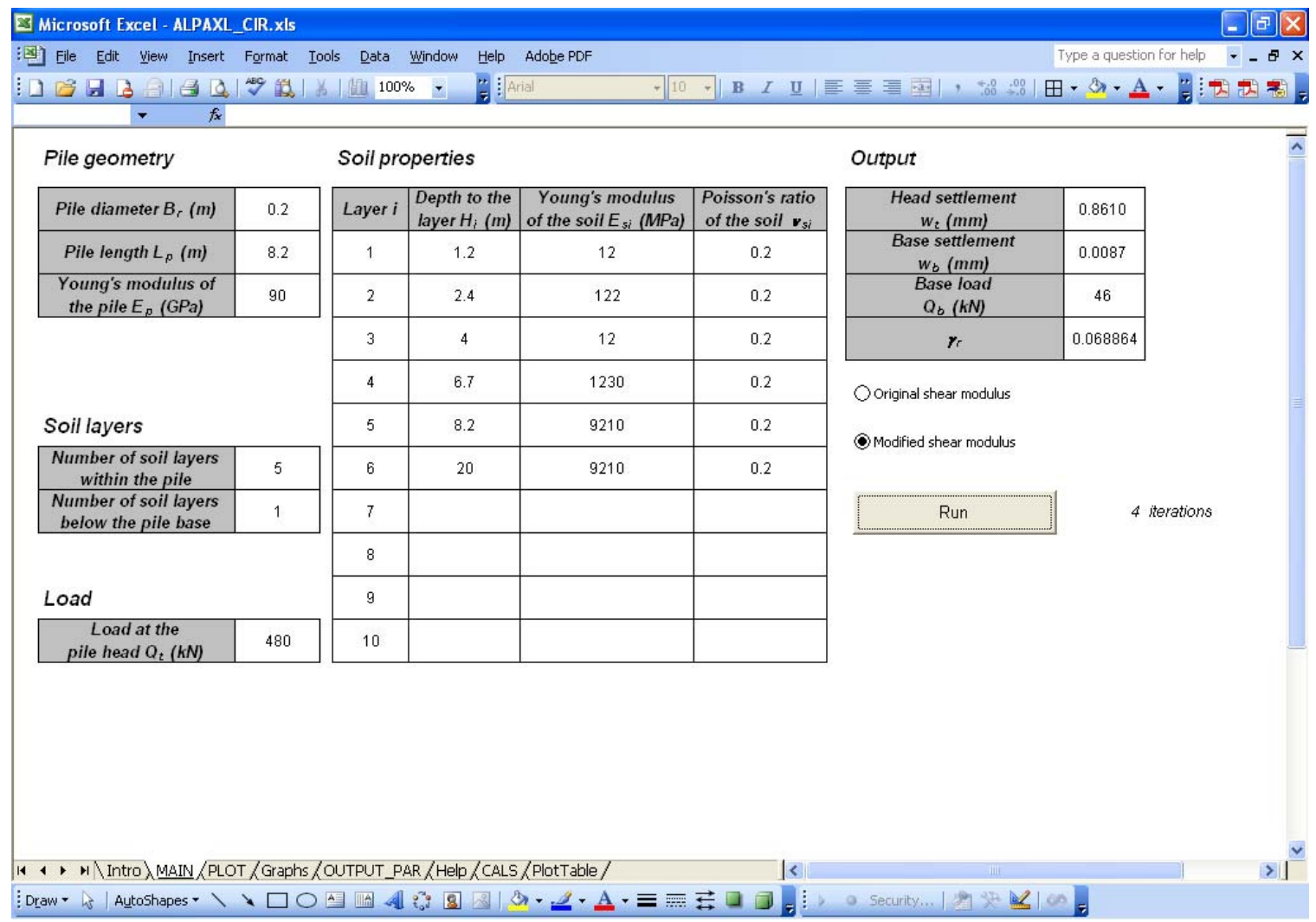

Figure 6.12 Screenshot of the input values and results from ALPAXL for the Orange County micropile 
Figure 6.13 shows the measured and predicted load-settlement curves for an applied load of $1610 \mathrm{kN}$. The predicted response is in reasonable agreement with the measured response up to a load of $800 \mathrm{kN}$. Beyond this load, the curves start to deviate because soil and rock nonlinearity is not accounted for in the analysis.

Figure 6.14 shows measured and predicted load-transfer curves for an applied load of $1610 \mathrm{kN}$. Even though there are small differences in the magnitude of the loads transferred at each depth, both these curves illustrate that the majority of the shaft resistance is mobilized in the rock layers.

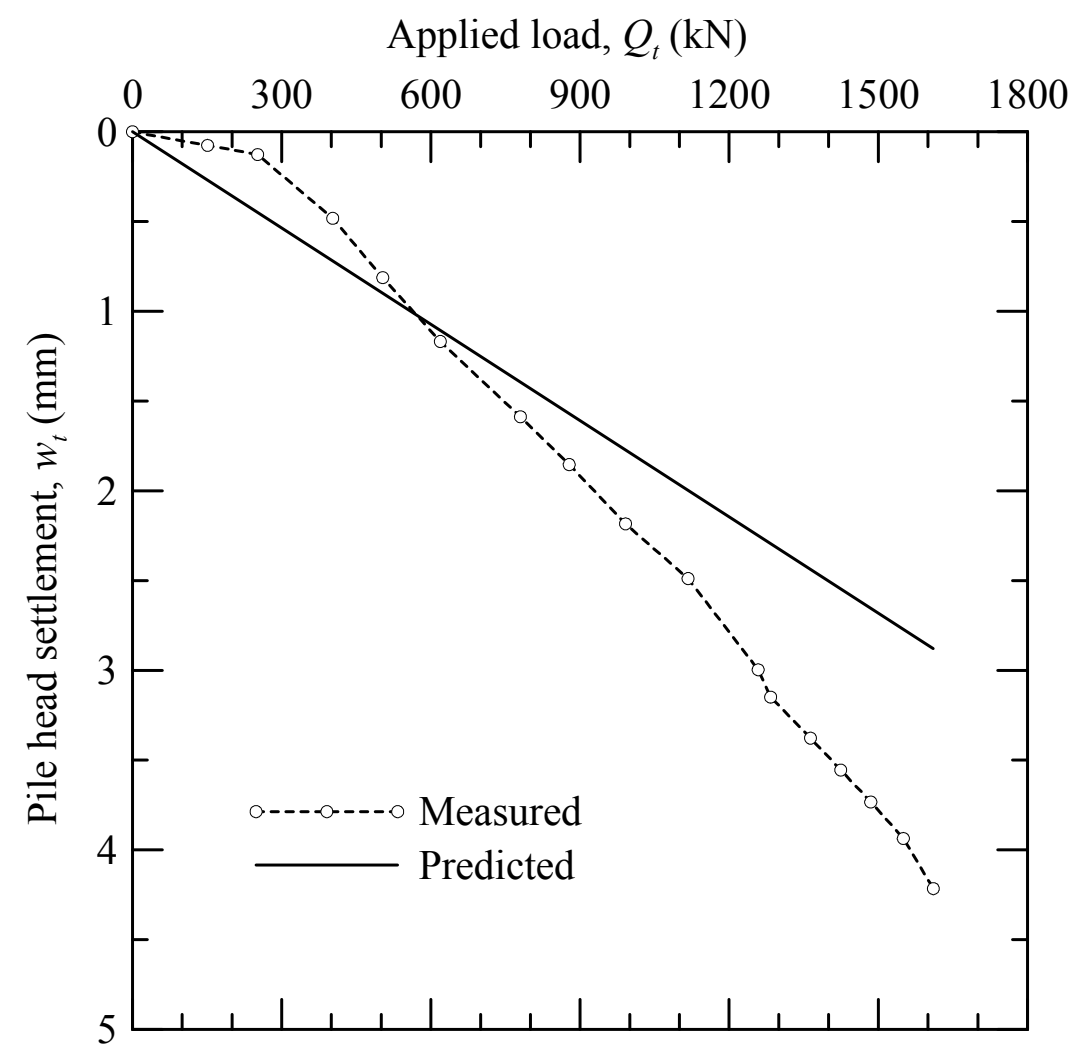

Figure 6.13 Measured and predicted load-settlement curve for the Orange County micropile 


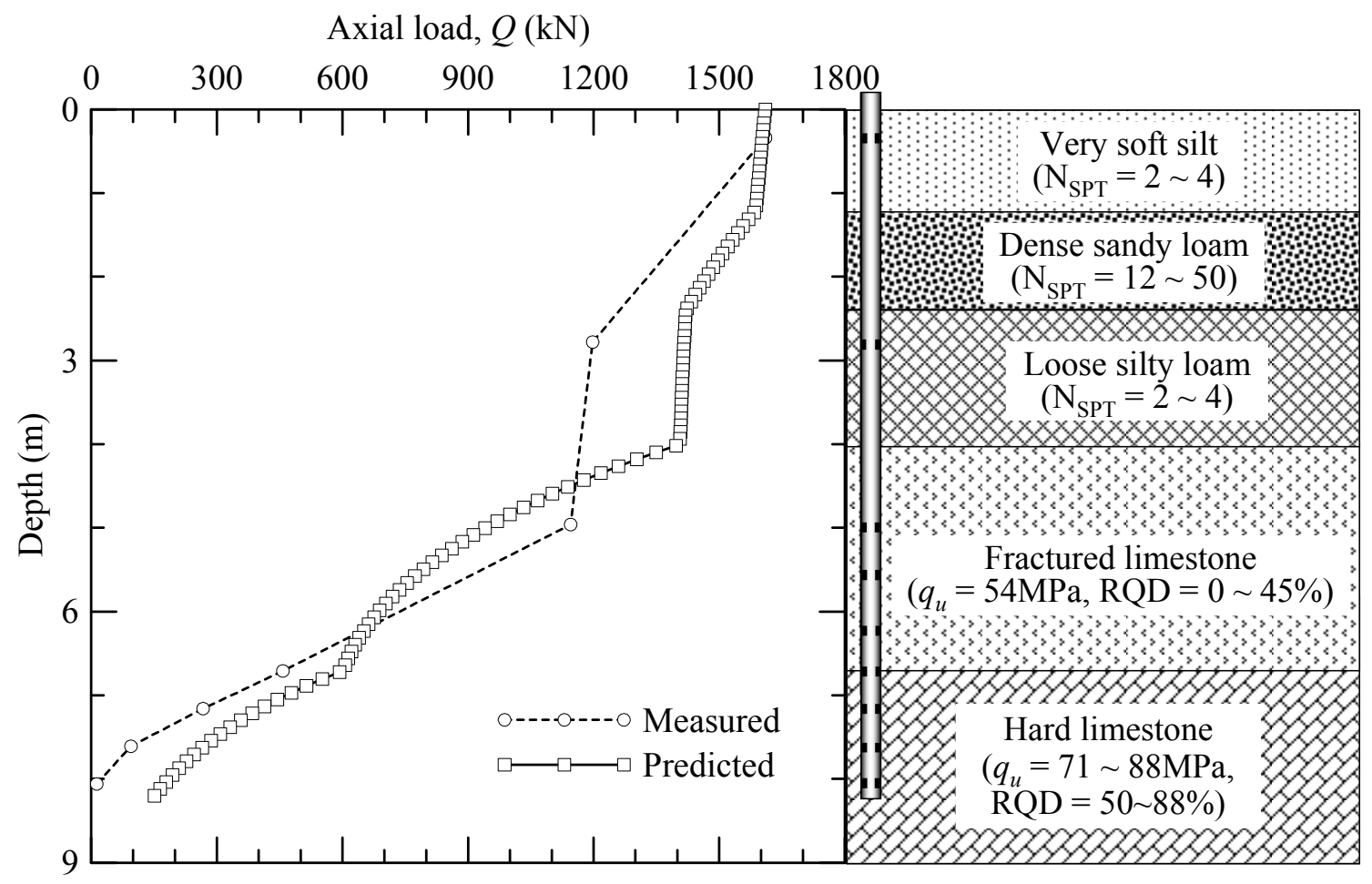

Figure 6.14 Measured and predicted load-transfer curves for a load of $1610 \mathrm{kN}$ 


\section{CHAPTER 7. SUMMARY AND CONCLUSIONS}

\subsection{Summary}

Pile foundations have been used in construction for thousands of years as an economical means of transmitting the loads from superstructures to the underlying soil or rock strata. In pile design, piles must be able to sustain axial loads from the superstructure without failing in bearing capacity of soil and structural damage. In addition, piles must not settle or deflect excessively in order for the serviceability of the superstructures to be maintained. In general, settlement controls the design in most cases because, by the time a pile has failed in terms of bearing capacity, it is very likely that serviceability will have already been compromised. Therefore, realistic estimation of settlement for the given load is very important in design of axially loaded piles. This notwithstanding, pile design has relied on calculations of ultimate resistances reduced by factors of safety that would indirectly prevent settlement-based limit states. This is in part due to the lack of accessible realistic analysis tools for estimation of settlement, especially for piles installed in layered soil.

Micropiles are small-diameter piles that are sometimes called minipiles, root piles, pin piles or needle piles. The motivation behind this important technological development was the need of developing a small-diameter pile that would be able to carry large loads and, at the same time, cause minimal vibration or disturbance of the in situ soil during installation. Because of these important advantages, micropiles have been widely used in situations where minimal disturbance of existing structures is a requirement, such as in seismic retrofitting and in the rehabilitation of foundations of structures that are very sensitive, as well as in locations with low headroom and severely restricted access conditions. Micropiles have also been increasingly used, not only as foundation underpinning elements but also as foundations of new structures. 
Prevalent design methods for micropiles are adaptations of methods originally developed for drilled shafts. However, the installation of micropiles differs considerably from that of drilled shafts, and micropiles have higher pile length to diameter ratios than those of drilled shafts. Improved understanding of the load-transfer characteristics of micropiles and the development of pile settlement estimation tools consistent with the load-transfer response of these foundation elements are needed.

In order to obtain rigorous analysis tool for load-settlement response of an axially loaded pile, we obtained explicit analytical solutions for an axially loaded pile in a multilayered soil. The soil was assumed to behave as a linear elastic material. The governing differential equations were derived based on energy principles and calculus of variations. The integration constants were determined using Cramer's rule and a recurrence formula. In addition, solutions for a pile embedded in a multilayered soil with the base resting on a rigid material were obtained by changing the boundary conditions of the problem. We also obtained solutions for a pile embedded in a multilayered soil subjected to tensile loading. We then compared our solutions with the results from FEA and also with others from the literature. Finally, we used the results of a pile load test from the literature to verify the results obtained using the solutions proposed in this study.

Using the obtained elastic solutions, we performed extensive parametric studies on load-transfer and load-settlement response of rock-socketed piles. The effects of geometry of rock socket, deformation modulus of rock mass, and quality of in-situ rock mass was investigated.

To facilitate the use of our analysis, user-friendly spreadsheet program ALPAXL was developed. This program is based on the elastic solution obtained in this study and uses built-in functions of Microsoft Excel. ALPAXL provides the results of the analysis, the deformed configuration of the pile-soil system and the load-settlement curve in seconds. It can be downloaded at http://cobweb.ecn.purdue.edu/ mprezzi.

A fully instrumented static load test on a rock-socketed micropile was performed. Total of 18 vibrating strain gages were attached outside the steel pipe at 9 different levels. The load testing program was designed to evaluate the load-transfer characteristics of 
rock-socketed micropile. Load test was performed to a maximum test load of the ultimate structural capacity. Using pile and soil properties, predictions were made using ALPAXL. The results from ALPAXL were in good agreement with the measured data at design load level.

\subsection{Conclusions}

Based on findings of the present study, we can draw conclusions as follows:

(1) The results from FEA and our analysis for a multi-layered soil showed good agreement; the results from our analysis for end-bearing piles also compared well with results from previous studies.

(2) When the soil layer surrounding the pile shaft becomes very stiff or the pile slenderness ratio is large, as is the case for micropiles, the normalized pile head stiffness is practically independent of the soil properties below the pile base.

(3) In the case of piles in multilayered soil, the elastic response of pile depends on soil layering, with the uppermost soil having the most effect on the pile head stiffness. A single layer with a simple weighted average of the soil modulus of different soil layers with layer thicknesses as weights will not produce correct pile head stiffness values.

(4) For rock-socketed piles, the load-settlement response of shorter socket is largely affected by the stiffness of the rock at the base, whereas that of longer socket is less sensitive to the stiffness of the base rock.

(5) Load-settlement response of pile socketed in a very hard rock is dominated by the shaft resistance even for relatively short socket length. 
(6) Base capacity may be ignored in design when a micropile is embedded in a very stiff rock, as there will be practically no load transferred to the base under working load.

(7) $R Q D$ has a more pronounced effect on load-transfer and load-settlement response for pile embedded in hard than weak rocks. As the $R Q D$ increases, less load is transferred to the pile base, and pile response becomes stiffer.

(8) For soft rocks, normalized pile stiffness increases as $L_{s} / B$ increases. However this trend vanishes and pile stiffness becomes independent of socket geometry as rock becomes stiffer.

(9) Normalized pile stiffness increases with increasing rock mass modulus, irrespective of socket geometry. When the deformation modulus of rock mass becomes bigger than elastic modulus of the pile $\left(E_{m} / E_{p}>1\right)$, socket geometry does not make any practical difference in pile stiffness.

(10) A fully instrumented load test on a rock-socketed micropile confirmed that most of the applied load was carried by the pile shaft with high slenderness ratio and high stiffness of surrounding rock.

(11) The shaft capacity of hard limestone obtained from the load test at the final loading step was 1.4 times bigger than highest value of limit unit shaft resistance suggested by FHWA (the limit unit shaft resistance $q_{s L}$ from the load test was $2950 \mathrm{kPa}$, while the suggested values from FHWA were 1035 - $2070 \mathrm{kPa}$ )..

(12) Using pile and soil properties, predictions were also made using ALPAXL. The results from ALPAXL were in good agreement with the measured data at the design load level. 


\section{LIST OF REFERENCES}

AASHTO (1989). Standard Specification for Highway Bridges. $14^{\text {th }}$ edition, American Association of State Highway and Transportation Officials, Washington DC.

AASHTO (1996). Standard Specification for Highway Bridges. $16^{\text {th }}$ edition, American Association of State Highway and Transportation Officials, Washington DC.

Armaleh, S. and Desai, C. S. (1987). "Load-deformation response of axially loaded piles.” Journal of Geotechnical Engineering, 113(12), pp. 1483-1500.

Bedenis, T. H., Thelen, M. J. and Maranowski, S. (2004a). "High capacity micro piles for utility retrofit: a case history at D. E. Karn power plant in Bay City, Michigan." Proceedings of GeoSupport 2004: Drilled Shafts, Micropiling, Deep Mixing, Remedial Methods, and Specialty Foundation Systems, pp. 662-673.

Bedenis, T. H., Thelen, M. J. and Maranowski, S. (2004b). "Micropiles to the rescue." Civil Engineering, ASCE, Vol. 74, No. 3, pp. 66-71.

Bieniawski, Z. T. (1978). "Determining rock mass deformability: experience from case histories." International Journal of Rock Mechanics and Mining Science: Geomechanics Abstracts, Vol. 15, 237-248

Bieniawski, Z. T. (1989). Engineering Rock Mass Classifications. John Wiley, Rotterdam

Blaney, G. W., Kausel, E. and Roesett, J. M. (1976). "Dynamic stiffness of piles." Proceedings of $2^{\text {nd }}$ International Conference on Numerical Methods in Geomechanics, Blacksburg, VA, pp. 1001-1012

Bruce, D. A., Bruce, M. E. C. and Traylor R. P. (1999). "High Capacity Micropiles Basic Principles and Case Histories." Proceedings of the $19993 \mathrm{rd}$ National Conference on Geo-Engineering for Underground Facilities, Geotechnical Special Publication No. 90, pp. 188-199. 
Bustamante, M., and Gianeselli, L. (1982). "Pile bearing capacity prediction by means of static penetrometer CPT." Proceedings of the 2nd European Symposium on Penetration Testing, Amsterdam, 2, pp. 493-500.

Butterfield, R. and Banerjee, P. K. (1971). "The elastic analysis of compressible piles and pile groups." Geotechnique, 21(1), pp. 43-60.

Callanan, J. F. and Kulhawy, F. H. (1985). "Evaluation of Procedures for Predicting Foundation Uplift Movements", Report to Electric Power Research Inst., NO. EPRI EL4107, Cornell University

Chang, M. F. and Wong, I. H. (1987). "Shaft Friction of Drilled Piers in Weathered Rocks", Proc., 6th Int. Conf. on Rock Mechanics, ISRM, A.A. Balkema, Rotterdam, Brookfield, pp. 313-318.

Chin J. T. and Poulos, H. G. (1991). "Axially loaded vertical piles and pile groups in layered soil." International Journal for Numerical and Analytical Methods in Geomechanics, 15, pp. 497-511.

Coyle, H. M. and Reese, L. C. (1966). "Load transfer for axially loaded piles in clay." Journal of the Soil Mechanics and Foundations Division, 92(SM2), pp. 1-26.

Davie, J. R. and Senapathy, H. (2002). "Underpinning a 3000-Ton Structure with HighCapactiy Mini-Piles." Proceedings of the International Deep Foundations Congress 2002, Geotechnical Special Publication No. 116, pp. 647-654.

El-Sharnouby, B. and Novak, M. (1990). "Stiffness constants and interaction factors for vertical response of pile groups." Canadian Geotechnical Journal, 27, pp. 813-822

FHWA. (1997). "Drilled and Grouted Micropiles, State-of-Practice Review" Rep. No. FHWA-RD-96-016/019, Federal Highway Administration, U.S. Dept. of Transportation, McLean, Va.

FHWA. (2000). "Micropile design and construction guidelines-implementation manual." Rep. No. FHWA-SA-97-070, Federal Highway Administration, U.S. Dept. of Transportation, McLean, Va.

Finno, R. J., Scherer, S. D., Paineau B. and Roboski, J. (2002). "Load Transfer Characteristics of Micropiles in Dolomite." Proceedings of the International Deep Foundations Congress 2002, Geotechnical Special Publication No. 116, pp. 1038-1053. 
Fleming, W. G. K., Weltman, A. J., Randolph, M. F., and Elson, W. K. (1992). Piling Engineering, Blackie, Glasgow, and London

Franke, E. (1991). "EUROCODE Safety Approach as Applied to Single Piles." Proc. of $4^{\text {th }}$ International DFI Conference, Balkema, Rotterdam, pp. $13-18$.

Gardner, W. S. (1987). "Design of drilled piers in the Atlantic Piedmont." Foundations and Excavations in Decomposed Rock of the Piedmont Province, GSP No. 9, pp. 62 - 86

Gibson, R. E. (1967). "Some results concerning displacements and stresses in a nonhomogeneous elastic half-space." Geotechnique, 17(1), pp. 58-67.

Goodman, R. E. (1989). Introduction to Rock Mechanics, John Wiley \& Sons

Guo, W. D. (2000). "Vertically loaded single piles in Gibson soil." Journal of Geotechnical and Geoenvironmental Engineering, 126(2), pp. 189-193.

Guo, W. D. and Lee, F. H. (2001). "Load transfer approach for laterally loaded piles" International Journal for Numerical and Analytical Methods in Geomechanics, 25(11), pp. 1101-1129.

Guo, W. D. and Randolph. M. F. (1997). "Vertically loaded piles in non-homogeneous media." International Journal for Numerical and Analytical Methods in Geomechanics, 21(8), pp. 507-532.

ISRM (1975). Commission on terminology, symbols and graphic representation. International Society for Rock Mechanics.

Kim, S., Jeong, S. Cho, S. and Park, I. (1999). "Shear Load Transfer Characteristics of Drilled Shafts in Weathered Rocks." Journal of Geotechnical and Geoenvironmental Engineering, 125(11), pp. 999-1010.

Kodikara, J. K. and Johnston, I. W. (1994). "Analysis of compressible axially loaded piles in rock." International Journal for Numerical and Analytical Methods in Geomechanics, 18, pp. 427-437.

Kraft, L. M., Ray, R. P. and Kagawa, T. (1981). "Theoretical $t$-z curves." Journal of the Geotechnical Engineering Division, 107(GT11), pp. 1543-1561. 
Lee, C. Y. (1991). "Discrete layer analysis of axially loaded piles and pile groups." Computers and Geotechnics, 11(4), pp. 295-313.

Lee, C. Y. and Small, J. C. (1991). "Finite-layer analysis of axially loaded piles" Journal of Geotechnical Engineering, 117(11), pp. 1706-1722.

Lee, K.-M. and Xiao, Z. R. (1999). "A new analytical model for settlement analysis of a single pile in multi-layered soil.” Soils and Foundations, 39(5), pp. 131-143.

Macklin, P. R., Berger, D., Zietlow, W., Herring, W. and Cullen, J. (2004), "Case history: micropile use for temporary excavation support." Proceedings of GeoSupport 2004: Drilled Shafts, Micropiling, Deep Mixing, Remedial Methods, and Specialty Foundation Systems, pp. 653-691.

Mattes, N. S. and Poulos, H. G. (1969). "Settlement of single compressible pile" Journal of the Soil Mechanics and Foundations Division, 95(SM1), pp. 189-207.

Mindlin, R. D. (1936). "Force at a point in the interior of a semi-infinite solid." Physics, 7, pp. $195-202$

Motta, E. (1994). "Approximate elastic-plastic solution for axially loaded piles." Journal of Geotechnical Engineering, 120(9), pp. 1616-1624.

Murff, J. D. (1975). "Response of axially loaded piles." Journal of the Geotechnical Engineering Division, 101(GT3), pp. 356-360.

Mylonakis, G. (2001). "Winkler modulus for axially loaded piles." Geotechnique, 51(5), pp. $455-461$.

Poulos, H. G. (1979). "Settlement of single piles in nonhomogeneous soil." Journal of the Geotechnical Engineering Division, 105(GT5), pp. 627-641.

Poulos, H. G. and Davis, E. H. (1968). "The settlement behavior of single axially loaded incompressible piles and piers." Geotechnique, 18(3), pp. 351-371.

Poulos, H. G. and Davis, E. H. (1980). Pile foundation analysis and design. John Wiley $\&$ Sons, New York. 
Rajapakse, R. K. N. D. (1990). "Response of an axially loaded elastic pile in a Gibson soil." Geotechnique, 40(2), pp. 237-249.

Randolph, M. F. (1981). "The response of flexible piles to lateral loading." Geotechnique, 31(2), pp. 247-259.

Randolph, M. F., and Wroth, C. P. (1978). "Analysis of deformation of vertically loaded piles." Journal of the Geotechnical Engineering Division, 104(GT12), pp. 1465-1488.

Randolph, M. F., Dolwin, J., and Beck, R. (1994). "Design of driven piles in sand." Geotechnique, 44(3), 427-448

Rowe, R. K. and Armitage, H. H. (1987). "A design method for dilled piers in soft rock." Canadian Geotechnical Journal, 24, pp. 126 - 142

Russo, G. (2004). "Full-scale load test on instrumented micropiles" Proc. of the Institution of Civil Engineers: Geotechnical Engineering, 157(3), pp. 127-135

Seed, H. B. and Reese, L. C. (1957). "The action of soft clay along friction piles." Transactions ASCE, 122, pp. 731-754

Seo, H. and Prezzi, M. (2007) "Analytical solutions for a vertically loaded pile in multilayered soil" Geomechanics and Geoengineering: An International Journal, 2(1), pp. 51-60

Serafim, J. L. and Pereira, J. P. (1983). "Considerations of the geomechanics classification of Bieniawski." Proc. Int. Symp. Eng. Geol. Underground Constr., Lisbon, Vol. 1, II33 - II42

Scherer, S. D., Walton, W. H. and Johnson, R. (1996). "Chicago's micropile debut." Civil Engineering, ASCE, Vol. 66, No. 8, pp. 51-53.

Stulgis, R. P., Barry, B. E. and Harvey, F. S. (2004). "Foundation underpinning with mini-piles 'a first' in Guyana, South America." Proceedings of GeoSupport 2004: Drilled Shafts, Micropiling, Deep Mixing, Remedial Methods, and Specialty Foundation Systems, pp. 700-711.

Taylor, G. E., Gularte, F. B. and Gularte, G. G. (1998). "Seismic retrofit of fourth street \& riverside viaducts with micropiles." Soil Improvement for Big Digs, Geotechnical Special Publication No. 81, pp. 313-325. 
Traylor, R. P. and Bruce, D. A. (2002). "High capacity micropiles in Karst: Challenges and Opportunities." Proceedings of the International Deep Foundations Congress 2002, Geotechnical Special Publication No. 116, pp. 743-759.

Vallabhan, C. V. G. and Mustafa, G. (1996). "A new model for the analysis of settlement of drilled piers." International Journal for Numerical and Analytical Methods in Geomechanics, 20, pp. 143-152.

Zelenko, B. H., Bruce, D. A., Schoenwolf, D. A. and Traylor, R. P. (1998), "Micropile Application for Seismic Retrofit Preserves Historic Structure in Old San Juan, Puerto Rico." Grouts and Grouting: A Potpourri of Projects, Geotechnical Special Publication No. 80, pp. 43-62.

Zhang, L. and Einstein, H. H. (2004). "Estimating the deformation modulus of rock masses.” Int. J. Rock Mech. Min. Sci., Vol. 41, pp. 337 - 341 